\title{
the con-fused identity
}

An expo-sition of the Barbadian-Caribbean culture

Leah Alesia Broome, M.Arch. candidate

A thesis submitted to

The Faculty of Graduate Studies and Research

In partial fulfillment of the requirements for the degree of

Master of Architecture [M.Arch Professional]

Azrieli School of Architecture and Urbanism, Carleton University, Ottawa, Canada 2012 C Leah A. Broome 
Library and Archives

Canada

Published Heritage

Branch

395 Wellington Street

Ottawa ON K1A ON4

Canada
Bibliothèque et

Archives Canada

Direction du

Patrimoine de l'édition

395 , rue Wellington

Ottawa ON K1A ON4

Canada
Your file Votre référence

ISBN: 978-0-494-91513-4

Our file Notre référence

ISBN: 978-0-494-91513-4
NOTICE:

The author has granted a nonexclusive license allowing Library and Archives Canada to reproduce, publish, archive, preserve, conserve, communicate to the public by telecommunication or on the Internet, loan, distrbute and sell theses worldwide, for commercial or noncommercial purposes, in microform, paper, electronic and/or any other formats.

The author retains copyright ownership and moral rights in this thesis. Neither the thesis nor substantial extracts from it may be printed or otherwise reproduced without the author's permission.
AVIS:

L'auteur a accordé une licence non exclusive permettant à la Bibliothèque et Archives Canada de reproduire, publier, archiver, sauvegarder, conserver, transmettre au public par télécommunication ou par l'Internet, prêter, distribuer et vendre des thèses partout dans le monde, à des fins commerciales ou autres, sur support microforme, papier, électronique et/ou autres formats.

L'auteur conserve la propriété du droit d'auteur et des droits moraux qui protege cette thèse. $\mathrm{Ni}$ la thèse ni des extraits substantiels de celle-ci ne doivent être imprimés ou autrement reproduits sans son autorisation.
In compliance with the Canadian Privacy Act some supporting forms may have been removed from this thesis.

While these forms may be included in the document page count, their removal does not represent any loss of content from the thesis.
Conformément à la loi canadienne sur la protection de la vie privée, quelques formulaires secondaires ont été enlevés de cette thèse.

Bien que ces formulaires aient inclus dans la pagination, il n'y aura aucun contenu manquant. 


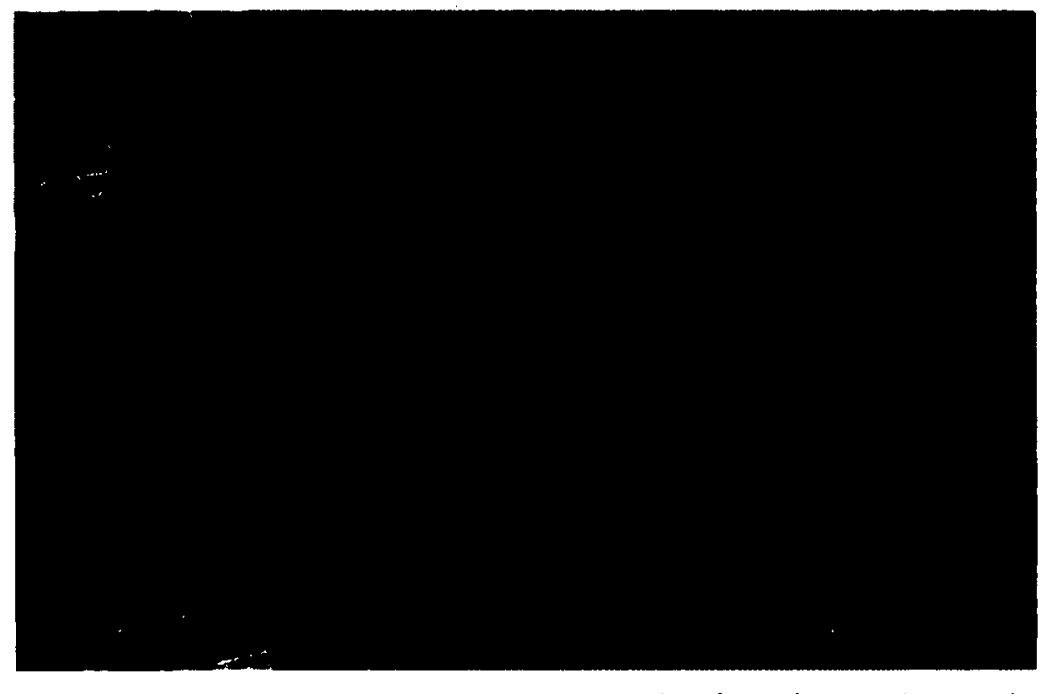

'Confusion' - Roswita Szyszka 
Eurocentric visual depictions and the resulting perceptions have masked the Caribbean and its cultural identity for centuries. This thesis begins the journey of unravelling those perceptions and makes an attempt to re-educate and re-appropriate the contemporary Caribbean cultural identity within the minds of its readers through the understanding of an aspect of material culture, which provides further insight into the psychological climate of the Caribbean people. The product will be a mapping of the resulting inferences into an architectural expression which more truthfully exudes the cultural ingredients of the Caribbean island of Barbados, the chosen representative for the region's case of the 'con-fused' identity. The gesture of adapting an existing site of previous European interest, is one which seeks to directly trace and unmask the origins of cultural dominance, and to place the necessary counterweight to the scale of Caribbean culture. 
For my parents who raised me to be the individual I am today. Thank you for always believing in me.

For my grandparents, especially my grandmothers, who quietly taught me the secrets of how to be a strong, independent and proud Caribbean woman.

For my ancestors whose existence runs through my veins.

To my significant other, close friends and other family members who offered all the support they could, thank you.

Thanks to my advisor and the professors at Carleton University who I collaborated with and who kindly offered assistance in the development of this thesis.

Acknowledgement must also be made of the following Barbados-based organisations who provided valuable information for this thesis: The Government of Barbados' Lands \& Surveys Department and the Statistical Department, SRM Architects Ltd., The Barbados Museum, The National Cultural Foundation,

The Barbados National Trust and the University of the West Indies, Cave Hill. 


\section{TABLE OF CONTENTS}

ABSTRACT 1

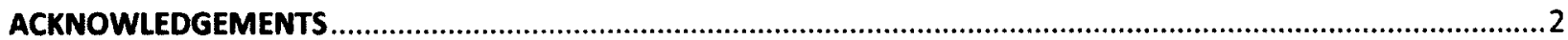

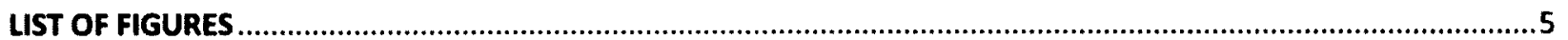

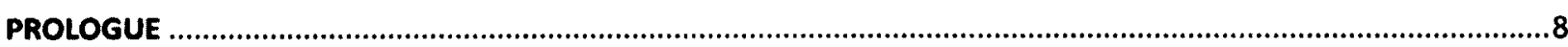

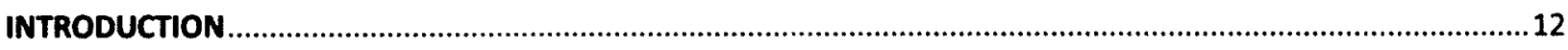

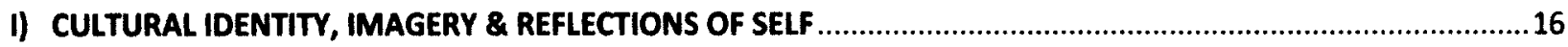

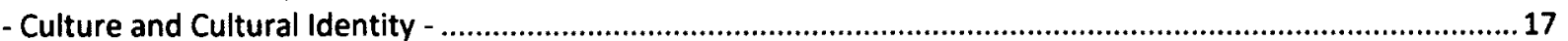

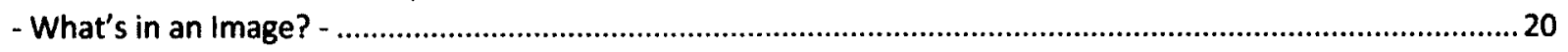

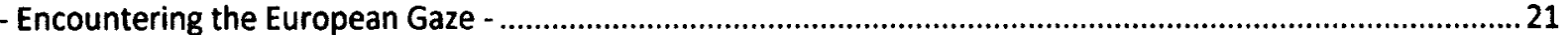

- Caribbean Impressions of Self \& the Prevailing Winds of the Political and Economic Agenda - .......................24

II) THE 'CON-FUSED' NATURE Of CARIBBEAN CULTURE: Post-colonial identities .............................................28

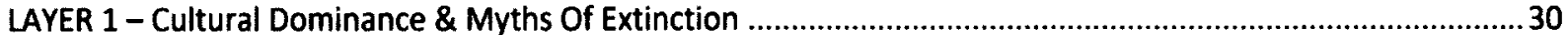

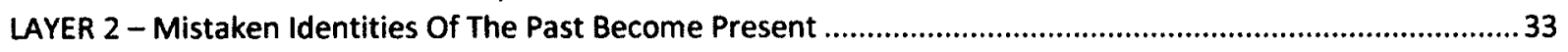

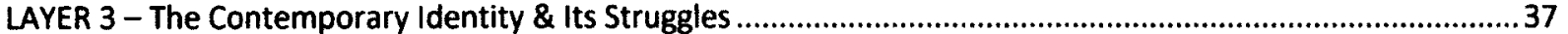

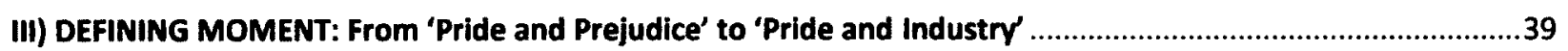

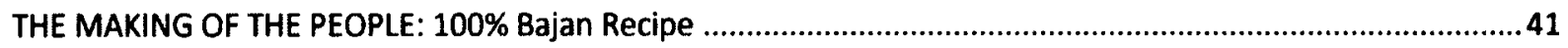

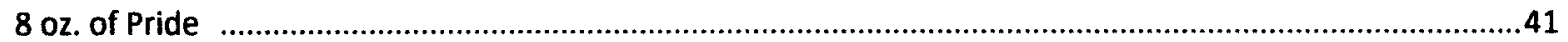

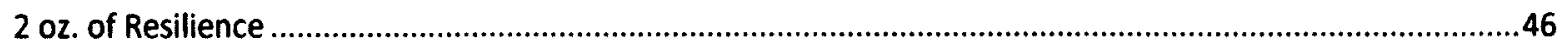

2 oz. of Quick Wit \& 1 1 12 of Laid Back - to be blended before adding to mixture .........................................53

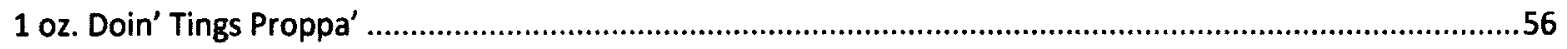

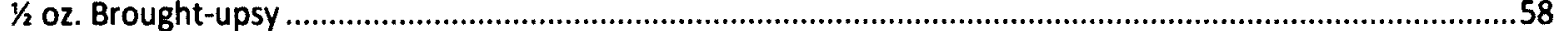

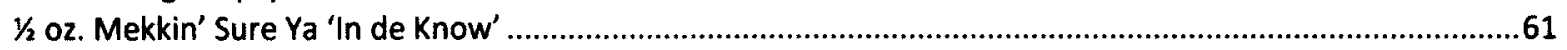

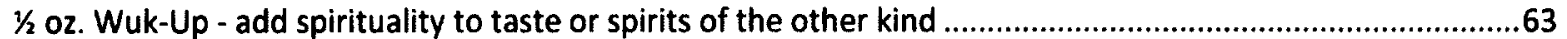

Taste-testing: Considering Barbadian Culture as it evolves ...................................................................65

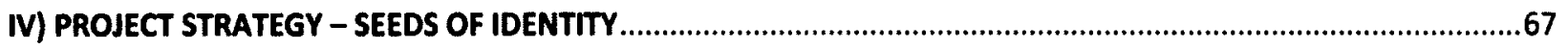

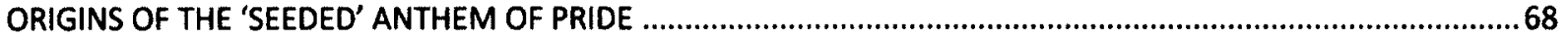

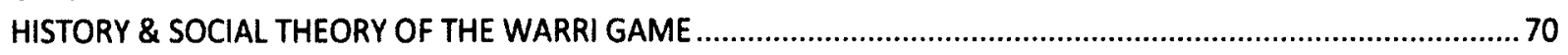


PLAYING IN THE FIELDS AND HILLS BEYOND RECALL: The Bajan Queen's Park.

Sowing Elements Of Bajan Culture In The Park

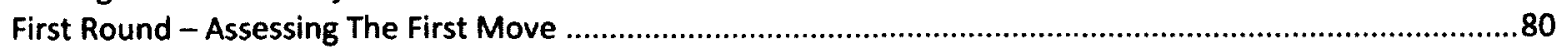

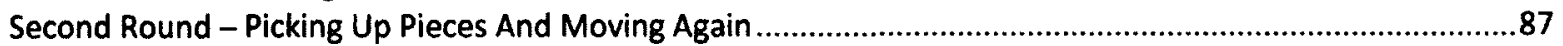

Third Round - Playing The Last Hole \& Waiting For The Next Play ......................................................101

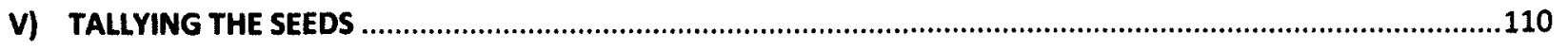

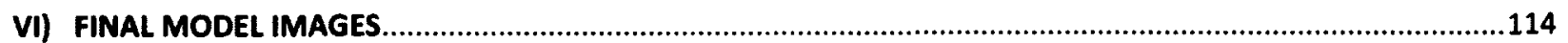

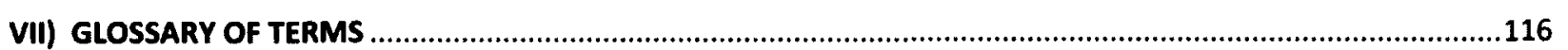

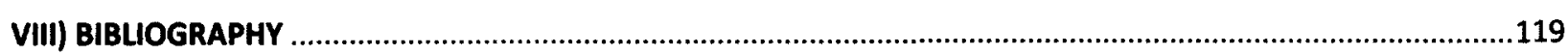




\section{LIST OF FIGURES}

\section{ALL IMAGES BY AUTHOR UNLESS OTHERWISE STATED.}

FIGURE 1 - A 17TH CENTURY IMAGE DEPICTING THE PERCEIVEd CANNIBALISTIC PRACTICES (REID 89) ........................................12

FIGURE 2 - A JAMAICAN POSTCARD DEPICTING THE IMPLIED PLEASURES OF 'SUN, SEA AND SAND' (DICK SCOONES) ............................13

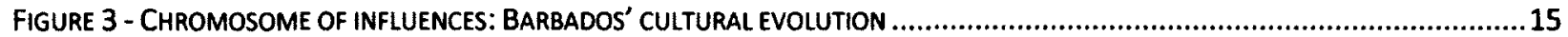

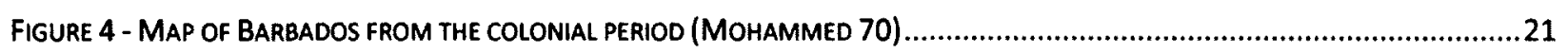

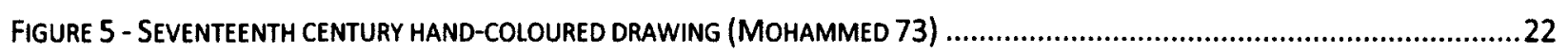

FIGURE 6 - SKETCH OF THE COAST OF GUYANA TRANSMITTED TO SPAIN (MOHAMMED 74) .................................................22

FIGURE 7 - SEVENTEENTH CENTURY SKETCH SHOWING DETAILS OF SETTLEMENT (MOHAMMED 74) .........................................22

FIGURE 8 - COMPARISON OF IMAGES CREATED BY COLONIAL SETTLERS WITH THE TOURISM INDUSTRY (MOHAMMED 147) .................24

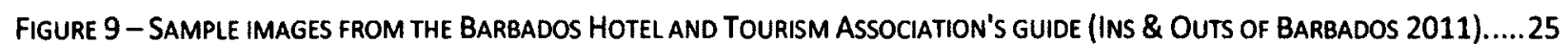

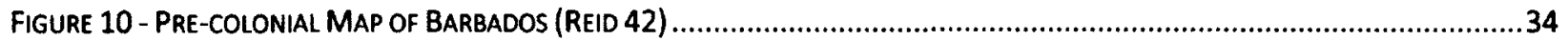

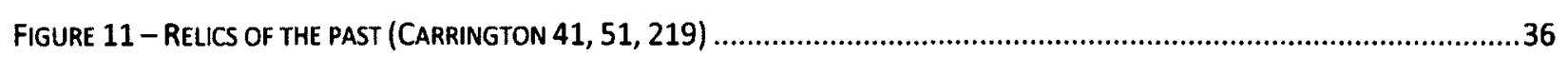

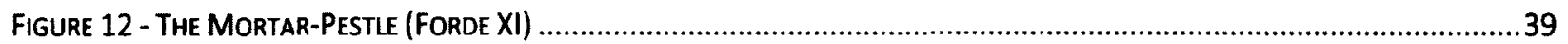

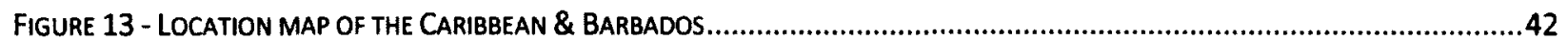

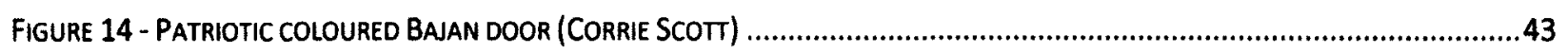

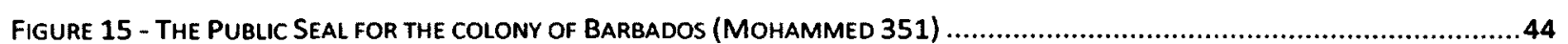

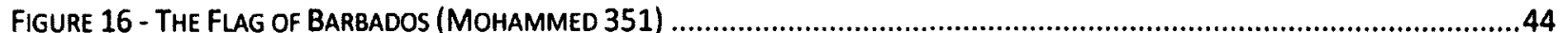

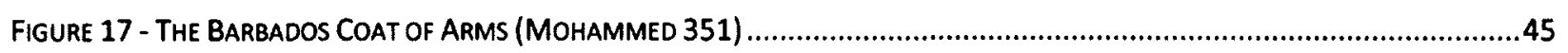

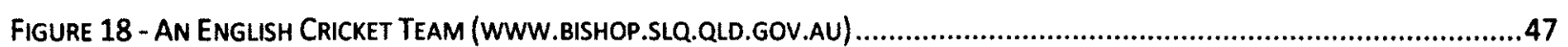

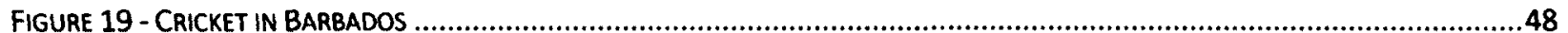

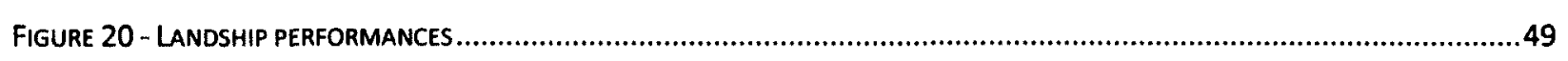

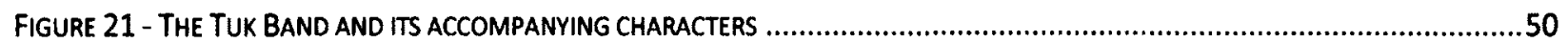


Figure 22 - The Chattel house With VARIOUS features AND Functions

FIGURE 23 - IMAGES FROM BARBADOS' CURRENT CROP OVER FESTIVAL (WWW.FUNBARBADOS.COM) ........................................53

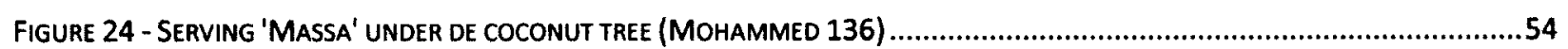

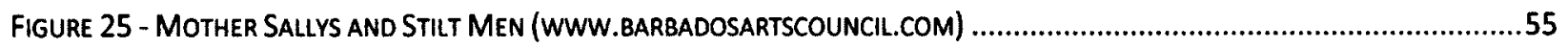

FiguRe 26 - LoCAL ARTIST'S IMPRESSIONS OF WOMEN IN SOCIETY (IVAN PAYNE, AILEEN HAMILTON, NORMA TALMA, BETTY SCOTT) ....59

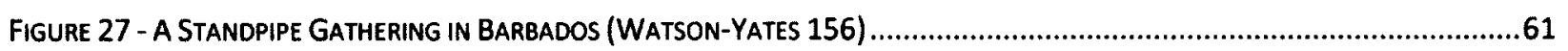

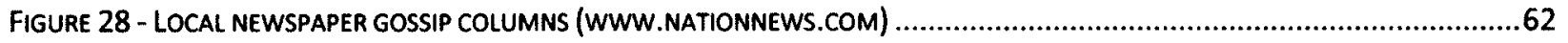

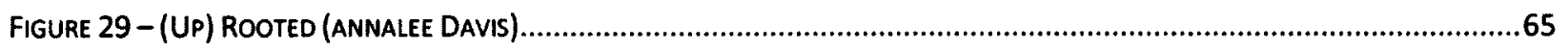

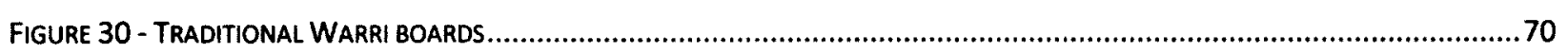

FIGURE 31 - A WARRI GAME BEING PLAYED IN THE SOIL (WWW.THEHOLIDAZE.COM) .....................................................

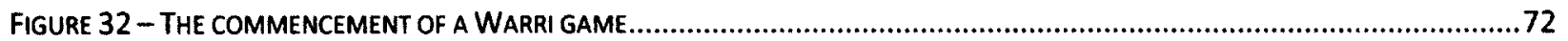

FIGURE 33 - TRADITIONAI WARRI BOARDS VERSUS CONTEMPORARY DESIGNED BOARDS ....................................................73

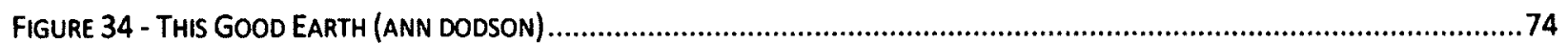

FIGURE 35 - BARBADIAN ARTIST'S IMPRESSION OF THE CITY'S PLAN (WWW.BARBADOSARTSCOUNCIL.COM) ...............................75

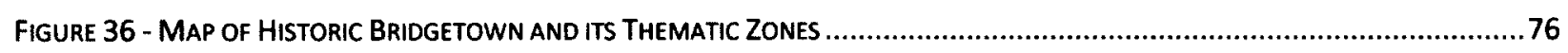

Figure 37 - Map of the Natural and CULtural Heritage Conservation AREAS \& BuILdings Of Historic INTEREST.................76

FIGURE 38 - AERIAL PHOTO THE QUEEN'S PARK SITE WITH SUPERIMPOSITION OF THEORETICAL WARRI GAME HOLES .........................83

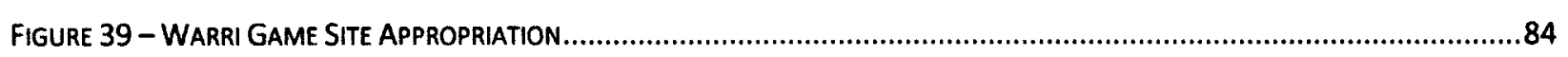

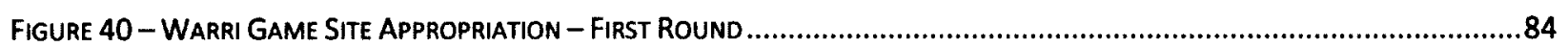

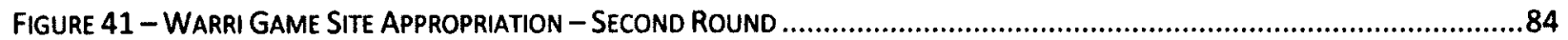

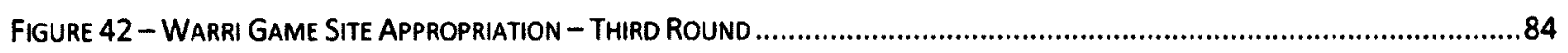

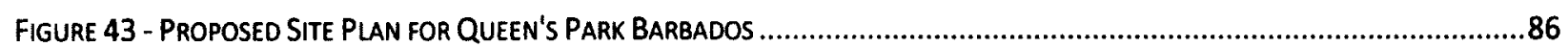

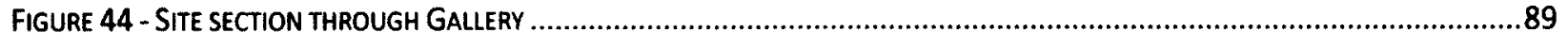

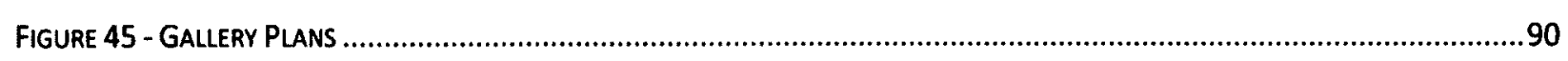

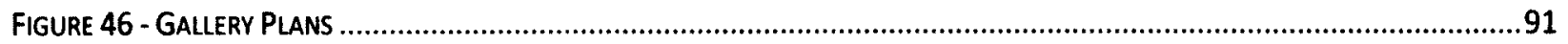




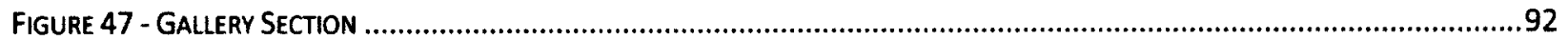

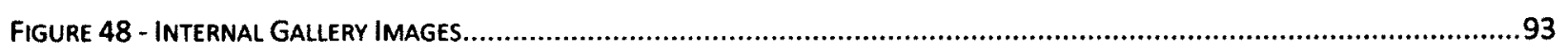

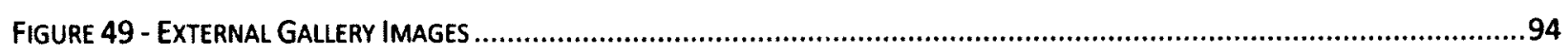

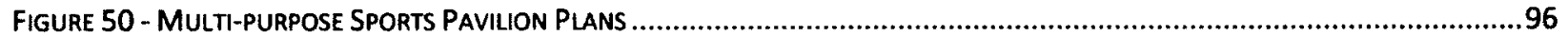

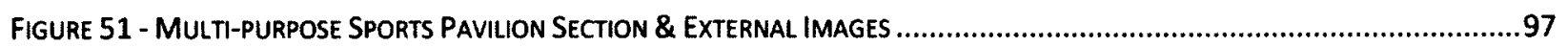

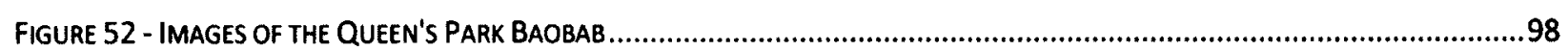

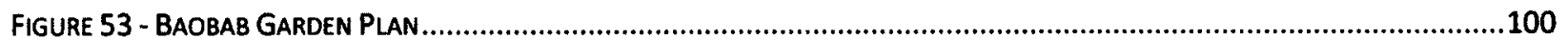

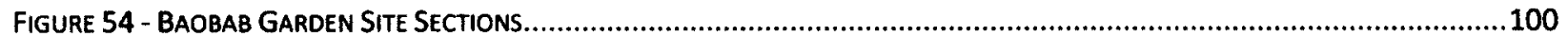

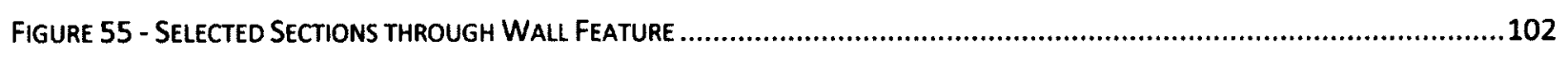

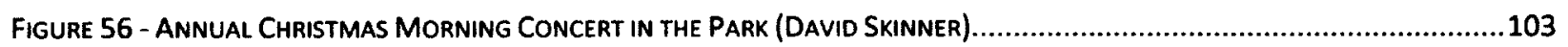

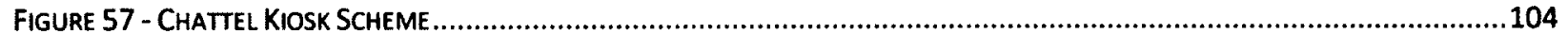

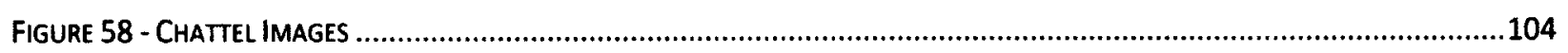

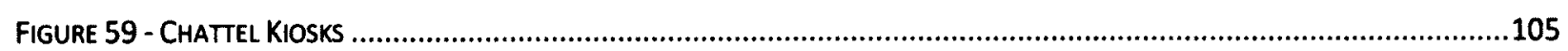

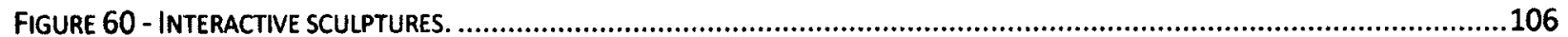

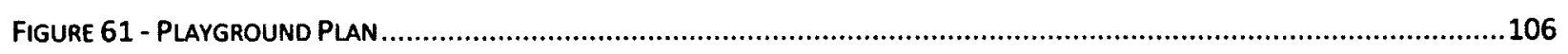

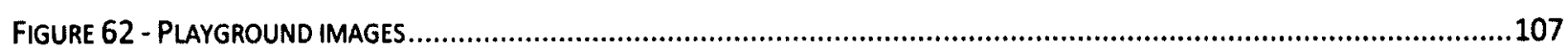

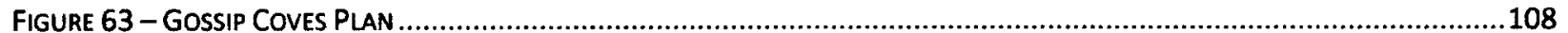

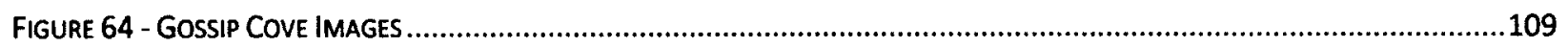

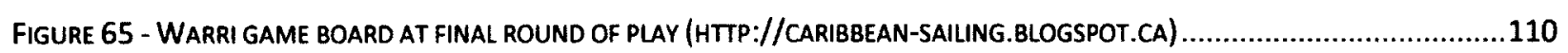

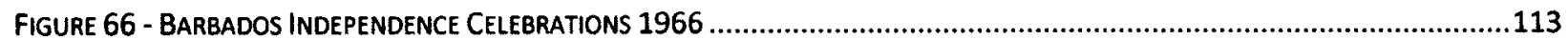


Encounter \#1 - Oooh! So you're from the Caribbean eh?!

I met a Canadian fellow named JP, while working on-campus, and as was my usual expectation of North Americans, he was eager for me to list every specific fact and figure possible about my tropical country of origin. The 'light' conversation was reminiscent of a political debate where fact for fact was matched and defences were made and dismantled. I learnt more than I thought I wanted to know about Canada in that short conversation and in exchange, $J P$ had learnt that my little island was far more significant than he imagined. The breaking point and humorous end to our conversation however, came with his final question "So, do you say you live on the island or do you live in the island?" We were back to the Robinson Crusoe ${ }^{1}$ and man Friday scenario of island life! I chuckled to myself, smiled wider than I probably should have and said, "Even though we do refer to the island amongst ourselves as 'the rock', we very proudly say, we live in Barbados just as you do Canada!" JP shyly smiled and said, "Well I had to ask eh, we have to be politically correct these days".

\section{Encounter \#2 - From the roots of my hair to the tip of my 'tongue'}

On my arrival in Ottawa, amongst my list of very important items for survival away from home was the quest to find a hairdresser who was well trained in the maintenance and styling of my chemically straightened black roots. I was made aware of the shortage of stylists who could provide this service in Ottawa and was warned of those who dared to experiment with "giving you a relaxer", without knowing the proper technique of doing so. I asked around and made a few calls, only to be referred and

${ }^{1}$ Defoe, Daniel. The Life and Strange Surprizing Adventures of Robinson Crusoe. London: William Taylor, 1719 - Robinson Crusoe is a fictional autobiography of a Scottish castaway who spends 28 years on a remote tropical island in the Caribbean, where he struggles with issues of cultural relativism in his encounters with cannibals, captives, and mutineers before being rescued. 
referred and referred again to a Textures Hair Salon. My new stylist was an eloquent, well dressed fellow who immediately on inspection of my hair said "where are you from?" 1 was somewhat puzzled at first, wondering to myself "was he making light conversation? Did I still have sand from the beach in my hair? Or did he catch a slight tinge of my accent?" What did this have to do with his intense assessment of my roots?

My response was, "I'm from Barbados". The stylist quickly responded "Oh yeah, I can see that you're from the Caribbean". I was a bit relieved that his geographic knowledge was clearly in 'tip-top' shape. Furthermore, he quickly rattled off a handful of facts about the 'mix-up' of the Caribbean people to his trainee who was closely observing, and then said "now you see, her hair is different to that of a black person straight from Africa. You can see she's not coming from a dry climate and you can also see that somebody got a little 'freaky' with a little Indian or something up in here! Her roots are totally of a different texture and won't take very long to break down once we apply the relaxer." Then he very excitedly hung over my shoulder and asked "Am I right? Do you have a grandparent or someone farther back who is of mixed ethnicity?" I very hesitantly responded "I suppose you could put it that way..." His next question to me was "So how long have you been here in Canada?" At this point I figured, "Okay, I guess we're moving on to the typical salon 'small talk' segment of my visit" but apparently he was still carrying out his 'assessment' of me as his new customer. When I responded "just about two months", his exclamation was "Girl! Where's your accent? You couldn't have lost it already!"

While I was slightly amused, the truth of the matter was that my Bajan² accent was never very pronounced; due to the way I was brought up and educated, and also to the fact that I am somewhat soft-spoken. Who would've thought this assessment of my hair would peel back so many layers of my identity?

\footnotetext{
${ }^{2}$ Bajan (adj.) - Barbadian dialect term used to refer to persons of Barbadian nationality, or originating
} from the country of Barbados. 


\section{Encounter \#3 - Reflections of who / am}

For many years prior, I thought about my identity especially during my teenage years. I had been teased in secondary school and accused of being a 'watered down' Bajan because I went to a private Catholic primary school, where we were never allowed to speak the broken-English, Bajan dialect while in school. This school experience was indeed private, and isolated from the Barbadian traditions of school days. We were taught to speak and write the Queen's 'perfect' English ${ }^{3}$ and nothing else was acceptable. On top of that, as private school students, we unconsciously spoke that 'perfect' English in a certain way, which my then new secondary school counterparts found to be very 'speakyspokey' or 'bougie' (bou-jee, slang term for bourgeois). Ironically enough, my new public secondary school was called Queen's College.

If ever there was a public school to be historically associated with the 'bourgeois' label, it was Queen's College (QC). From its founding, QC was probably the most prestigious girls' secondary school, as it was known to produce some of the most reputable female professionals, including some of the first female political figures. I remember my father telling me stories of his school days as a Harrison College boy (the equivalently respected all-boy school at the time), eagerly waiting for the school bell to ring; which signalled the time to hustle out of school in order to get a glimpse of, or if so bold, to make the acquaintance of a QC girl or two, as they walked through Bridgetown4.

As a QC girl, I was burdened with the challenge of being amongst the best and the brightest in the island. My results in the secondary schools' common entrance examination determined my status as a 'bright' girl. Both sides of my family were considered to be of the middle class for many generations before and were known to be either very educated people or educators, or both. Due to the vision of our national hero and 'father of independence' Errol Barrow, education in Barbados has for several years been as common as having a birth certificate. Once you are born Barbadian, you are

\footnotetext{
${ }^{3}$ Referring to Standard British English.

4 Bridgetown - the capital city of Barbados
} 
guaranteed a free education. Although my grandparents did not have this privilege, they were down-to-earth Barbadians who could speak the Queen's English but could put down a Bajan cussin' in the same breath. Any post-colonial education that they received did not remove the Bajan in them. It is therefore my birthright to follow in the same footsteps of not only my family, but also to move in the ways of a proud Barbadian who feels deeply about honouring traditions which highlight my culture, and doing "credit to my nation, wherever I go"5.

\footnotetext{
${ }^{5}$ The National Pledge. Ministry of Foreign Affairs \& Foreign Trade, n.d. Web. 10 Jan. 2012.
} <http://www.foreign.gov.bb/pageselect.cfm>. 


\section{INTRODUCTION}

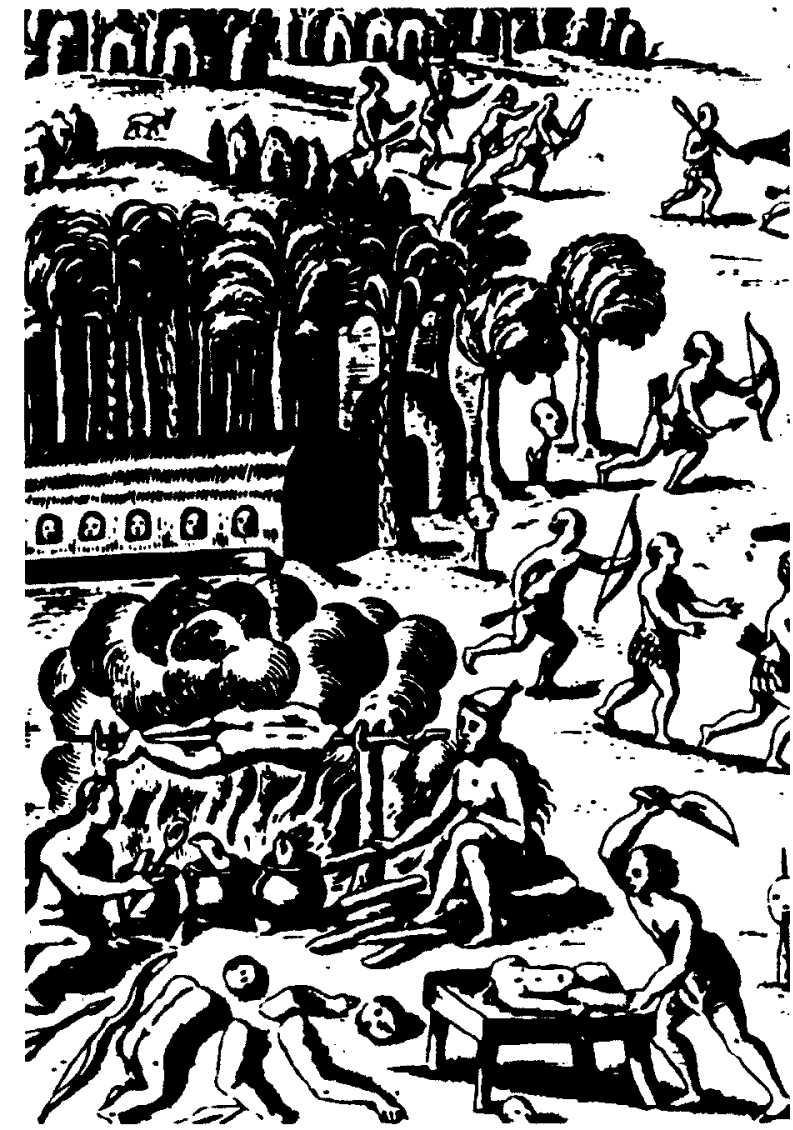

Figure 1 - A 17th century image depicting the perceived cannibalistic practices of the native Caribbean inhabitants
The ability to identify and preserve culture has always been important to mankind. In discussing the active nature of culture, Amos Rapoport states that "cultures may be regarded as the distinctive means whereby populations maintain their identity" ${ }^{\prime 6}$. As human beings, we are defined by our culture; allowing the knowing of 'self' to be diluted therefore means that cultures could eventually be lost as a homogeneous group of 'no names'.

The increasingly visual character of modern society has allowed for the amplification and spread of universalised stereotypes of Caribbean culture. Caribbean culture has long been a victim of idealised perceptions and iconic messages of the Caribbean as a place of sun, sea and sand with connotations "of a once-leisured colonial existence, the presumed early hedonism of the Region, the obvious attractions of sun over snow, heat over cold, and the idea of

${ }^{6}$ Moore, Keith D., ed. Culture, Meaning, Architecture: Critical Reflections on the work of Amos Rapoport. England: Ashgate Publishing, 2000. 180. 
heaven reflected in the clear blue sky"7, according to Patricia Mohammed. Given the region's long history of migration and fusion of cultures, the associated imagery and perception should, we might think, be far more interconnected and progressive than the aforementioned 'hedonistic' remnants of colonial times.

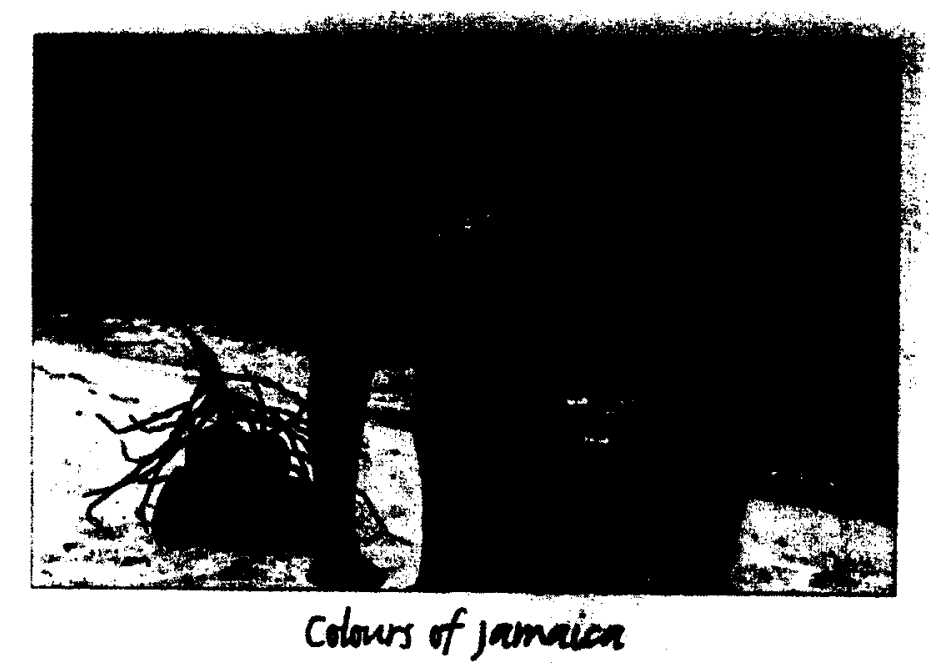

Figure 2 - A Jamaican postcard depicting the implied pleasures of 'sun, sea and sand'

In discovering the Caribbean, the Europeans transmitted information back to the Monarchy via personal written encounters, self-drawn maps, and through paintings and drawings of the indigenous people and the land they inhabited. More often than not, personal bias and subjective opinion resulted in the production of varying or skewed impressions of the real situation. This is the basis from which the 'mockery' of Caribbean identity began.

${ }^{7}$ Mohammed, Patricia. Imaging the Coribbean. Oxford:Macmillan Publishers Ltd., 2009. 10. 
Patricia Mohammed in the book Imaging the Caribbean, states that "it must be appreciated that it is impossible for either academic or popular discourses to determine a unified Caribbean sensibility. This is and continues to be contested terrain, past and present, from within and without the Region" 8 . While there may be widely held agreement on the previous statements, a rhizomatic ${ }^{9}$ understanding rather than a linear one, might perhaps present the beginnings through which a collective narrative, if not a definition, maybe derived.

Caribbean origin stems far beyond its 'European-established' discovery to the native American Indians (or Amerindians) who were the first inhabitants, and common base for Caribbean beginnings. Apart from the Europeans, the region's cultural melee generally includes African, East Asian and Middle Eastern descendants. In the case of Barbados however, the blend of enslaved migrants was slightly different, with Barbados being the recipient of the largest portion of the white Irish indentured servants who were brought to only four islands during colonial times. The existence of these white servants, who were largely treated as slaves, created an interesting polemic for the 'black and white' social system of hierarchy which underpinned the colonial plantocracy period of the island. The clear existence of a system of discrimination via 'class' more so than race, as established by the English colonisers of the time, is still relevant in modern Barbadian society; but this is also relevant in many other places in the world today.

Given the apparent multifaceted nature of the group of people to be discussed, the thesis will seek to generally discuss the role of all parties prior to, during and after the colonial period until present day, in order to outline the background against which the creation of the Barbadian cultural subset can

\footnotetext{
Mohammed, Patricia. Imoging the Caribbean. Oxford:Macmillan Publishers Ltd., 2009. 7.

${ }^{9}$ Rhizomatic adj. (rhizome n.) - as a model for culture, the rhizome resists the organisational structure of the root-tree system which charts causality along chronological lines, looking for the point of origin of a thing towards the pinnacle or conclusion of that thing. The rhizome presents history and culture as a map or wide array of attractions and influences with no specific origin or genesis.
} 
be approached. Through this method of exploration, it is intended that the Barbadian, and by extension the Caribbean society, will be able to better understand and measure its growth and maturity beyond the colonial period, in ways that strengthen and preserve its unique cultural identity. Through attempting to materialise what that cultural identity truly is however, one might ask whether there is even a singular cultural identity to be defined.

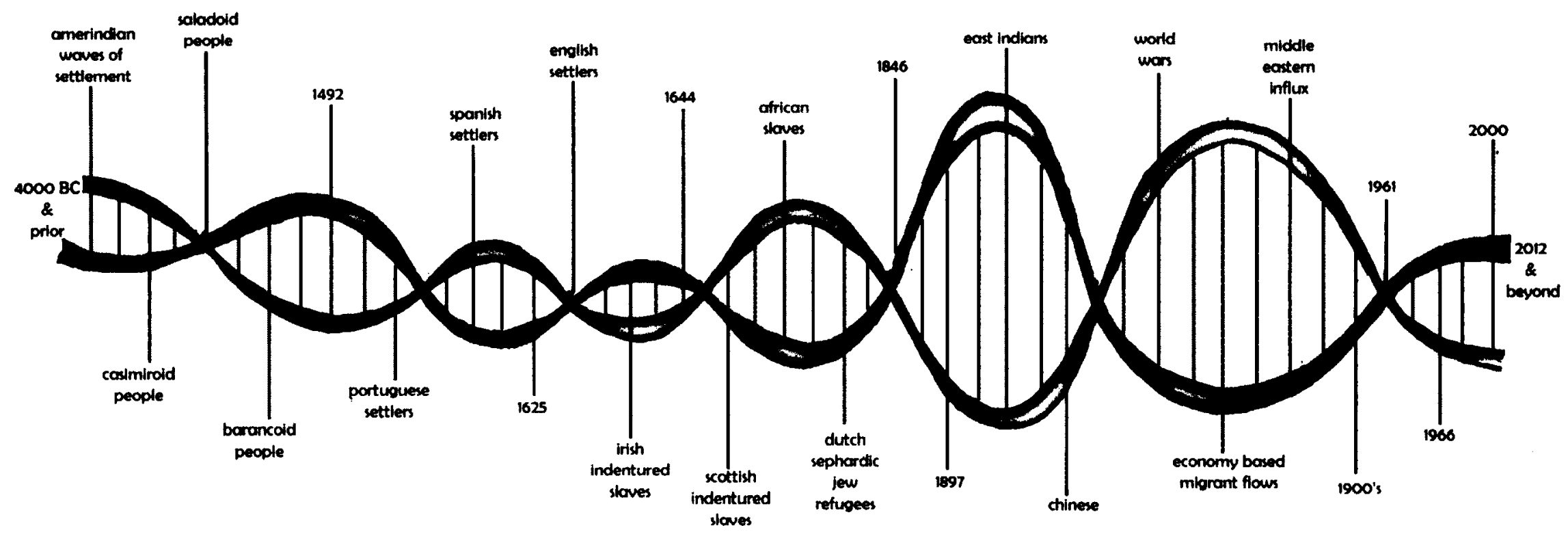

Figure 3 - Chromosome of influences: Barbados' cultural evolution

The thesis will seek to dispel the commercially tainted imagery; and re-present the content of the Bajan identity. Later, the design project's material intention will be to develop a proposal for an architecture which is a product of mapping the resulting inferences made from the investigation of the island's culture. Thus, the adaptive re-use of an existing cultural heritage site is intended to be the vehicle for deepening public understanding of Bajan Caribbean-ness. 
I) CULTURAL IDENTITY, IMAGERY \& REFLECTIONS OF SELF

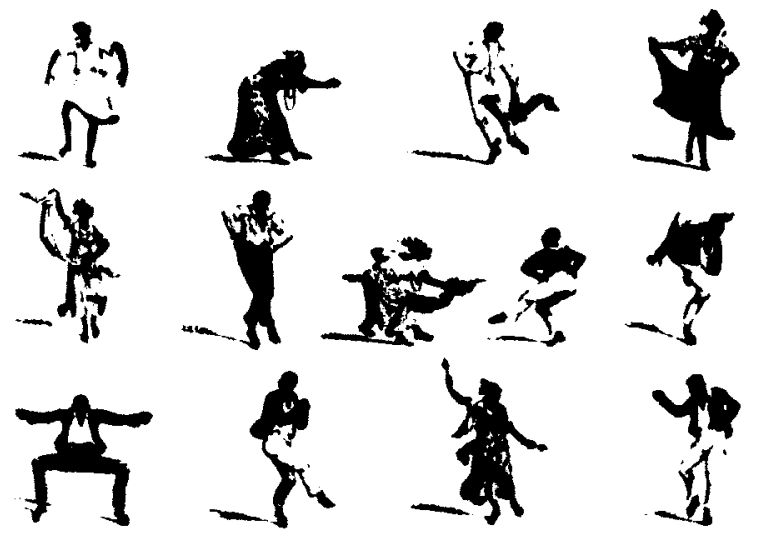

Image Source: Richard Bridgens, 'Negro Figuranti' (1844) 
In discussing the ideas of culture and cultural identity one must first discuss the notion of identity, as an introduction to the root of the issue to be discussed. According the Webster's Online Dictionary, 'identity [noun] is the fact of being who or what a person or thing is' ${ }^{10}$. An individual's or group's identity differentiates them from other groups or individuals. The Webster's Online Dictionary provides several definitions of culture but for the purposes of this thesis, only two will be referenced:

- Culture [noun]: -

- The shared values, traditions, norms, customs, arts, history, institutions, and experience of a group of people. The group may be identified by race, age, ethnicity, language, national origin, religion, or other social category or grouping.

- A particular society, at a particular time and place ${ }^{11}$.

Edward B. Tylor, in his book Primitive Culture, made observations that "culture is a holistic integrated thing. Culture isn't just art, or families, or ways of making a living, or religion. Culture is all of these and more because the things that comprise it, fit together"12. There lies the understanding that where external customs or institutions might have been imposed, their incompatibility with overall shared social norm rejects them from being a part of the 'particular society at that particular time and place'. This however does not mean that culture remains stagnant in its definition or in the advancement of its values. Like time, culture is a continuous ever-moving, ever-changing element, hence its careful definition as being a 'particular society, at a particular time and place'. Within the Caribbean

\footnotetext{
${ }^{10} \mathrm{http} / /$ www.websters-online-dictionary.org/definitions/identity

${ }^{11}$ http://www.websters-online-dictionary.org/definitions/culture

12 Tylor, Edward B. Primitive Culture. 6th ed. Vol. 1. London: John Murray, 1920. ii. 2 vols.
} 
context, the European 'discovery' helped to both strengthen and denigrate various elements of the cultural identity at the time. The positive and negative experiences of this encounter now shape the future strategy of the morphosis of Caribbean culture.

In the book The Origins of Culture by Penn Handwerker, it is stated that "because new things arise as new combinations of old things, cultural change exhibits the properties of evolutionary change. This means that what exists now could not exist without what went before. This means, too, that the things of the moment set the options for our immediate future ${ }^{\prime 13}$. In the current atmosphere of existence, the acknowledgement of what went before as the root of what exists now implies that on some level, there needs to be an acceptance of the European values and belief systems which were imposed on the peoples who populated the Caribbean at the time of colonialism. For positive growth therefore, there needs to be a re-interpretation of the events that occurred from 1492 onwards, as more than "simply an encounter between two worlds, but the positive consequences of several encounters among several worlds" ${ }^{14}$.

Cultural identity therefore, may be described as the identity of a group of people or culture. It is the identity of individuals who belong to and are influenced by the shared values, traditions, norms, customs, arts, history, institutions, and experiences of that group. Jamaican scholar, social critic and cultural icon Rex Nettleford, describes the Caribbean cultural identity as an innate structure created through "thought systems, ontologies, cosmologies and a Caribbean way of knowing, a Caribbean way of seeing, nurtured not out of magic, though the Caribbean imagination is fertile to a fault, but out of

\footnotetext{
${ }^{13}$ Handwerker, W. Penn. The Origin of Cultures: How Individual Choices Make Cultures Change. Walnut Creek, CA: Left Coast Press, 2009.43. ${ }^{14}$ Rex Nettleford, 'Afterword: A "New Worid" View from the Periphery', in Race, Discourse and the Origins of the Americas, ed. Rex Nettleford and Vera Lawrence Hyatt. Washington, DC: Smithsonian Institution Press, 1995. 280.
} 
empirical experience of a collision of cultures ${ }^{\prime 15}$. In acknowledgement of the known compromises made in the Caribbean experience of cultural collision, Nettleford further expresses his thoughts on the future of the Caribbean cultural identity by stating the its people "should not waste psychic energy on the problems of Europe's ethnocentric view of world history - the only thing that such people can take into the next half millennium with confidence is who and what they are. Therefore, the matter of who and what they are is critical to their own grasp of the urgency of positioning themselves for constructive participation in whatever is likely to develop by way of discourse and action in this decade and well into the $21^{\text {st }}$ century - indeed far into the next millennium" ${ }^{16}$. It is for this reason of 'grasping identity' that the understanding and fitting representation of Caribbean culture is immensely important; not only to its people but also to those with whom they interact.

In approaching the issue of grasping the Caribbean cultural identity, it is clear that some of the problems of the Eurocentric view of Caribbean history must first be highlighted; the most significant problem being that of perception and the images generated from those perceptions. The issue here is not so much to do with the Eurocentric opinion or perception but more so to do with its permeation into the Caribbean people's perceptions of themselves and the knowing of their own collective identity.

\footnotetext{
${ }^{15}$ Rex Nettleford, op.cit.. 278.
}

${ }^{16}$ ibid. 284. 
After Columbus' voyage to the Caribbean, no culture remained unchanged. In addition to the fact that the 'Columbian exchange' facilitated the intermingling of peoples, animals, plants and diseases, his discovery also enabled a biased process of cultural documentation. In relaying their discovery of the New World, the Europeans sought to illustrate the physical and non-physical features of the Caribbean islands. As far as the Europeans were concerned, there was no 'known' existence of the islands and they therefore needed to be "named, drawn, mapped and quartered into divisions from which profit might be accumulated, and land, people, flora and fauna controlled"17. These illustrations now remain the imprinted images and perception of the Caribbean cultural identity.

The Webster's Dictionary defines an image as "an imitation, representation, or similitude of any person, thing, or act, sculptured, drawn, painted, or otherwise made perceptible to the sight; a visible presentation; a copy; a likeness; an effigy; a picture; a semblance" ${ }^{18}$. It also states that an image may be "a representation of anything to the mind; a picture drawn by the fancy; a conception; an idea" 19 . Additionally, images may be two dimensional, three dimensional or simply exist as a figment of one's imagination; which is unrestrained by no dimension. Regardless of the image's materialisation or lack thereof, the outcome is a perceived representation of a message.

\footnotetext{
${ }^{17}$ Mohammed, Patricia. Imoging the Caribbean. Oxford:Macmillan Publishers Ltd., 2009. 135

${ }^{18} \mathrm{http}: / / \mathrm{www}$.websters-online-dictionary.org/definitions/image

19.bid.
} 
During colonial times illustrating or 'playing up' the potential assets of discovered lands and people was highly important to the building of an empire. Maps and drawings such as that shown in figure 4 , were therefore key to giving account of agricultural interests or any other means by which profits could be extracted for The Crown and the discoverers as individuals. The attractiveness of these 'accounts' also meant increased likelihood of financial support and approval by the Crown for conquest of the 'encountered' regions.

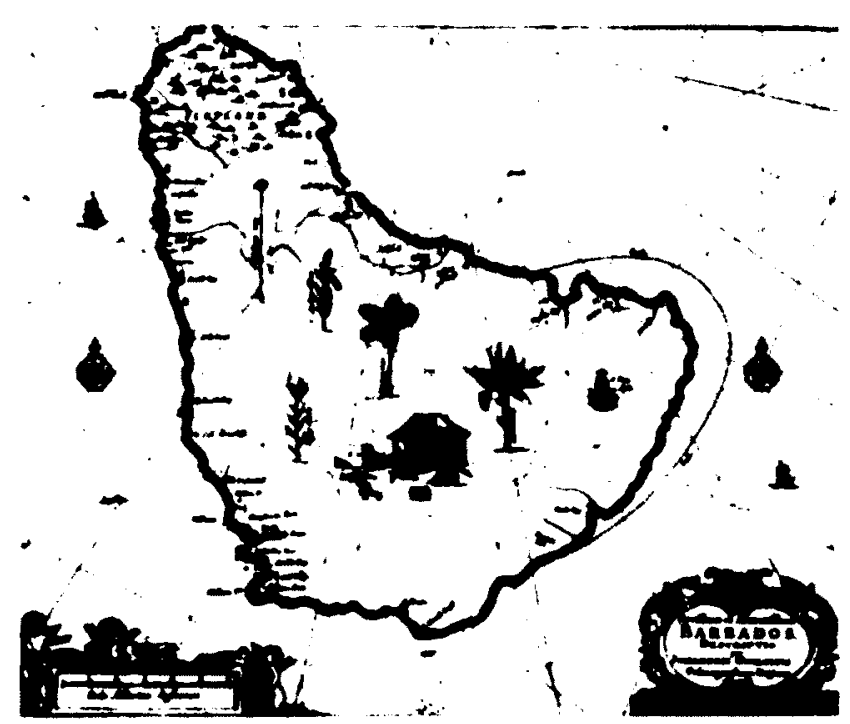

Figure 4 - Mop of Barbados from the colonial period which illustrates the island's exploitable resources
Overseas expansion could only be understood by Europeans at 'home' through the use of maps. "Only through maps could administrators hope to visualise the regions they were dealing with" ${ }^{20}$ and through these visualisations, varying skewed perspectives were transmitted. Figures 6,7 and 8 below show hand-drawn perspective maps which are evidently rudimentary, with little detail shown in care for perspective or resemblance; while the images lack realism, we must assume however that the desired effect was achieved in their production. In addition, the said images provide some insight into the minds of the European conquerors at the time.

\footnotetext{
${ }^{20}$ Mohammed, Patricia. op.cit. 72.
} 


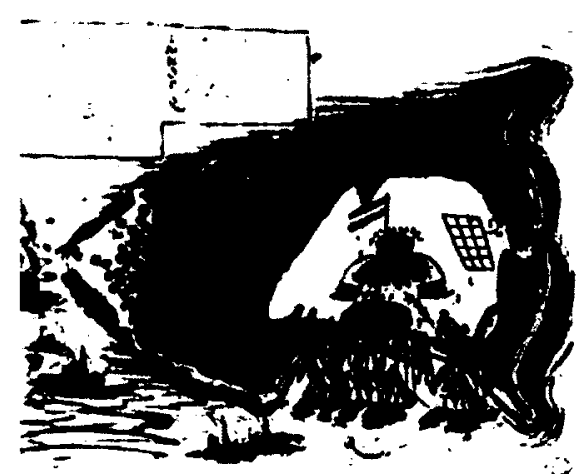

Figure 5 - Seventeenth century handcoloured drowing

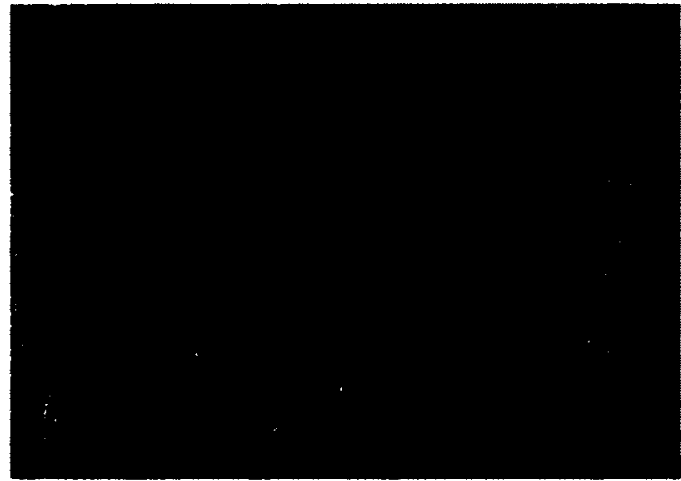

Figure 6 - Sketch of the coast of Guyana transmitted to Spain

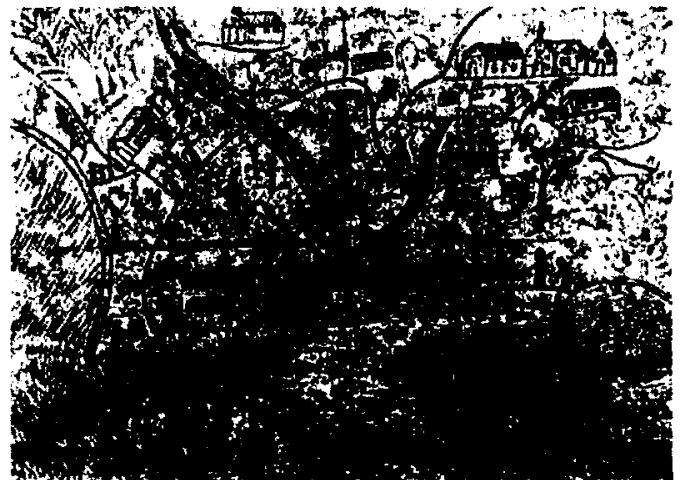

Figure 7 - Seventeenth century sketch showing details of settlement on the coast of South America

The Europeans used what they knew as a basis for relaying information about the 'unknowns' which they discovered. Anthony Pagden called this the 'principle of attachment'. Mohammed suggests that "the major problem with the principle in the act of colonisation is that it viewed the unfamiliar through the lens of the known"21. Pagden clarified the principle by explaining that "our eyes and our scientific understanding move from the known to the unknown, not the other way. Having made the attachment, we name the unknown for the known. Having named, we have recognised and having recognised, we have also taken possession"22. As a result of the need to 'identify' and take possession, several elements of Caribbean culture were criticised and submerged because they were unknown and therefore simply deemed to be 'uncivilised practices'.

It became clear that no effort was made to understand the so-called 'uncivilised practices' from any other viewpoint than that of the Eurocentric view. The damaging effects of the European failure to accept things as they were, ultimately caused an internal and external shift in respect and

\footnotetext{
${ }^{21}$ Ibid. 78.

${ }^{22}$ Ibid.
} 
acknowledgement of $a b$ origine heritage; this shift compromised the natural progression of the native people's cultural identity. "Among settlers in the Caribbean, European values and traditions were premised as the hierarchically superior ones, with all others located lower down on a Western scale"23, hence the Eurocentric view became contagious.

Even today the Caribbean culture remains within the grasp of the remnants of iconic symbols created in colonial times. Some map-makers still make use of the iconic symbols which were used for mapping and physically representing the Caribbean and as a result are still consciously (or unconsciously) advocating the mystification and myth-making which encapsulated the islands for centuries before. In speaking about the mapping of the West Indies, Patricia Mohammed suggests that "cartographic symbols continue to invite conquest but of another sort. To retain the commercial mystery of the Region, history is reinvented by the new pirates of the Caribbean, films representing the contemporary visual maps which convey a similar diet of truths blended with fiction"24.

Through the previous statement it is understood that the $17^{\text {th }}$ century mapping of the Caribbean region has now morphed into a mapping of identity; a map that although isn't physically drawn, is also as rudimentary in its shape as those that were physically drawn. The question should now be asked then, how can the identity map now be redrawn in a fashion that is systematic and suitable to the content it represents? An examination of the content to be mapped is therefore immediately relevant, an examination which should firstly be based on the 'drawing' of Caribbean impressions of self.

\footnotetext{
${ }^{23}$ Mohammed, Patricia. op.cit. 36.

${ }^{24}$ Mohammed, Patricia. op.cit. 90
} 
With the removal of the plantocracy and the decline in importance of agriculture in contemporary times; the Caribbean has fallen back on its previous European branding, as the destination of ultimate hedonistic pleasures - all that encompasses the tourism industry. Following on from the marketing strategies of colonial times, the majority of Caribbean countries attempt to 'paint pictures of themselves' in order to entice and re-invite Europeans and others to the shores of Caribbean beaches, in the vein of maintaining economic survival.
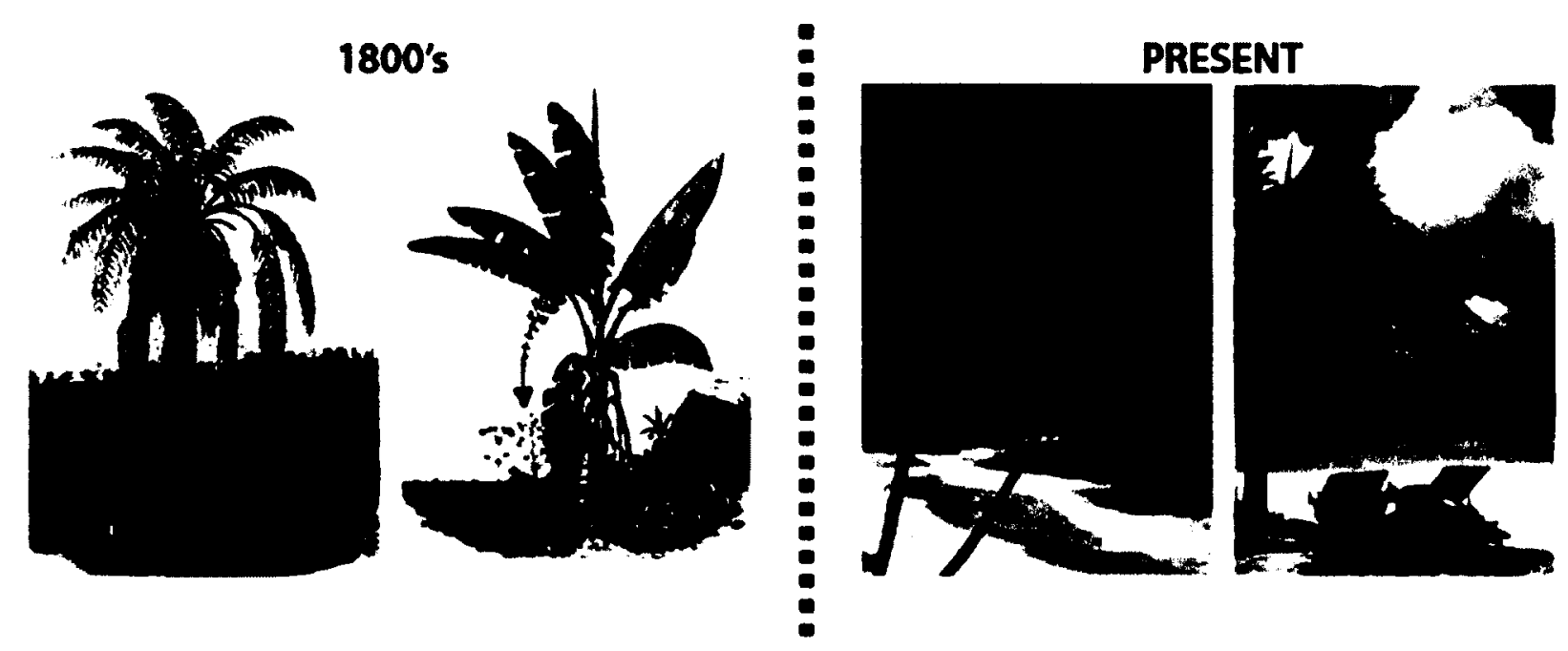

Figure 8 - Comparison of images created by colonial settlers with those used by the current tourism industry

The heavy economic dependency on tourism has provided the vehicle for several types of commercialised images which have been a source of knowledge and stimulation for perception of the region's identity - its people and their culture. It can be argued then that images, especially photographs, are often perceived as reproductions of reality, and are therefore the reality as far as the 


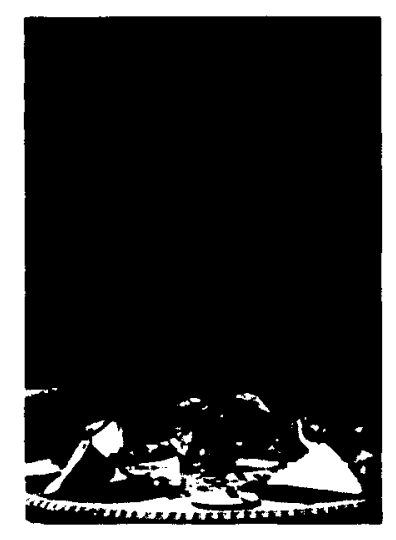

observer is concerned. However according to Bertolt Brecht, "less than ever does a simple reproduction of reality express something about reality"25. His sentiments are precisely directed at the 'images' conveyed through photography and its manipulated imagery. Given the Caribbean's long history of migration and sharing of cultures however, the region's associated imagery should be far more interconnected and progressive than some commercialised images would have us believe.

According to Patricia Mohammed, "almost from the moment we are born into a writing culture,
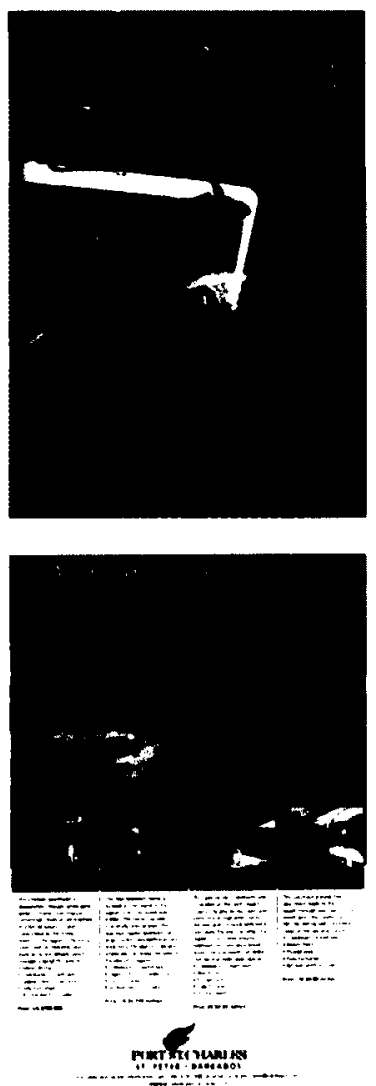

Figure 9 -Sample images from the Barbados Hotel and Tourism Association's recommended guide on Barbodos.

${ }^{25}$ Marien, Mary W. Photography: A Cultural History. London: Laurence King Publishing, 2006. 7.

${ }^{26}$ Mohammed, Patricia. op.cit. 24. we are trained to be visually oriented. Our education is almost entirely dedicated to teaching us how to understand and to communicate visually through reading and writing...[yet] our basic thoughts and values quickly come to be expressed in visual terms and metaphors ${ }^{\prime 26}$. We are taught to read and to recognise the relationship between objects and words - for example, ' $a$ is for apple, b is for bat, $c$ is for cat'. Aristotle explained this methodology very elegantly when he said that "the soul never thinks without an image". Similarly, when a European or North American thinks 'the Caribbean', images of perceived realities are displayed in their minds; the origins of these perceptions however are usually linked either to the historical or current commercial images of 'understanding' that have been produced by, or for the Region.

The Caribbean people themselves therefore, are not blameless in the production of images which skew the perceptions of the external eye. One might argue that the question of self is not as immediately relevant as the question of economic survival and hence the lesser need is sacrificed to service the greater. The concern in this argument however is that in servicing economic survival, cultural values are lost through commercial re-fashioning. There is a need therefore, to reconnect the images of 
self with the actual self. In doing so, one must make sure there is a knowing on some level, of what constitutes the actual self.

In addition to the complexity of the pressure for economic survival, Patricia Mohammed observes that "the legacies of looking north for goods, markets, exchange and approval still undoubtedly persist, not incidentally, but as part of the global chain which links economies and societies tightly to each other. Perhaps the most unfortunate aspect of dependency is that it grows accustomed to seeking affirmation from others, in the case of the Caribbean, primarily from Europe and North America - the fount from which all presumed high culture flows" ${ }^{27}$. These observations also suggest that there is still a psychological inferiority complex and an identity struggle, in the background of the 'Old World-New World meets Caribbean' relationship. Not only is effort being made to appeal to the tastes of others at the expense of the identity of native culture, but low-levels of self-esteem and self-worth seem to be resultant from seeking such external affirmation.

According to The Unknown Self by George Frankl, "every culture has a certain image of itself which acts as a model to its citizens, it represents a collective Superego which upholds certain values which are meant to express people's psychological needs and aspirations. By holding up a mirror to people in which they are expected to recognise their true selves, a culture exercises a powerful influence upon the collective self-image of its members and upon the formation of dominant charactertraits" ${ }^{28}$. National symbols are therefore very influential in their portrayal and shaping of the psyche of the people which they are intended to represent. Likewise commercial advertising campaigns may have similar influence whereby it is understood that 'this is the image we need to project', if we want our

${ }^{27}$ Mohammed, Patricia. op.cit. 24.

${ }^{28}$ Frankl, George. The Unknown Self. London: Open Gate, 1921. 201. 
tourism product to seem attractive; the tourism product which is now the root of the Region's economic survival. If tourism campaigns are essentially authorised by the national government who also authorises the composition of national symbols, what then can be said of the values of national identity? How do the people which national symbols represent unravel the confusion caused by the outward portrayals of the tourism industry? Should there not be some correlation between the outwardly exhibited values of frivol and luxury versus the inward values of conservative tradition and fulfilment of basic necessity? As a response to these questions, it might be argued that due to the versatile, multifaceted nature of the Caribbean group and their shared history of adaptation, that the idea of wearing multiple 'masks of identity' is a simple, if not effortless task. 
"I am a West Indian, not to be confused with those of Indian nationality or ethnicity.

I am a West Indian woman of Caribbean origin

Within that description of myself alone are so many separately defined layers but none are all encompassing of my identity as a Caribbean person..." 
The previous opening statements of this section allude to the general narrative of the identity of a Caribbean person. The relationship and the ability of the reader to identify with all of the layers of description may seem to be a task of piecing together incoherent fragments of thought. Through the juxtaposition of these fragmented layers of identity however, emerges the amalgamated sensibility of the Caribbean person.

To consider the prefix and suffix of the root word 'confuse'; con ${ }^{29}$ is defined as with, together, jointly or altogether and fuse $e^{30}$ is defined as to unite or blend into a whole as if by melting together. While the text of the previous chapters discusses the Caribbean people in the original confused form we shall consider the Caribbean people to be con-fused using the previous prefix and suffix definitions, for the purposes of this thesis. For those who have not been born, bred or educated in the history and culture of the Caribbean one might dare to ask, who are these con-fused people?

An exploration of their con-fusion will be made in the following text through discussion of remnant influences in the said layers of the con-fused cultural experience, in order to make informed suggestions in the section following this one, for the suitable architectural intervention which expresses a subset, of what we shall term 'Caribbean-ness': the Barbadian-Caribbean identity.

\footnotetext{
${ }^{29} \mathrm{http}: / /$ dictionary.reference.com/browse/con-

${ }^{30}$ http://dictionary.reference.com/browse/fuse
} 
The encounters between the Africans, Europeans and the indigenous Native Americans (Amerindians) on the 'foreign' soil of the Caribbean, along with the later arrival of peoples from Asia and the Middle East have created the platform for the con-fusion of the Caribbean cultural climate as it continues to evolve. Rex Nettleford, notes that this blending of peoples has "resulted in a cultural texture and diversity held together by a dynamic creativity severally described as creative chaos, stable disequilibrium or cultural pluralism"31.

While the circumstances of every encounter involved battles for establishing titles of conqueror and conquered, it was never intended to create the situation of cultural pluralism (which it inevitably did) but rather a situation of cultural dominance. The history of the 'West Indian' according to George Lamming, is neither brief nor is colonialism "the very base and structure of the West Indian cultural awareness $^{\prime 32}$. Eurocentric views have overpowered the influence and even the existence of any 'other' culture ever since the European 'discovery' of the Caribbean. In fact, the European-given dates of Caribbean discovery seem to nullify the existence of any cultural establishment prior to the dates of 'discovery' and colonization. In the case of several Caribbean islands, it is still taught that the original Caribbean peoples were already extinct, or were made extinct upon encountering the European invaders. In the earliest stages of the establishment of educational institutions in the Caribbean, "colonial schooling was education for subordination, exploitation, the creation of mental confusion and the development of underdevelopment. Such 'schooling' also encouraged the divisiveness of class. It is

\footnotetext{
${ }^{31}$ Nettleford, Rex M. Caribbean Cultural ldentity: The Case of Jamaica: An Essay in Cultural Dynamics. 2nd ed. Kingston, JA: lan Randle Publishers, 2003. xi.

${ }^{32}$ Lamming, George. "The Occasion for Speaking." The Post-Colonial Studies Reader. Ed. Bill Ashcroft, Gareth Griffiths, and Helen Tiffins. New York: Routledge, 1995. 15
} 
"I wear this past I

borrowed;

history bleeds

behind my

hollowed eyes"

Brathwaite, $K$.

'Sunsum', The

Arrivants no accident that in schools, no attempt was made to include the study of African and Caribbean history and literature. Therefore, generations of West Indians emerged and continue to emerge with ambivalent attitudes" about their ethnic background and cultural heritage. In addition, some writers have very plainly written and led their readers to believe that "the history of the Caribbean has been the history of imported peoples" ${ }^{33}$; a description in itself which lends to the idea that the Caribbean does not have a unique identity of its own, only the borrowed fragments of others.

From this, it is apparent that a critique of history as it is taught, is also relevant where Frederico Mayer points out in the preface to the UNESCO General History of the Caribbean (2000), that "in seeking to promote the preservation of cultural identities and greater understanding among peoples through exchange of cultural information, UNESCO has found it important to facilitate the writing of a new history of this region". In agreement, the discriminating observer must be allowed another point of departure for identifying with the Caribbean and its people. The people themselves however, must also be allowed another point of departure for how they perceive themselves in relation to others, in a way that becomes a continuous process of finding and defining themselves, while composing individual and collective narratives of identity.

History is often associated with the introduction of writing but for the sake of the Caribbean and its native people who existed hundreds of years before writing, history must also be understood to be based on "all human actions, including those recorded orally and reflected exclusively in archaeological record" ${ }^{\prime 34}$. From the combination of all records - oral, written, visual and other - an all-encompassing and more fitting story can be told. Forte, further supports this idea stating that "by filling a critical gap in

\footnotetext{
${ }^{33}$ Forte, Maximilian C., ed. Indigenous Resurgence in the Contemporary Caribbean. New York: Peter Lang Publishing Inc., 2006. 4.

${ }^{34}$ Reid, Basil. Myths and Realities of Caribbean History. Alabama: University of Alabama Press, 2009. 1.
} 
the literature of the modern Caribbean by focusing on contemporary indigenous peoples of the region, which does not mean forgetting history [already taught], indeed, most of the contributions offer significant historical foreground, without conflating indigeneity with archaeology"35. In re-telling the history of the Caribbean region, we must also reconsider the name by which it is identified. It is not known as yet what the so-called Carib Indians called themselves due to discrepancies in deciphering the language used. The name Carib was given by the Europeans, based on the mythical practices of cannibalism. If the mythology behind the cannibalistic practices and by extension the provision of the Caribbean name becomes refuted in the re-writing of history, removing the name with which the contemporary indigenous people identify would essentially be an attempt to forget the circumstance of history. Instead, moving forward with the addition of substantiated information would signal the evolution from archaeology to the contemporary.

\footnotetext{
${ }^{35}$ Forte, Maximilian C., op. cit. 5.
} 


\section{LAYER 2 - MISTAKEN IDENTITIES OF THE PAST BECOME PRESENT}

It is accepted that Christopher Columbus described the inhabitants of the Western Hemisphere as Indians because he thought he had reached the islands on the eastern side of the Indian Ocean. Columbus could not use the term Native American because he was not aware of the American continents as yet; this is the origin of the West Indian title which Caribbean people today still 'identify' with. The identification with the West Indian title however, is not with Columbus's ignorance but rather with the fact that the Caribbean has a Native American Indian ancestry - referred to as 'Amerindian', in Caribbean historical accounts. As it would turn out, the Amerindian people are the most misunderstood ancestors of the Caribbean region, with archaeological discoveries still revealing and dispelling several myths about the existence and cultural complexity of the Amerindian people.

Writers Peter Hulme, Irving Rouse, Sven Loven and Thomas Coke ${ }^{36}$ in their separate examinations of the history of the West Indies, provide lengthy discussions and analyses of the types of Indians who peopled the Caribbean. In general these analyses all attempted to 'lump' the said people into two very generalised groups: the Island Caribs and the Tainos (Island Arawaks). These groupings were based on vague similarities of several different groups of Indians who migrated from the Amazon basin at various times. The writers' accounts also assigned the early migrants to various segments of the island basin and even went so far as to eliminate the possibility of their existence in some areas - as in the example of Barbados. Later archaeological evidence and discourse however, deems the writers to be guilty of over-generalisation through the assignment of mistaken identities to the Amerindian people and under-estimation of the native people's reach of existence. The archaeological evidence, based on circumspect research points to "the presence of multiple cultural groups in the region before 1492

${ }^{36}$ Refer to Bibliography. 
namely the Casimiroid, Ortoioroid, Saladoid, Barancoid, Troumassan Troumassoid, Suazan Troumassoid,

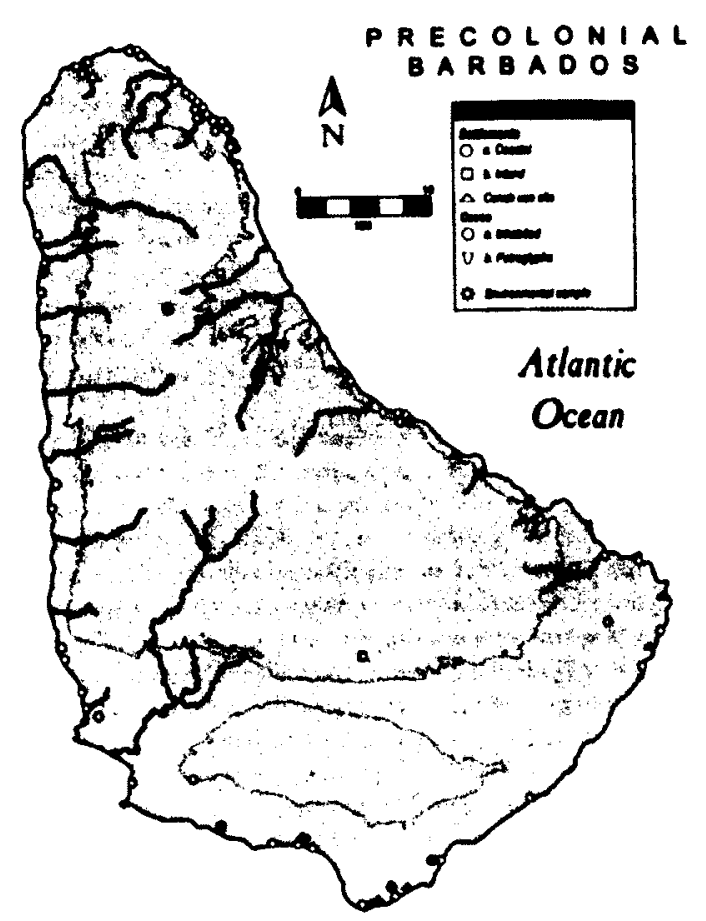

Figure 10 - Pre-colonial Map of Barbados with locations of several archaeological sites of Amerindian habitation on the island. The existence of any permanent habitation was previously refuted based on the generalised habits of a few groups elsewhere. and Ostionoid peoples" ${ }^{37}$, especially in islands that were previously overlooked. While it is understood that these people had very similar characteristics, it was agreed that the differences in language and the levels of cultural division merited distinction and the award of individual identities. Lessons of history taught in Caribbean schools however, still very loosely refer to the early ancestors as 'the Arawaks and the Caribs'. This is an example of the ambivalent manner with which the Caribbean still considers the history of its culture and its transmission to successive generations.

Continuing with the use of Barbados as an example of mistaken identities delineating the present identity, it must be noted that the island's name is the only known remnant of Portuguese and Spanish presence on the island. For later observers and inhabitants, Barbados' name provided clues about whom and what occupied the island at the time of Spanish arrival. Besides the loose English translation of the original Spanish name of 'Los Barbados' into 'The Bearded Ones', the mystery of the reasoning behind the island's name remains unsolved. It has been widely speculated and unofficially

\footnotetext{
${ }^{37}$ Reid, Basil. op.cit. 11.
} 
accepted, that the description was given based on the hanging roots of the Bearded Fig Trees, which were widespread on the island on discovery. Another speculation suggests that the name instead describes the "fierce-looking Afro-Arawakan dwellers of the island" ${ }^{38}$, who carried a bearded appearance. The Arawak (Amerindian) people however were not characteristically known to be bearded, which lead to the claim that "prior to [any] European arrival, the island had been discovered by Africans whose bearded descendants would have been in stark contrast to the beardless Amerindians ${ }^{\prime 39}$. It is not difficult to believe that there might have been an African presence in the island before European discovery, since Barbados is geographically the closest Caribbean territory to West Africa. There is however, no evidence to date that substantiates the latter theory of African presence prior to colonisation.

Regardless of when the Africans might have travelled to the Caribbean region in general, "the Africans and their Creole progeny have constituted the demographic majority since the mid-seventeenth century [leaving] behind a rich cultural tradition clearly expressed in language, social ethics, trade, religion, sport, dance, song and political radicalism ${ }^{\prime 40}$. Thus, according to Professor Hilary Beckles, many of the Caribbean's cultural traditions are a clear reminder that "there is much of West Africa within"41. Although a major portion of the Caribbean populous' ancestral identity has been recognised and accounted for as being of African descent, a similar situation to that of the region's Amerindians still exists with regards to the understanding of the creolised ${ }^{42}$ version of the African cultural heritage in the Caribbean. The identities molded from the African heritage are still in the state of being resolved and

${ }^{38}$ Carrington, Sean, Henry Fraser, John Gilmore, and Addinton Forde. A-Z of Barbados Heritage. 2nd ed. Oxford: Macmillan Publishers Ltd, 2003. 16.

${ }^{39}$ Ibid.

${ }^{40}$ Beckles, Hilary M. op.cit. xvii.

${ }^{41}$ Ibid.

${ }^{42}$ Creolised (adj.) - incorporating a considerable range of features from one or more unrelated cultures, as the result of contact between cultural communities. (http://dictionary.reference.com/browse/creolised) 
understood by the Caribbean people themselves, but with a far less degree of unidentified territory as that of their pre-historical native Amerindian ancestors, whose "cultural and linguistic relationships remain poorly resolved" ${ }^{\prime 3}$. However, through the resurgence of elements of material culture gathered from archaeological findings, coupled with more sensitive research theorisation, additional pieces to the puzzle of the Caribbean identity are being found. The below images illustrate sample elements of material culture which are either considered relics or are on the verge of being classified as such.
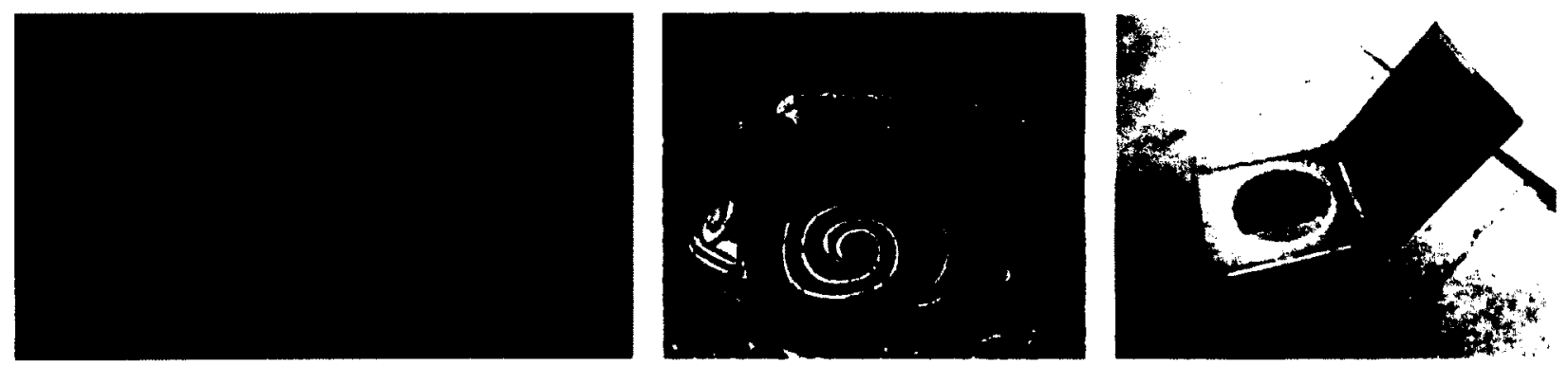

Figure 11 - Relics of the past: (left to right) A Warri board, An Amerindian clay pot, A commode

\footnotetext{
${ }^{43}$ Heckenberger, Michael J. "Rethinking the Arawakan Diaspora: Hierarchy, Regionality, and the Amazonian Formative." Comparative Arawakan Histories: Rethinking Language Family and Culture Area in Amazonia. Ed. Johnathan D. Hill and Fernando Santos-Granero. Chicago: University of Illinois Press, 2002. 99.
} 


\section{LAYER 3 - THE CONTEMPORARY IDENTITY \& ITS STRUGGLES}

At the international level, the Caribbean is often imagined as a single place, "a projection of EuroAmerican fantasies and desires...[yet] each Caribbean society has its own rich history, literature, language, music, art, cuisine, and quite different political and economic situations" ${ }^{\prime 4}$. Rather than Maximillian Forte's reference to the impersonal description of the Caribbean region's history as being that of "imported peoples", the history of the region can be likened to that of an ever-boiling stew, with ingredients constantly being added, con-fusing and expanding the stew's range of flavour.

In Beating a Restless Drum, June Bobb alludes to the Caribbean con-fusion as being a regional point of interest: "historically, the Caribbean world has been seared by the fires of slavery and colonisation. The result is a peculiar fragmentation of the psyche of its people. This debilitating fragmentation permeates the life and the literature of the region and may be traced to the racist, paternalistic attitudes and practices of the early colonists, slave holders and historians ${ }^{\prime \prime 45}$. Is the fragmented psyche perhaps the unifying layer of Caribbean cultural identity? Could the acceptance of this fragmented nature be the way in which it is bound?

In contemporary Caribbean societies, the issue of cultural identity remains of high priority, alongside political independence and economic self-sufficiency in the process of decolonisation. Independent-nation status is perceived as being a significant benchmark in the struggle against external domination. However, independence has not been the 'be-all, end-all' solution it was believed to be. The date of independence for each nation represents the points of fissure where each begins its separate journey of standing on its own; seeking to create a new 'name' or identity for itself.

\footnotetext{
"4heller, Mimi. Consuming the Caribbean: From Arawaks to Zombies. London: Routledge, 2003. 8.

${ }^{45}$ Bobb, June D. Beating a Restless Drum: The Poetics of Kamau Brathwaite \& Derek Walcott. Trenton, NJ: Africa World Press Inc., 1998. 17.
} 
National symbols, anthems, pledges and other heraldic charges are the devices by which each Caribbean nation now 'identifies' itself. These national images are a reflection of "a particular form and content that is symbolically relevant to the presentation of the nation's history ${ }^{\prime 46}$; and seemingly its present context as well. Patricia Mohammed cites however that "while there is apparent freedom of choice in selecting a nation's flag design, in the sense that this can change with each head of state, heraldic charges in the Commonwealth Caribbean as a general rule are subject to the approval of, and are officially granted by the Royal College of Arms in London"47; this rule however is only an example of the remaining arm of British colonial governance and does not speak for the French and Spanish colonisers.

The language and style of governance imposed by colonisers and the groups of people which were selectively transplanted for the purpose of each empire, are the first points of differentiation for the everyday cultures that developed in the Caribbean. The understanding of the similarities and the differences of the Caribbean people however, makes the case for any Caribbean-born individual to assume the title of at least two identities: the regional identity - which in itself is a multiple identity and the national identity - which confusingly is a subset of the preceding identity but yet seeks to separate itself from all others who are also a subset of the preceding.

So who are the Barbadian people and what makes them different from the Belizeans, Cubans, Guyanese, Haitians, Trinidadians and the Vincentians, etc.? Are they all not 'of the Caribbean'? In the text that follows, the points of differentiation which allow for an understanding of the 'flavour' of the Barbadian-Caribbean identity, as it differs from other subsets of the Caribbean identity.

${ }^{46}$ Mohammed, Patricia. op.cit. 353.

${ }^{47}$ Ibid. 


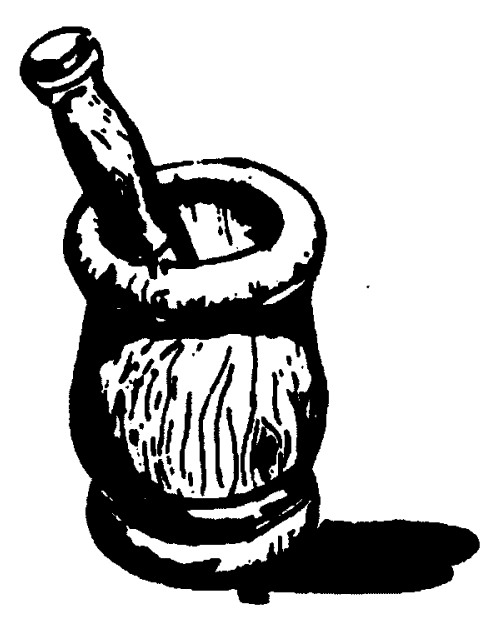

Figure 12 - The Mortar-Pestle A two-piece utensil of African origin, used to pound and blend condiments and other ingredients together. The mortar is the hollowed container and the pestle is the pounding stick. 
In discussing the cultural identity and the overall significance of Barbados - an island totalling 166 square miles - it is fitting to apply the Bajan proverb "duh is more in the mortar dan de pestle" ${ }^{48}$, meaning that there is more to the issue than appears on the surface.

As small as the island may seem in relation to the continents, and even to some of its Caribbean neighbours, little Barbados is considered by its locals and counterparts to be "punching well above its weight" ${ }^{\prime \prime 9}$. Barbados' movements throughout history as one of the more stable, forward-moving and forward-thinking societies in the Region has often times caused its Caribbean neighbours to not only be intimidated by its 'strength' and 'will' to succeed, but has also at times incited envy. Within the last few decades, the Caribbean Community (CARICOM) has been attempting to implement of a Caribbean Single Market and Economy, based on the 'cohesive model' of larger nations of the United States which share one land mass and one currency. The vast differences in the levels of cultural, economic and political development however have made it extremely difficult to accomplish. For many years Barbados has been at the head of these discussions and has been highly influential in 'setting the bar' of standards to which its fellow Caribbean country men must rise. One must therefore ask what has brought this little island to be placed on such a pedestal and where does this culture of pride come from? What does it consist of? And how can Barbados strengthen its internal and external sense of identity for the benefit of the prideful advancement of its cultural roots?

${ }^{48}$ Forde, G. Addinton. De Mortar-Pestle: A Collection of Barbadian Proverbs. 6th ed. Bridgetown, Barbados: National Cultural Foundation, 1987. 16.

"Fraser, Henry. "The Barbados Experience." Ins \& Outs of Barbados 2011 Jan. 2011: 13-28. 


\section{The Making of the People: 100\% Bajan Recipe}

The $100 \%$ Bajan Recipe which makes one pound of Barbadian 'flesh', begins to tell the story of what makes up the Barbadian cultural identity:

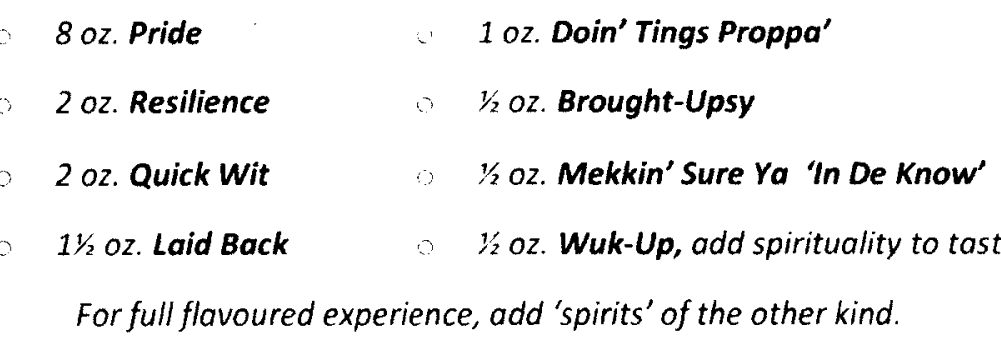

The above ingredients of the Barbadian cultural identity will be discussed in the following text as a means of illustrating the values, traditions, institutions and experiences of the Barbadian or Bajan culture.

Pride [noun] - $a$ high or inordinate opinion of one's own dignity, importance, merit, or superiority, whether as cherished in the mind or as displayed in bearing, conduct, etc.

\section{0z. of Pride}

The largest ingredient of Barbadian cultural flesh is their pride; pride is a badge that they wear passionately. Professor Henry Fraser, President Emeritus of the Barbados National Trust in his article titled The Barbados Experience, describes his fellow Barbadian people noting that "one of our characteristics is that we're all full of ideas and opinions, all passionately chauvinist, and all with our own views of what makes us special. Much is due to our history...and fierce pride in the fact that we've never been invaded by a foreign power... In fact, the reputation of being 'the brightest jewel in the English Crown' by the 1660 s has sustained the Bajan psyche ever since!" ${ }^{50}$.

${ }^{50}$ Fraser, Henry. op.cit. 13-28. 



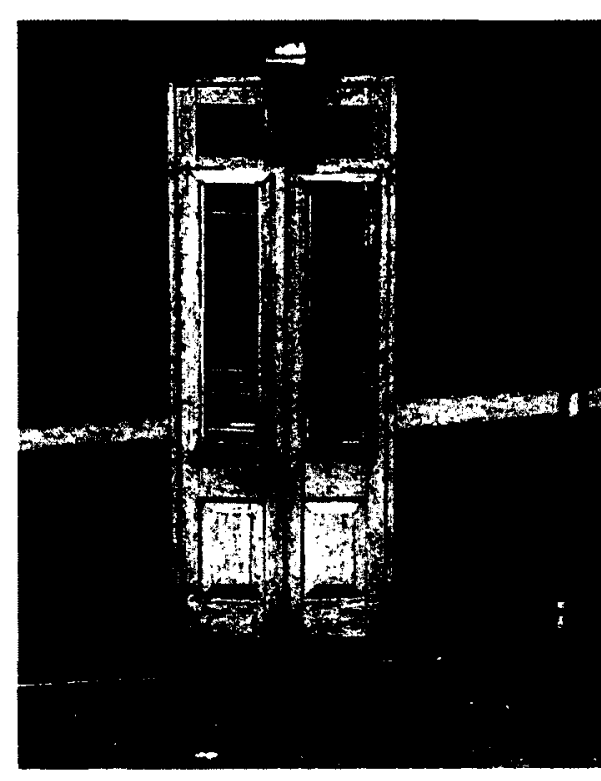

Figure 14 - Patriotic coloured Bajan door
Located at $13 \mathrm{~N}, 59 \mathrm{~W}$, the island of Barbados is the most easterly of the Caribbean islands and is the only one to 'fall out' of the natural line of the island chain. This location has provided the island with a natural preservation advantage, saving it from the effects of earthquakes and the annual plague of hurricanes which mercilessly devastate the islands. Due to the stroke of luck in the island's location, proud Bajans are well known for naughtily saying that "God is a Bajan" when a hurricane spares the island ${ }^{51}$. Barbados has generally experienced direct hits by hurricanes every twenty $(20)$ years on average, compared to some of its Caribbean neighbours who might experience two (2) per year ${ }^{52}$. Barbados has therefore never really experienced significant damages or hindrances to the continuous development of its physical infrastructure; this fact has made Barbadians complacent in their foresight of natural disasters.

As a colony, Barbados' geographic location gave it "significant commercial and military advantages at the height of imperial conflict in the $18^{\text {th }}$ century. The property's natural harbour, Carlisie Bay, was perfectly positioned as the launching point for the projection and defense of British imperial power to defend and expand Britain's trade interests in the region and the Atlantic World" ${ }^{\prime 3}$; Barbados was guilty of aiding and abetting the English colonial powers in the exploitation of the Region's local and

\footnotetext{
${ }^{51}$ Hoyte, Harold. How to be a Bajan: A Souvenir Handbook for Those Who Want to Learn the Bajan Way of Life. Bridgetown, Barbados: HH Investments Ltd., 2007. 120

${ }^{52}$ Williams, Jim. Hurricane City.com: Barbados History with Tropical Systems. N.p., Dec. 2011. Web. 1 Jan. 2012

<http://www.hurricanecity.com/city/barbados.htm>.

${ }^{53}$ UNESCO. Decision - 35COM 88.42 - Cultural Properties - Historic Bridgetown and its Garrison (Barbados) . United Nations, 7 July 2011. Web. 23 Sept. 2011. 〈http://whc.unesco.org/en/decisions/4313>.
} 


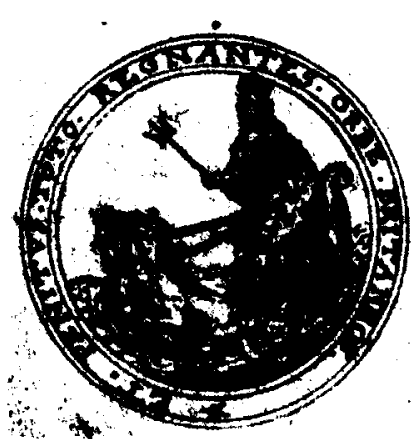

Flgure 15 - The Public Seal for the colony of Barbodos

Issued in 1663 - a borrowed image from the Medici tapestries which depicts seohorses led by Roman mythological character, Neptune holding a trident. For the Barbadian seal however, Neptune is substituted by the likeness of King Charles II.

The Latin inscription 'Et Penitus toto Regnantes Orbe Britonnos' translates to 'And the Britons, ruling throughout the whole world'.

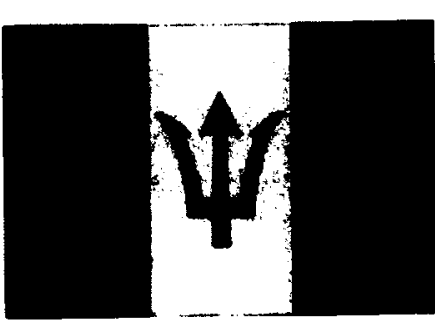

Figure 16 - The Flag of Borbados The flag consists of two ultra-marine panels on either side of a gold panel which holds the broken trident. The gold is representative of the sand and the ultra-marine represents the sea. implanted resources as it was the "staging post for the struggle in the Caribbean" 54 . Being born into a natural strategically placed locale seems to be what Barbadians are proud of rather than the fact that its strength of geographic location facilitated the protection of English colonial possessions for several years. The English presence, their influence and the localised allegiance of the Barbadian people to the Crown has been present for a long time and is still present today. The casually written article by one of Barbados' most respected historians is testimony to this where he states that it is "a fact that we've never been invaded by a foreign power" ${ }^{55}$. English 'belonging' is perhaps then a generally accepted element of Barbadian pride.

The flag of Barbados however, referred to loosely as 'the Broken Trident' signifies the breaking away from the British in 1966. The flag's depiction as a broken trident was an assertion of the colony's desire to break diplomatically, without revolt, the Neptune's trident and symbol of power as shown on the Crown's public seal for the colony of Barbados. The coat of arms similarly attempts to establish a separation from colonial past through the inclusion of indigenous symbols; however all symbols are composed in the accepted form of what a coat of arms should be. The established accepted form is approved by the Royal Crown as was previously noted in the thesis' section on the contemporary identity and its struggles.

\footnotetext{
${ }^{54}$ UNESCO. op. cit. <http://whc.unesco.org/en/decisions/4313>.
}

${ }^{55}$ Fraser, Henry. op.cit. 13-28. 


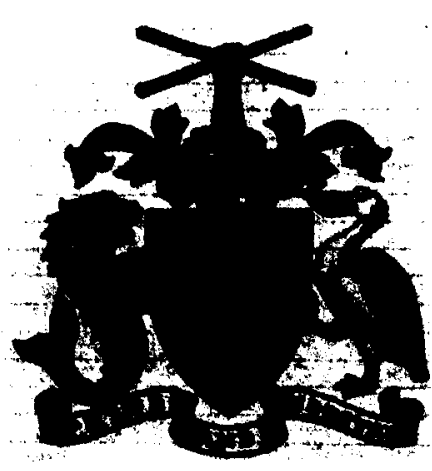

Figure 17 - The Barbodos Coot of Arms

Depicted on the shield of the coat of arms is the native flora and fauna of the island: the Bearded Fig Tree, after which the island is named and the Pride of Barbados flower, a symbol of the island's defining characteristic.

The fist above the shield is the fist of a Barbadian cane-cutter holding two stalks of cane, crossed, as homage to the patron saint, St. Andrew. The dolphin and the pelican are references to the fishing industry and Pelican Island which is now joined to the mainland at the capital's port of entry.

The question of true independence therefore, is still imminent in Barbadian society as the country's table of governmental precedence ${ }^{56}$ still lists the Queen as the Head of State and her representative - The Governor General - as the highest authority in the system of government, directly above the Prime Minister. Many more signifiers of remaining allegiance to the Crown still exist including the long standing debate of why the Admiral Lord Nelson's Statue should or should not stand in the area designated as Heroes Square. Lord Horatio Nelson protected Barbados and "other British West India Islands from the grasp of a powerful enemy" 57 , the French fleet who sought to overthrow the British and claim 'their' land. I believe that this is an indicator of the fact that while Barbadians wish to 'belong' to no one, they have accepted that they once did, and that there are both feelings of appreciation and sentimentality for the British presence, which prepared the base on which the society today is moulded.

With $90 \%$ of the society being of African descent ${ }^{58}$ however, there are still small pockets of resistance for any praise to be given to the 'White Man' - an unspoken truth of the prejudice and hypocrisy given that the genetic make-up the Caribbean people has been blended for centuries. While some may primarily identify with one ethnicity, the ethnicities of other ancestors prior are often times forgotten. How plausible is the pride of nationhood then, if Barbadians (black, white and 'in-between') cannot identify or equate themselves with being the con-fused people that they are? Are Barbadians really proud or still as industriously prejudice as the early settlers?

\footnotetext{
${ }^{56}$ Table of Precedence for Barbados. Ministry of Foreign Affairs \& Foreign Trade, n.d. Web. 10 Jan. 2012.

$<\mathrm{http}: / /$ www.foreign.gov.bb/pageselect.cfm>.

${ }^{57}$ Mohammed, Patricia. op. cit. 354.

${ }^{58}$ Barbados Statistical Senvice. Barbados Population and Housing Census 2010. Bridgetown, Barbados: Barbados Statistical Service, 2012. 22
} 


\section{0z. of Resillence}

Resilience [noun] - the power or ability to return to the original form, position, etc., after being bent, compressed, or stretched; elasticity.
Resilience through adaptation is the guise under which local cultural traditions have survived. The Barbados Experience article notes that the "personality of the people, the games we play and the way we worship, the food we eat and the way we celebrate are all the result of nearly four hundred years of plantation society, with the rigidly organised social hierarchy, in which merchants and planters dominated an agricultural society ${ }^{\prime \prime 5}$; the game of Cricket, the performance of the Landship, the music of the Tuk Band and the creation of the mobile Chattel house, are perfect examples of the writer's sentiments. Though these are not the only examples of resilience through adaptation to the order of planation society, they are sufficient to illustrate resilience as a feature of Barbadian culture.

- Cricket

Professor Hilary Beckles qualifies the previous writer's statement in his account of Barbados' history and the role of cricket: "from the 1870 s, the game was not seen by the planter elite as simply a form of recreation; there were visions of its role as a force for social cohesion, as well as an index by which social classes could be clearly distinguished during this time of unprecedented restructuring of the social order...The establishment of cricket clubs and competitions during the late nineteenth century gave rise to the use of sport as a mirror-image of the old order...Meanwhile, the impoverished children on the tenantries and in the urban ghettos played their adopted version of the game in a robust spirit that signified some measure of cultural resistance and autonomy. They transformed the spirit and

\footnotetext{
${ }^{59}$ Fraser, Henry. op.cit. 13-28.
} 
structures of the game, reduced its degree of formality and hammered it into a shape best suited to urban alley and plantation tracks" ${ }^{\prime \prime 0}$.

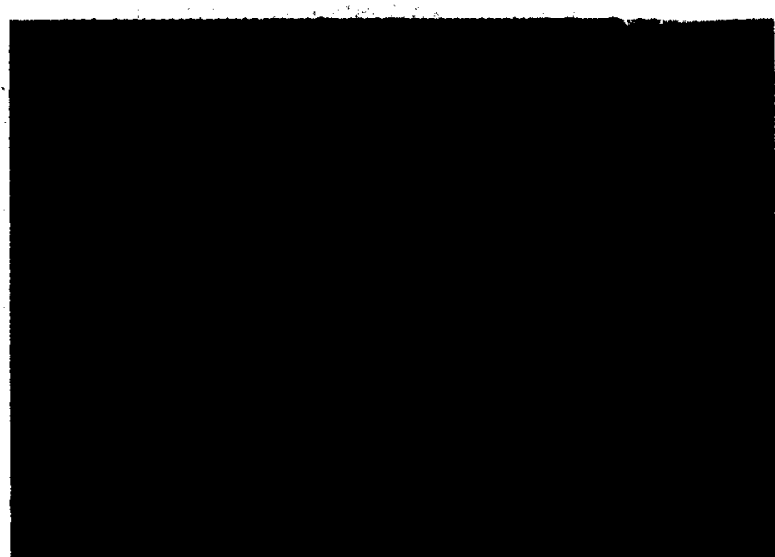

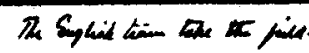

Figure 18 - An English Cricket Team walking on to the field at the beginning of play.

The game of cricket, was transformed into the tool with race and class divisions were metaphorically removed, through West Indian mastery of cricketing skill which on several occasions, brought the English to their knees. Cricket was not just a sport, it was also a symbol of beating the English at 'their own game'. Despite the game's significance as a regional symbol, the West Indies cricket team (a compilation of regional players) seems to have lost its ambition to play as passionately as they once did. This could be an indicator of changing times and changing battles through which it may now be determined that the Caribbean people have nothing more to prove via this sport. Older players were once meticulous about the form, skill and technique with which the game was to be played and rigorously analysed their opponents' techniques in order to administer the required strategy of play for defeat. The spectators were equally as invested in the team's strategy of play and ultimate conquer. In modern times however, the game has become more of a limer's event where few are anguished when the team loses but many are happy that drinks were had, food was eaten and friends were made; as a young Barbadian, I can relate to the latter sentiment.

${ }^{60}$ Beckles, Hilary. op. cit. 214-216. 


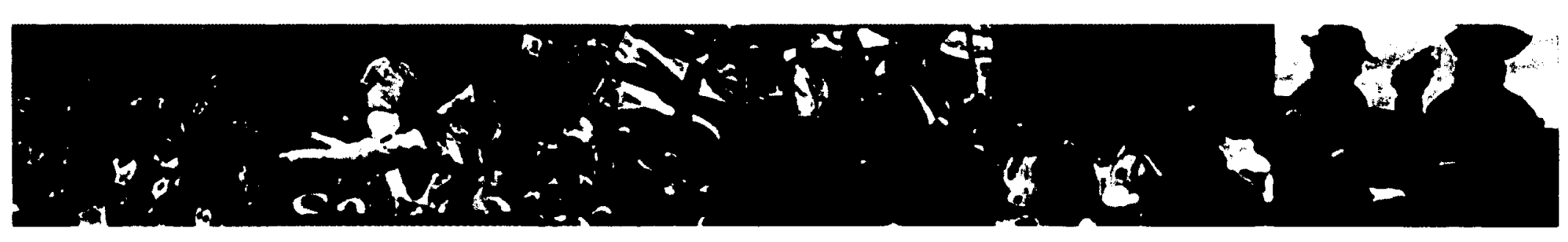

Figure 19 - Cricket in Barbados

While the apparent re-situation of the importance and cultural significance of the cricket game may seem to be an element of culture nearing the end of its life-cycle, it must be acknowledged that the spirit of its lessons of reform and resilience are still active in today's society where Barbados is one of the main stalwarts of the proposed Caribbean Single Market and Economy which seeks to unite the entire Caribbean region as a single world market ${ }^{61}$. To further complicate the previous theory of influence, one might consider then, that other dormant cultural elements should be investigated for revival of their deeper socio-cultural purposes. The Warri game is an example of another culturally significant sport which reveals undertones of mental tenacity and resilience which may have translated into core societal values. Its importance will be discussed in a later chapter.

\footnotetext{
${ }^{61}$ The Caribbean Single Market and Economy. Ed. BGIS Media. Barbados Government Information Service, 20 Dec. 2011. Web. 28 Feb. 2012. $\langle$ http://www.gisbarbados.gov.bb/index.php?categoryid=14>.
} 
The Landship is the second example of the resilient Barbadian character. The Landship is a prime example of a dying social phenomenon which originated in England. It is a group which was originally formed as one of several friendly societies of which there were 43 such groups in the island from around 1843 (pre-emancipation). The Landship was founded by a former naval officer who felt that the discipline and camaraderie of the navy was worth emulating in Barbadian society, whereby groups could be formed to function similar to the crew of a naval vessel, watching out for each other. The friendly society functioned to provide an economic safety net for poorer Barbadians; a function which has now been taken over by contemporary government's social security system and credit and trade union establishments. At inception, friendly societies were governed and sponsored by the Anglican church, which maintained very strict rules and required that its members lived what was considered to be a 'moral life'. The black labouring poor however, showed resistance to the rigidity of this social system and began forming their own versions of the friendly society. The Landship, is the only remaining friendly society in Barbados created by the black labouring class.
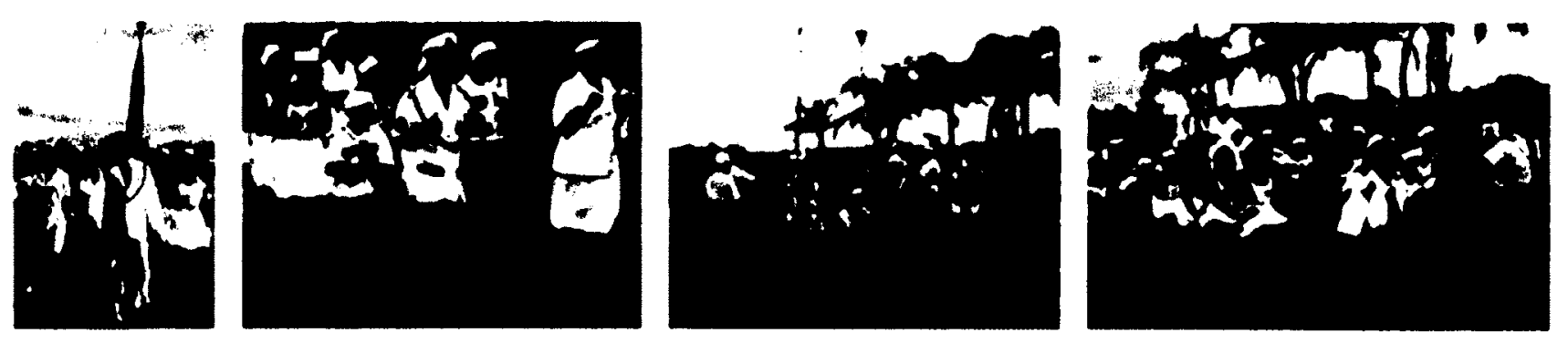

Figure 20 - Landship performances 
As a celebration of its accomplishments, the Landship has historically participated in ceremonial performances where its "members parade in uniforms of naval pattern, and have naval ranks and titles assigned to them"62. The dance movements of the members are a display of the "Barbadian genius for creolisation, for fusing European and African elements into a new creation"63. The Landship's manoeuvres are designed to imitate the movements of a ship at sea and of its crew, through African influenced dance movements.

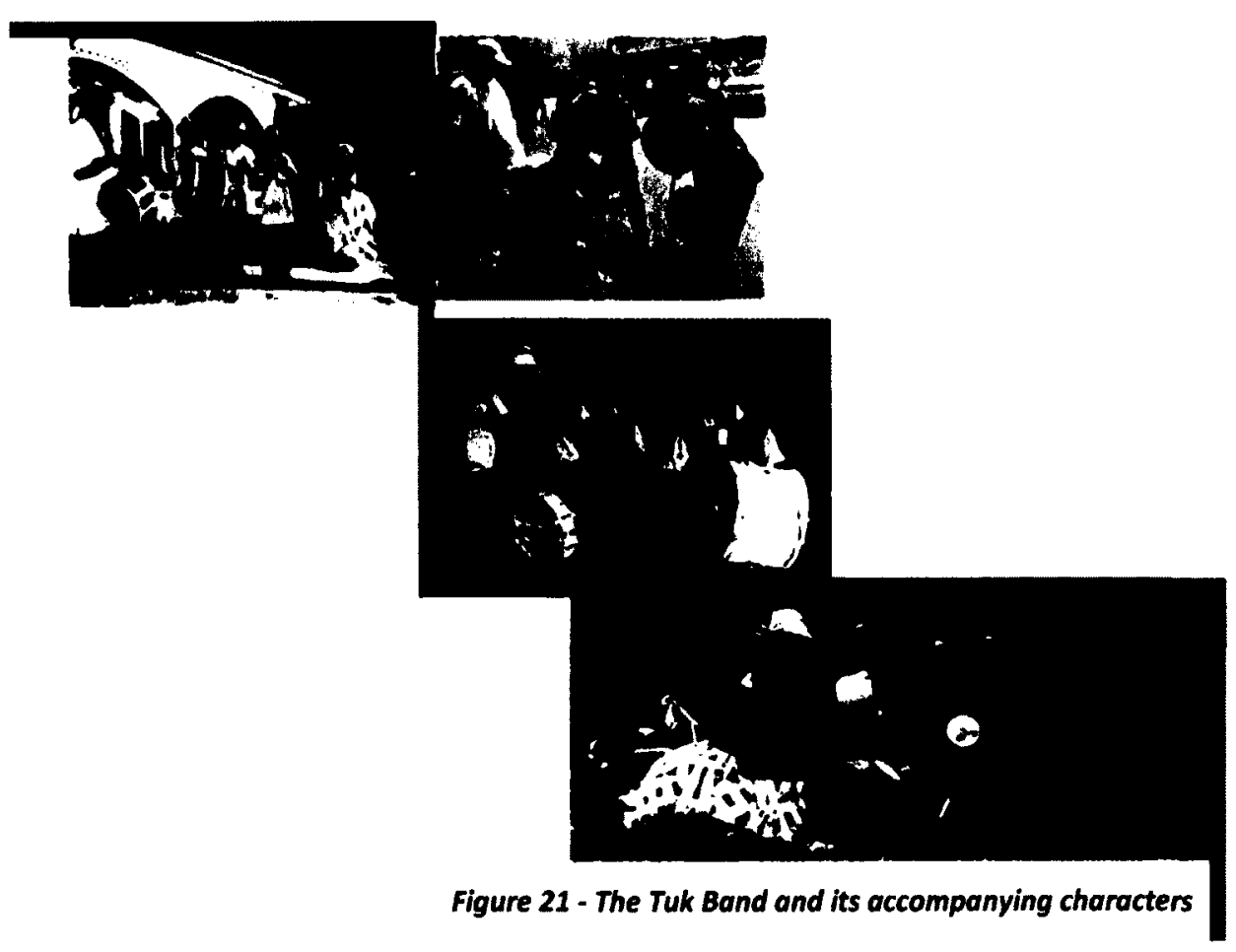

The Tuk Band is closely related to the Landship, and is often seen sharing performances especially at Independence and at Crop Over celebrations. The band is referred to as the 'engine' of the ship. The name 'tuk' is believed to be derived from a Scottish word meaning "to beat or sound an instrument, 'touk of drum' meaning 'beat of drum'...the Tuk band itself perhaps owes its origin to the fife and drum marching band of an eighteenthcentury British regiment" ${ }^{\prime 64}$. Tuk band music was created as a creolised version of British military music by the black African slaves in the Barbados militia during the mideighteenth century. The Tuk band is usually a four-man band consisting of: a penny-whistle player, a kittle man (or a snare-drummer), a bum-drummer (or bass drummer)

\footnotetext{
${ }^{62}$ Carrington, Sean, Henry Fraser, John Gilmore, and Addinton Forde. A-Z of Barbodos Heritoge. 2nd ed. Oxford: Macmillan Caribbean, 2003. 112

${ }^{64}$ Carrington, Sean, Henry Fraser, John Gilmore, and Addinton Forde. op. cit. 211
} 
and a triangle player. Tuk music, although derived from regimental life, is not for marching but for dancing. The associated dancing can be seen as a mockery of the rigid structure of regiment life, now translated into the loose rhythms of dancing bodies. It was in effect a means through which a Colonial institution was manipulated to suit unsolicited cultural activities.

\section{- Chattel House}

The creation of the chattel house structure is the last example of Barbadian cultural resilience. Since slaves were landless after emancipation, they were allowed to build humble homes on marginally productive plantation lands through the Located Labourers Act of $1840^{65}$. Even though the slaves paid small rents for the use of the land, the plantation owners reserved the right to evict tenants at short notice. The house therefore had to be 'Chattel', meaning a movable possession. This was the only way Barbadians could own a home, even if they did not own the land.

The Chattel house is the symbol of both adaptability and versatility; the basic chattel was designed so that it could be easily dismantled in sections and reassembled just as easily. The house was assembled without being fixed to its foundation, which was a few layers of coral stone blocks set on the ground. The size of the house was determined by the pre-cut dimensions of imported timber; the cheapest and most suitable building material at the time. If the house needed to be larger, similar modules could easily be added to the original structure. The evolution of this typology is seen not only through the growth in the size of the structure but also with the addition of various features of Victorian architectural details; a tell-tale sign of fascination with all things English and rise in affluence.

\footnotetext{
${ }^{65}$ Carrington, Sean, Henry Fraser, John Gilmore, and Addinton Forde. op. cit. 43.
} 
In the contemporary Barbadian lifestyle, the modesty and versatility of the chattel house no longer fulfils the aspirations of the current generation. A select few chattel houses remain proudly preserved while others have continually been adapted over time to suit a range of uses. Throughout the island, the chattel house and variations of it have been adapted for use as neighbourhood corner stores, rum shops, restaurants, small churches, boutiques and tourist villas, to name a few.

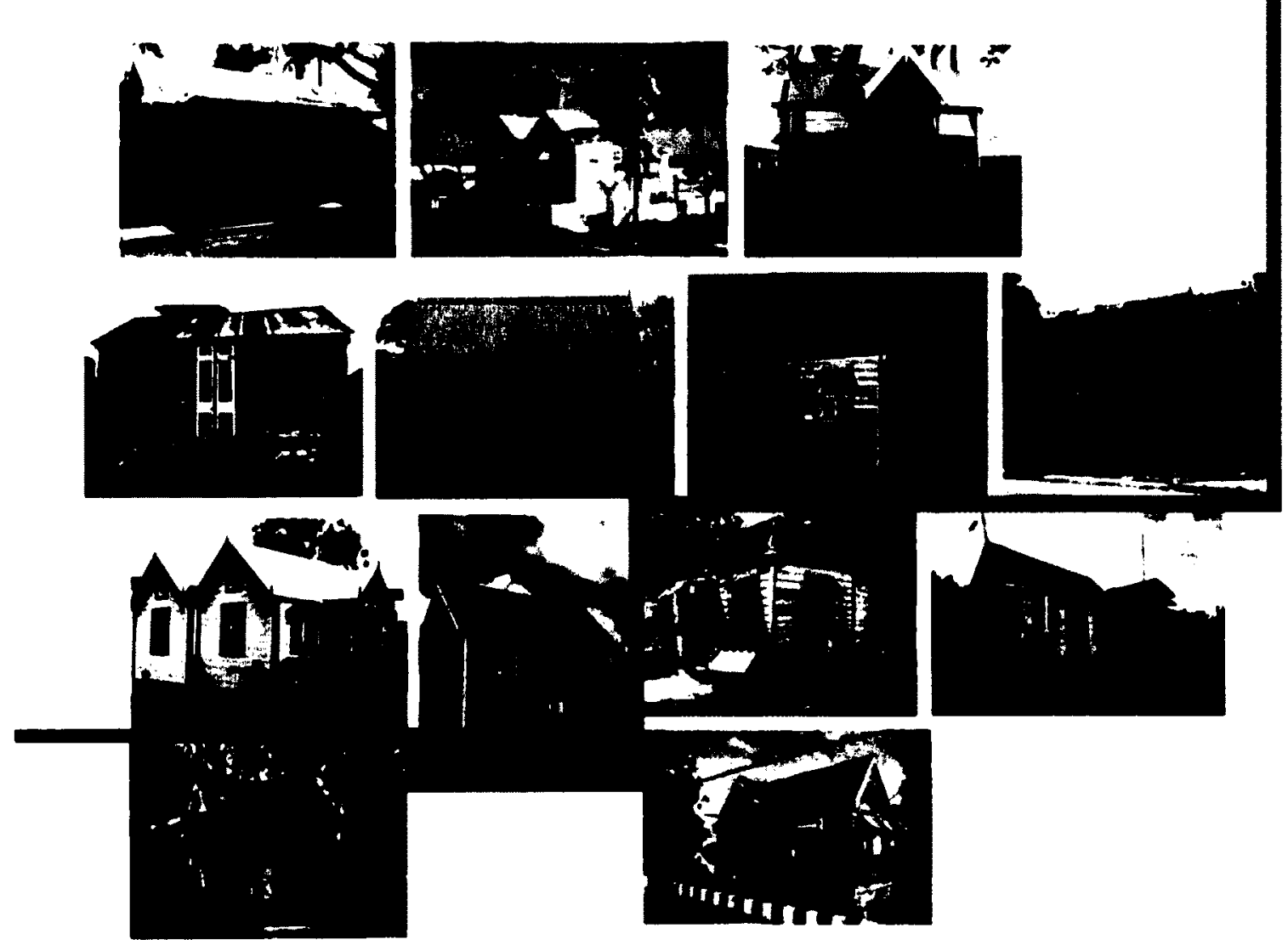

Figure 22 - The Chattel House with various features and functions 


\section{2 oz. of Quick Wit \& 11/2 of Laid Back - to be blended before adding to mixture}

The Barbadian proverb "tekkin' time 'en laziness"

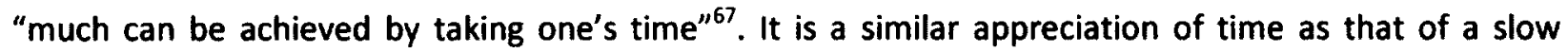
cooked Italian dish - the longer the time, the richer the flavour and the greater the enjoyment: an enjoyment celebrated in the eating after preparation. Barbadians are largely considered to be easy going persons by nature, in comparison to their European ancestors. This is by no means an indication of laziness but simply a mentality which often allows for the quiet resolution of conflict and calmly planned action.

The easy-going characteristic of the island's (and the Region's) inhabitants can perhaps be attributed to the commonality of an entertainment or 'festival' culture throughout the Caribbean

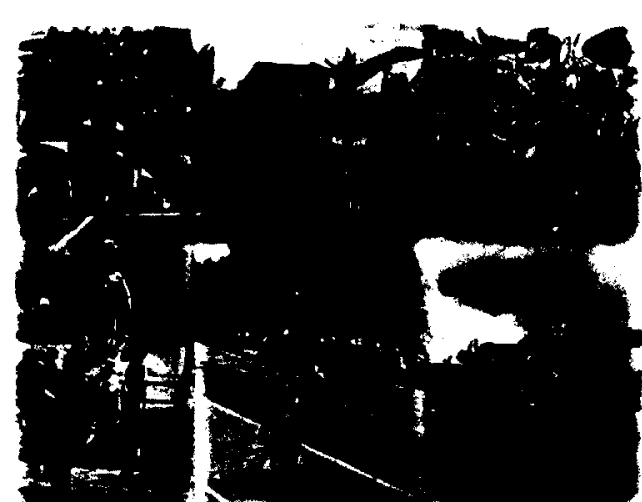

Figure 23 - Images from Barbados' current Crop Over festival countries. The history of festivals in the Caribbean is generally derived from past celebratory rituals of the end of a work period - whether daily, monthly, seasonally, or annually. In current times, modified versions of these festivals are packaged with the tropical climate and sold as the premier tourist experience; an experience which largely marks the peak period for the tourism industry and foreign exchange activity in the Caribbean islands.

${ }^{66}$ Forde, G. Addinton. op. cit. 30.

${ }^{67}$ Ibid. 
The Barbados Crop Over Festival, traced back to 1780 , was originally a celebration of the last crop to be reaped for the agricultural season; it was festival of gratification that the crop season was over and that it was successful. The festival in died with the agricultural industry and its original sentiment, but was later revived for the purposes of the tourism industry. As a dazzling display of dance, colour and live musical performance, the festival climaxes in one of the largest, most high-energy,

"Lick an' lock-up done wid,

Hurrah fuh Jin-Jin!

(Queen Victoria)

De Queen come

from England to

set we free,

Now lick an lock-up

done wid,

Hurrah fuh Jin-Jin!"

- Excerpt from

Barbadion

emancipation folk

song themed costume street parties in the Region. The historical significance of the festival culture and its

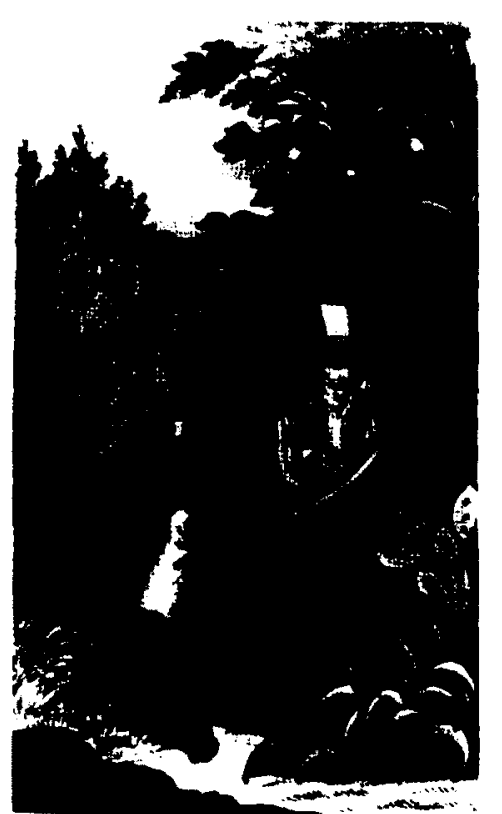

Figure 24 - Serving 'Massa' under de coconut tree

present day importance now suggest the idea of productivity and industriousness through providing entertainment for self and others, as a significant feature in the Barbadian attitude. Consequently, the following questions might be asked: How has this attitude evolved from servicing the master's need for entertainment? Is tourism and its title as an industry, a more politically correct disguise for the resurgence of subservience to modern day 'visitors'? Based on interpretations of current commercial imagery, it may be fair to say that the Barbadian people still exhibit signs of subservience in the way that the tourism service product is marketed. From another standpoint however, the quick witted nature required to succeed in meeting the needs of the differing personalities and cultural traits of tourists may prove to be a valuable quality for the advancement for the country as a whole.

To reduce the weight of the previous questions, the double entendre device is commonly used in everyday Barbadian life for deflecting and adding a light-hearted twist to the seriousness of impending matters. Calypso, the trademark sound of Caribbean festivals, and the quick witted lyrical 
"Horatio Nelson...he was $a$ bastion of

colonialism fighting fearlessly for Great Britain. Ah tell

Wilberforce an'

company, Britain

will always engoge in slavery!

He only once visit

we island,

rou should hear

how Ne/son cuss out

we place!

But de planter class,

actin' fast,

Wouldn't let Lord

Nelson pass,

Demignore

whoever complain and erect statue in

his name!

And now Lord

Nelson, instead of

pulling you down.

some jokers dey in

Bridgetown turn you

around!" - (Mighty

Gabby 1990)

picong $^{68}$ are prime examples quick witted performance. Some of the previously described institutions, which were developed with serious purpose, are also illustrative of this cultural characteristic. Within the ceremonial displays of the landship and tuk band groups for example, costumed characters emerge both symbols of the social truth and jest: the donkey man - a dancer in a legless donkey costume -

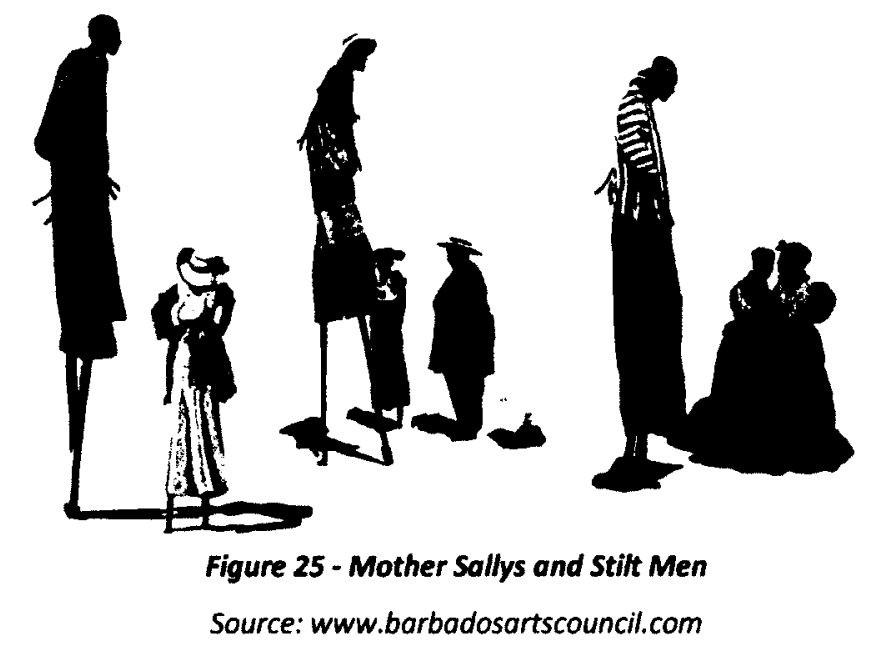

agile characters who provide acrobatic display and additional comic effect. The playfulness of the Barbadian-Caribbean culture and its aversion to conflict sets the scene for an architectural intervention with a theme of recreation.

which symbolises the role of the ass in the sugar cane crop and the 'ass' in jest, mother sally - a woman with large hips, buttocks and bursting bosom - the symbol of the multifaceted market woman, wife and mother who balances the burden of her 'produce' on her head but yet the movement of the rest of her body is unhampered, tilt man - a man on stilts who is as tall as the sky, shaggy bear and the green monkey -

with a theme of recreation.

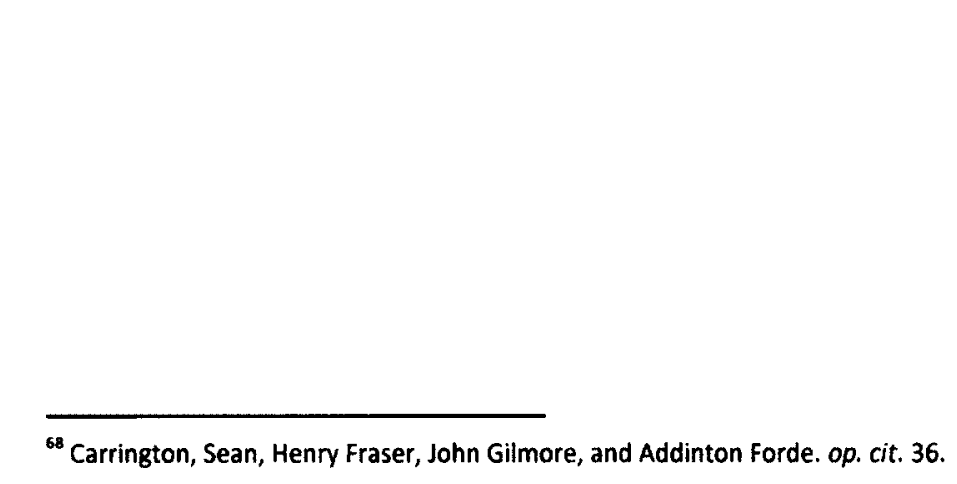

\footnotetext{
${ }^{68}$ Carrington, Sean, Henry Fraser, John Gilmore, and Addinton Forde. op. cit. 36.
} 


\section{1 oz. Doin' Tings Proppa'}

Proper [adjective]

conforming to

established standards

of behavior or

manners; correct or

decorous: a very

proper young man.
'Proppa' is the Barbadian dialect adaptation of the English word 'proper'; an improper twist to the proper, with precisely the same meaning. Given the long-standing nature of the British rule, the strict moral standards of behaviour and decorum of the British took root as a major factor in Barbadian life. The establishment of the Anglican Church had much to do with this and still stands firm as the country's declared primary religious denomination. The stability of the British rule and the permeation of its social orders can perhaps be credited for the country's stable social, political and economic atmosphere, and its general success as a nation.

In maintaining the 'proper' intellectual standards, education and the desire to be educated are of high priority on the Barbadian agenda. Testimony to this is the fact that each successive government (regardless of political party), spends "more than $20 \%$ of its annual revenues on education, an extraordinarily high figure by the standards of most countries" ${ }^{\prime 69}$. As a result, the Barbadian literacy rate is approximately $98 \%$, almost as high as the UK literacy rate of $99 \%$. The heavy promotion of education in Barbados is perhaps one indicator of the mirroring of the British socio-cultural value system.

A highly educated society provides the necessary resources for positive development on all levels; a resource which has driven Barbados to reaching the goals of being ranked as a country with a high level of human development, and of being the only nation with developed status in the Anglophone Caribbean $^{70}$. Acquisition of higher learning was the commonly agreed ethos of Barbadian society from

${ }^{69}$ Carrington, Sean, Henry Fraser, John Gilmore, and Addinton Forde. op. cit. 70.

${ }^{70}$ Population \& Education. Ministry of Foreign Affairs \& Foreign Trade, n.d. Web. 10 Jan. 2012. <http://www.foreign.gov.bb/pageselect.cfm>. 
the early 1960s. Errol Barrow's "what kind of mirror image" ${ }^{\prime 71}$ speech is one which resonates with all post-independence generations and continues to rally the society to better themselves on all levels; holding to a standard that is to be determined by internal expectations.

From the previous statements, it might be said then, that the use of the educational institution and the intellectual attractiveness of education itself is perhaps one of the ways through which the spirit of Barbadian-Caribbean receptivity can be effected. The formal nature of the educational framework provides merit to the necessary repositioning of the Barbadian socio-cultural value system which is still evidently burdened to some extent by the remnants of Eurocentric visions. Through the provision of a facility which provides the opportunity for the Barbadian-Caribbean people to refresh their sense of identity amidst colonial Eurocentric remnants, I believe that the internal images of self might be much different.

${ }^{71}$ Barrow, Errol. "What kind of mirror image do you have of yourself?" Democratic Labour Party. Bridgetown, Barbados. 13 May 1986. Web. 26 Feb. 2012. <http://notesfromthemargin.wordpress.com/2008/01/21/happy-errol-barrow-day-for-all/>. 


\section{1/2 0z. Brought-upsy}

'Brought-upsy' is the way in which Barbadians describe their up-bringing. Following on from colonial Christian moral legacy in 'doin' tings proppa', the scrutiny of social happenings and the indoctrination of socially accepted orders have become important moulding the youth into proud Barbadians. The ten Christian commandments form the framework under which Barbadian society functions in general.

Respect for self, others and honouring thy father and mother were therefore the core values enforced in every setting.

Barbadian author John Wickham adds to the previous description of Barbadian society by noting that "the inability of people to remove themselves from one another has led to concern for public order, a compassion for others, and a compelling sense of a neighbor's rights and integrity" ${ }^{\prime 27}$. Renowned anthropologist W. Penn Handwerker also cites in his article on Barbados that "Barbadians are known for their politeness and civility; a legacy both of British influence and of the island's high population density-living in close proximity to others imposes pressure to avoid censure and unpleasant confrontations" ${ }^{\prime 3}$. The result was the functioning of small communities as networks of extended families, who raised and disciplined each other's children in the way that produced individuals who met the civil standards of Barbadian society.

Despite the church's teaching of "the stereotype of woman as housewife...[and] the perpetuation of the inferior status of women in society in Barbados" ${ }^{\prime 4}$, mothers and women in general were especially

${ }^{72}$ Countries and their Cultures: Barbados. Ed. W Penn Handwerker. Advameg Inc., 2005. Web. 28 Feb. 2012. <http://www. everyculture.com/ABo/Barbados.htmls.

${ }^{73}$ Ibid.

${ }^{74}$ Drayton, Kathleen. "Art, Culture and National Heritage." Borbados: Thirty Years of Independence. Ed. Trevor Carmichael. Kingston, JA: lan Randle Publishers, 1996. 199. 
respected since the reality of society saw the women as breadwinners and "the major participants in the rituals and work of the established churches" ${ }^{\prime 75}$. The man's role of providing income often times required them to be away from home most of the time or largely absent in some cases. As a result women were responsible for homemaking and earning extra income as necessary. Women therefore played significant roles in the up-bringing of the Barbadian society.

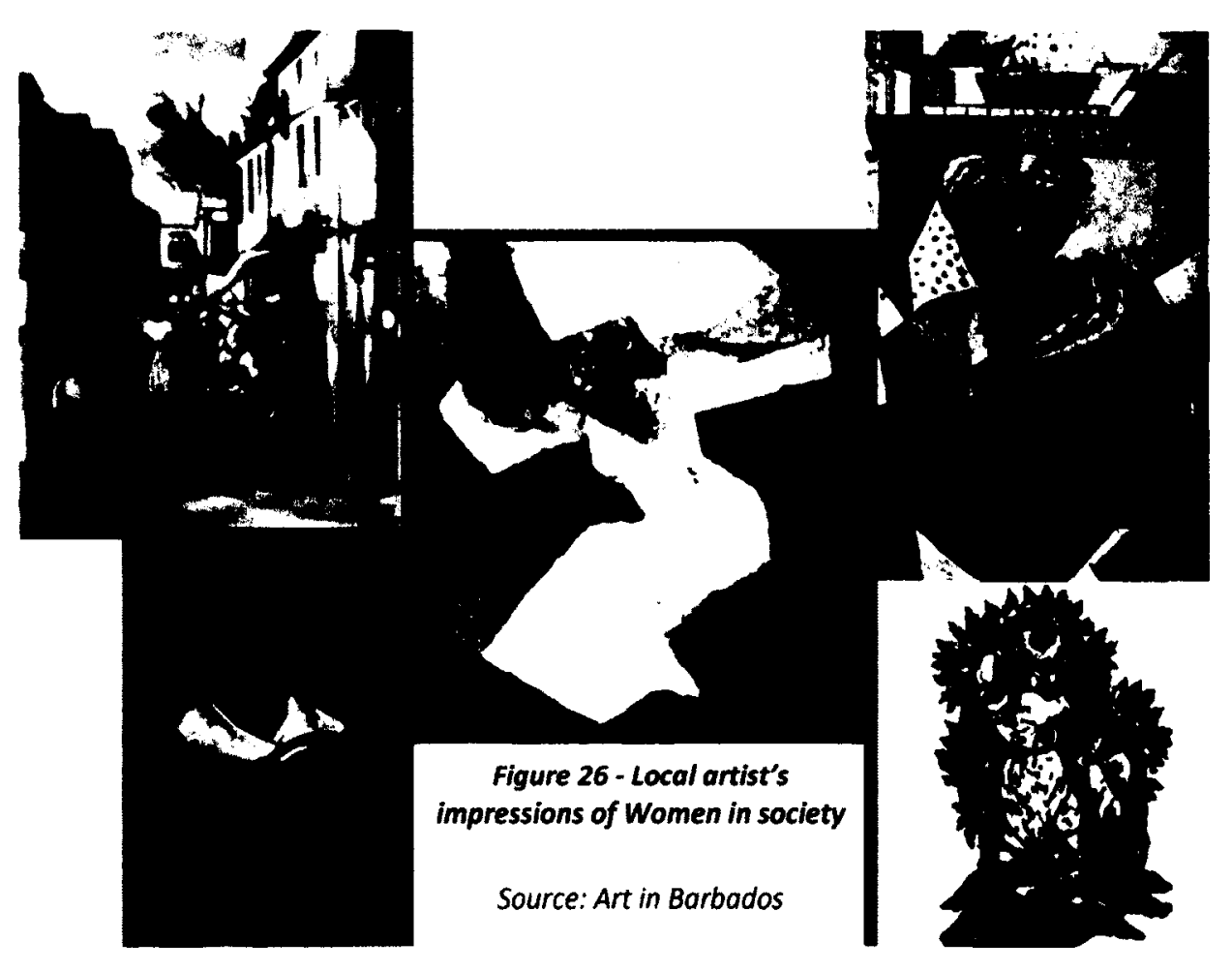

${ }^{75}$ Drayton, Kathleen. op.cit. 199 
Given that the school and the church worked together to feed colonial culture into local society, there was very little room for the influence of community folk culture. Children were "exposed only to the products of English culture. Barbados [then] lost or forgot the traditions of the majority of its black" ${ }^{76}$ or African-descended population. "Local folk songs, for example, remained in limbo, until some were rescued and made available first by the Merrymen in the late fifties and sixties" 77 , followed by the publication of several folk song books with music and lyrics. Despite the intentions of the formal educational and religious systems, the close-knit relationship of Barbadian communities and families was the channel through which the practices and folklore of the suppressed cultures were allowed to quietly exist, until later resurgence.

The fragile existence and proposed resurgence of the Warri game will later be discussed as a parallel to the values of brought-upsy illustrated in the previous discussion of the informal community system of education and upbringing. In addition, it must be noted that the cultural values which allow the accommodation of varying and possibly opposing social functions within close proximity to each other, is a quality which removes restriction in space planning but also suggests considerate use of space by occupants if functions of space are to clash.

${ }^{76}$ Drayton, Kathleen. op. cit. 199 


\section{1/2 oz. Mekkin' Sure Ya 'In de Know'}

'Maliciousness' or 'gypsy-ness' are Barbadian dialect terms which differ from their use in Standard British English. The terms refer to anyone who is excessively inquisitive or who wishes to be wellinformed of all affairs. The history of oral tradition, folklore and what might be termed as a 'stand-pipe' culture have fostered the Barbadian 'gypsy-ness' or desire to be well-informed. The stand pipe was "a

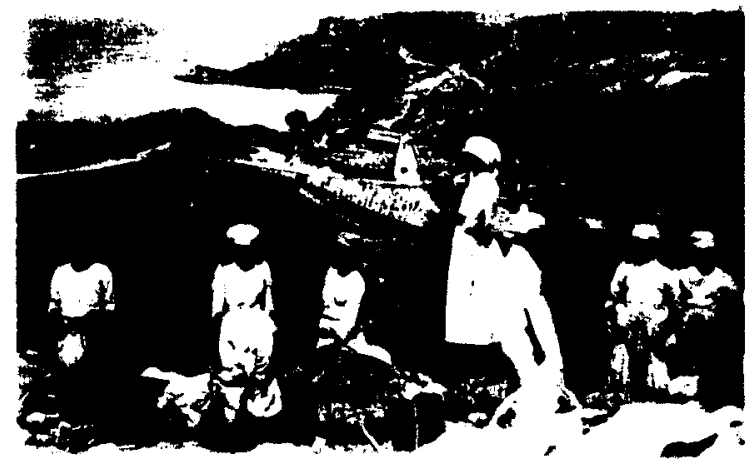

Figure 27 - A Standpipe Gathering in Barbados point of social gathering for most villages where the latest news was heard, children's games were played, young lovers chatted, and quarrels, even fights

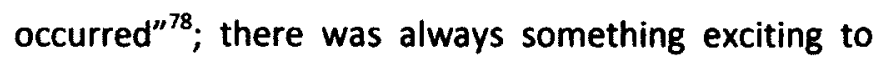
observe or engage in at the standpipe. However, the commonality of running water as an amenity within the home has reduced the relevance of the standpipe as the 'fount' for publicly sharing affairs.

In addition to being a source of everyday wit, calypso is another medium through which current issues are publicly 'discussed' and made known. The musical art form of calypso developed simultaneously in different Caribbean territories being ussed for social commentary or celebration, "having from Africa the tradition of the griot story-teller, the call and response type of singing, the rhythms augmented by some Carib [Amerindian] influences and the French style of using eight-line verses in lyrical writing. The earliest calypso was sung by slaves, singing often extemporaneously, using satire, poking fun at those in authority and trading insults" ${ }^{\prime 79}$.

\footnotetext{
${ }^{78}$ Carrington, Sean, Henry Fraser, John Gilmore, and Addinton Forde. op. cit. 198
} ${ }^{79}$ lbid. 35. 
Although the "Standard variety of English became the official language of Barbados and the Commonwealth Caribbean. Standard English is not, however, the variety of language spoken by the vast majority ${ }^{\prime 80}$. The creole language known as Bajan, is the primary form of communications amongst Barbadians, especially in relaying the latest news of public and personal affairs. The use of this language is especially kept alive in the lyrical content of calypsos, and even via more formal mediums such as the regularly published Lick Mout Lou, Blabber Mout Babsie, Mavis Beckles and Pudding \& Souse ${ }^{81}$ columns in the local newspapers.
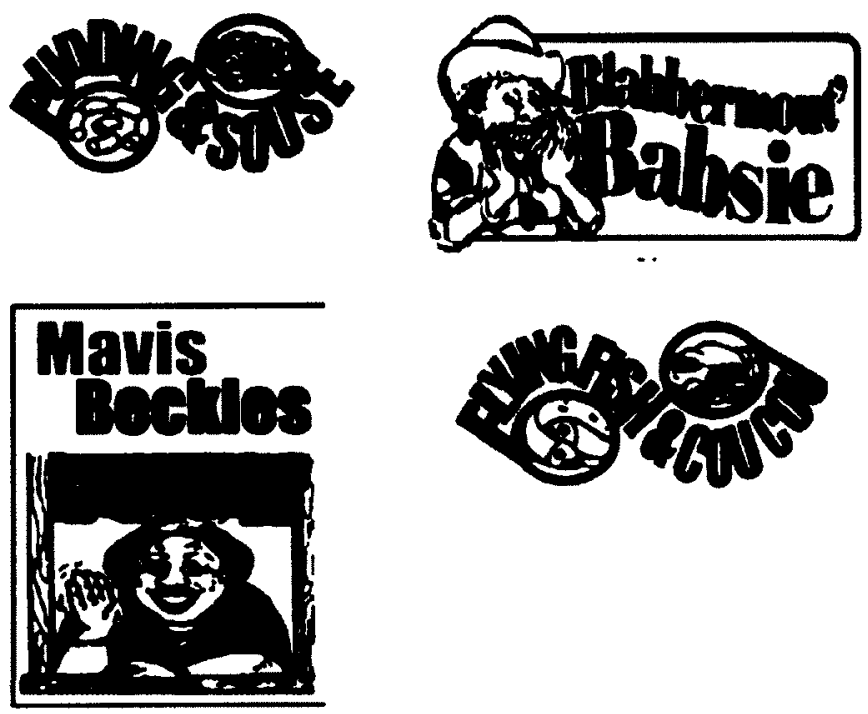

\section{Figure 28 - Local newspaper gossip columns}

Pudding \& Souse, Blabbermout Babsie, Mavis Beckles, Flying Fish \& Cou Cou are regularly published articles in the local Barbadian newspapers.

Source: Barbados Nation Newspaper

\footnotetext{
${ }^{80}$ Drayton, Kathleen. op. cit. 202.
}

${ }^{81}$ Pudding \& Souse is a Barbadian delicacy which is eaten especially on Saturdays. The titling of the newspaper column with this name is a likening of gossip to the routine with which Barbadians partake in this dish. 
The blend of formal and informal communication lines has been significant historically, especially in the relay of controversial information. The use of satire, unusual metaphorical reference, and the witted Bajan language dialect create added excitement in gaining information; and excitement which encourages Bajans to be excessively inquisitive.

\section{1/2 02. Wuk-Up - add spirituality to taste or spirits of the other kind}

For as many types of people and cultures that have made up the Caribbean, there are just as many bodily motions to express them. Calypso music and its associated dance motion of 'wukking up' is uniquely Caribbean and despite any and all differences between the Caribbean nations, calypso music and dance magically brings the people of the Caribbean together time and time again. Calypso music is "syncopated, poly-rhythmic and poly-metric, a description fitting other Caribbean music forms" ${ }^{\mathbf{8 2}}$ which include: soca (soul calypso), ring bang (a combination of tuk and calypso), and even a few versions of reggae.

On the religious front, some churches in their musical ministry have altered their music to into similar syncopated rhythms to appeal to the congregation. Roman Catholic, Pentecostal and Evangelic denominations in Barbados are particularly known to have taken this approach while the dominant Anglican Church has remained strongly traditional in its format.

The Crop Over festival is the ultimate display of calypso music, dance and other cultural activities. As with any party event, alcohol and the associated spirited behaviour, are part and parcel of these activities. Criticisms are often made about the hedonistic messages that may be sent to the youth and the outside public about the morality of the Caribbean people. For a long time calypso had been

\footnotetext{
${ }^{\text {a2 }}$ Carrington, Sean, Henry Fraser, John Gilmore, and Addinton Forde. op. cit. 35.
} 
"deemed undignified, inferior and for lower-class people. One reason was the prevailing attitude which saw 'cultural activities' originating solely in Europe. The other is that many early calypsos were sexually suggestive and thus socially unacceptable ${ }^{\prime \prime 3}$. During the final Grand Kadooment Crop Over parade in Barbados however, the Walk Holy religious band emerges as one of the first groups to pass through the stadium as a part of the annual street parade of scantily clad revellers, dancing to the soca rhythms. Despite being fully-dressed and engaging in more conservative dance to the soca bass line of lyrically religious sounds, there is constant discussion about whether the group should have a place in the parade. In years before, public calypso performances were suspended to give way to holy seasons such as Lent and on Sundays. In modern times however, festival performances are scheduled regardless of any religious observances. The Party Monarch and Sweet Soca Monarch finals are examples of events usually held on Sundays.

Another point of collision exists between the 'spirited' and spiritual Barbadian personas in the phenomenon of the ratio of churches to rum shops. The A-Z of Barbados heritage states that "rum shops vie with churches for first place as the largest number of non-dwelling buildings on the island" ${ }^{\prime 24}$. Given that statistic, it is not unusual to find a rum shop being located next to or directly adjacent to a church; spirits and spirituality coexisting as significant rituals in Barbadian life.

\footnotetext{
${ }^{83}$ Ibid. 36.

'Aarrington, Sean, Henry Fraser, John Gilmore, and Addinton Forde. op. cit. 172.
} 


\section{Taste-testing: Considering Barbadian Culture as it evolves}

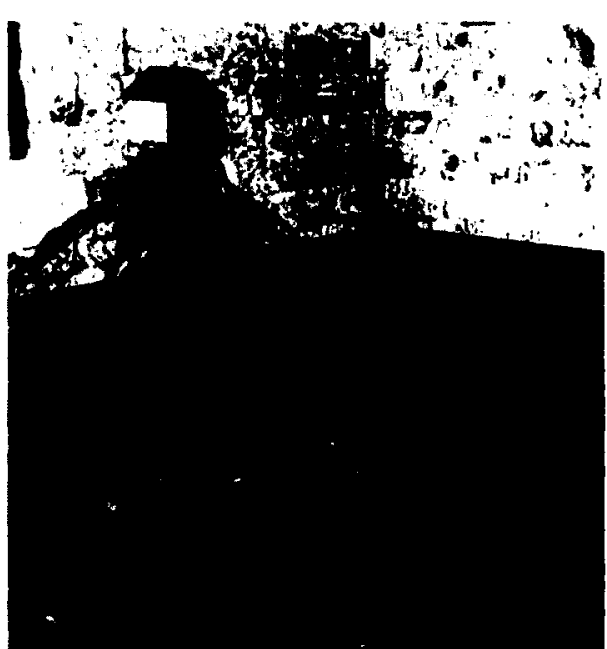

Figure $29-\left(U_{p}\right)$ Rooted

Recalling the definition of culture as the "shared values, traditions, norms, customs, arts, history, institutions, and experience of a group of people" ${ }^{\prime 85}$, the Barbadian culture has been discussed briefly via the previous recipe. Its evolution however is one that cannot be predicted as is the case for any culture. The intention of this thesis is not to restrictively define Barbados' culture by any means but to briefly illustrate its qualities through an understanding of the strengths and weaknesses of its experiences, and the rootedness of those experiences in the overall Caribbean culture. Analogous to the ever changing motions of dance, and the poly-rhythmic qualities of Caribbean music that penetrates local Barbadian life, the Barbadian-Caribbean culture should be metaphysically represented in a similarly responsive format.

Culture in general is a difficult thing to define in a finite way, and should in fact not be constrained to such. The previously discussed ingredients provide insight into the following ideas which can be used for the design intervention of this thesis:

1. Pride - the consideration of the strategic positioning of main design elements, the removal of unnecessary colonial restraining frameworks where possible and thoughtfully accepting or keeping those 'restraints' where necessary or suitable.

\footnotetext{
${ }^{85} \mathrm{http}: / / \mathrm{www}$.websters-online-dictionary.org/definitions/culture
} 
2. Resilience - consideration of the continuation of adaptive approaches, reappropriating site resources to suit the current cultural atmosphere and needs.

3. Quick Wit \& Laid Back - consideration of the inclusion of the elements of recreation or playfulness as features which support the larger framework of a less playful overall responsibility.

4. Doin' Tings Proppa - the creation of a device or devices which appeal to the intellectual nature and zeal for education.

5. Brought-upsy - consideration of the inclusion of an element which appeals to and is instrumental in transmitting cultural ideas and values to the younger generation.

6. Mekkin' Sure Ya in de Know - the changing element of informal communication.

7. Wuk-up - incorporation of the idea of the juxtaposition and coexistence of opposing functions within reach of each other. 
"In plenty and in time of need When this fair land was young Our brave forefathers sowed the seed From which our pride is spmung,

A pride that makes no wanton boast Of what it has withstood That binds our hearts from coast to coast The pride of nationhood..." - excerpt from the Barbados National Anthem 


\section{ORIGINS OF THE 'SEEDED' ANTHEM OF PRIDE}

In examining Barbados and the Caribbean's 'history of encounter', the final determining questions of identity remain; is Barbados' success in being a stable, developed, independent nationhood, a result of the effective and stable measures of European attempts to civilize the island's people?' And more importantly how have the people matured beyond beating 'the old restless drum' of fighting European civilization to become a society of proud survivors?

The national anthem which begins "In plenty and in time of need" ${ }^{86}$ reflects on times of hardship, struggle and survival. As an anthem - a song of devotion or loyalty to a nation (or school) - it provides an omnipresent acknowledgement and sense of allegiance to the Barbadian ancestral heritage. It is also an understanding that the ancestral heritage of survival, is at the base of the 'independent' Barbadian nationhood's identity. Many generations of Barbadians have memorized and internalized the words of the National Anthem without recognizing the underlying meaning of sowing "the seeds from which our pride is sprung" ${ }^{\prime 7}$. With a large portion of the current Barbadian population being of African descent, it is understandable that African influences are more dominant than those of other sources of ancestral origin. While mention of sowing seeds in the anthem refers to times of slavery and the plantocracy regime (after the abolition of slavery) which all ethnicities on the island experienced; the sowing of seed is also reminiscent of a particular recreational game of strategy, played by African ancestors: the Warri game. This game as was mentioned before, may be considered to be a remnant source of the Barbadian characteristic of resilience.

${ }^{86}$ Notional Anthem of Barbados. Ministry of Foreign Affairs \& Foreign Trade, n.d. Web. 22 Jan. 2012. <http://www.foreign.gov.bb/pageselect.cfm?page $=23>$.

87 Ibid. 
The use of seeds is a feature which makes the Warri game special as an almost forgotten element of culture which still invisibly exists in current society's strategic psyche. In addition, the game's multicultural recognition and variations under the same theme as a 'pit and pebble' game of strategy, further supports its use in 'playing the field' of the Caribbean cultural atmosphere of Barbados. I therefore believe that a manipulation of the game's principles may be useful for the re-articulation of a site of colonial origin such as the urban Queen's Park site, which is reminiscent of the colonial and native elements which Barbadians both grudgingly and gratefully accept. 


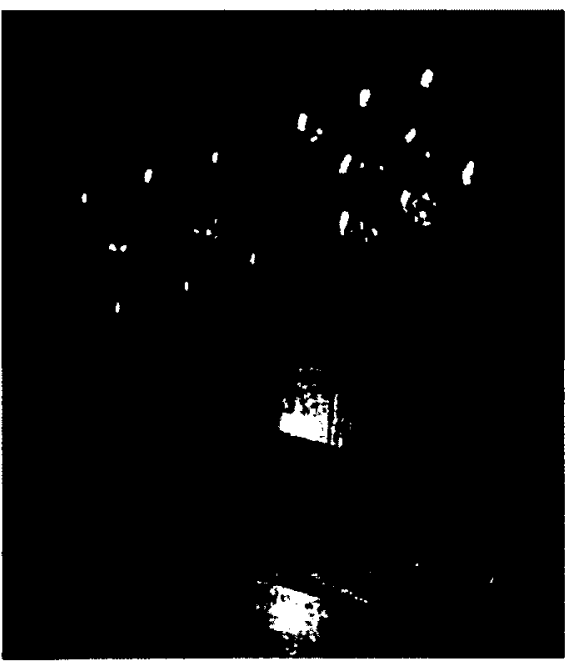

Figure 30 - Traditional Warri boards

Warri (or Oware) is Barbados' oldest surviving game of African origin. It is also considered to be one of the oldest board games in the world ${ }^{88}$. It is a game of strategy, much like chess or draughts and was played mainly to teach "the strategic importance of planning and the discipline involved in the actual implementation of long-term strategies, appreciating the importance of foresight, correct timing and an awareness of the principle of cause and effect" ${ }^{\prime \prime 9}$. The Webster's Online Dictionary which defines a game as "a scheme or art employed in the pursuit of an object or purpose; method of procedure; projected line of operations; plan; project ${ }^{\prime 90}$, supports the previous theory of the

Warri game's teachings. In my opinion, I believe that this game is symbolic of the way in which the locals have both consciously and unconsciously emerged from the trials and tribulations of "growing up stupid under the union jack"${ }^{\prime 1}$.

\footnotetext{
${ }^{88} \mathrm{http}: / / \mathrm{www}$.warrisociety.com

${ }^{89} \mathrm{http}: / / \mathrm{www} \cdot$ barbadosphotogallery.com/warri/warrigame.htm

${ }^{90} \mathrm{http}: / /$ www.websters-online-dictionary.org/definitions/game

${ }^{91}$ Clarke, Austin. Growing Up Stupid Under the Union Jack. Toronto: McClelland \& Stewart, 1980 - the novel describes a young boy's

experiences whilst growing up in the English colony of Barbados.
} 
According to Warri enthusiast William Lee Fanum-Badley; "the game has probably played an important role in shaping the personality of the communities that used it for entertainment ${ }^{1192}$. As a retired business development strategist and sole manufacturer of Warri game boards on the island, Badley believes that "some of the sharp evaluation skills for which older Barbadians are known can be attributed to their use of childhood game-playing competencies as effective reference to analyze the situation" ${ }^{\prime 93}$. The game was "kept alive over the years entirely by word-of-mouth or what is known as the oral tradition, but games with such formidable technical integrity as Warri are for obvious reasons

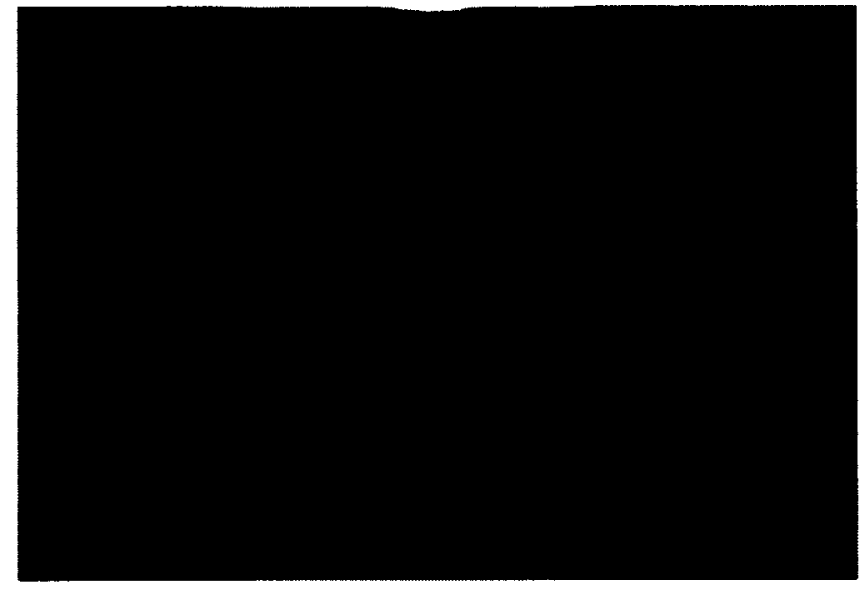

Figure 31 - A Warri game being played in the soil handed down from generation to generation of players very accurately"94 . The Warri game, like many of the slaves' other native cultural practices was treated with contempt by plantation owners and as a result was stealthily set-up and played in unusual locations, through digging the Warri holes into the soil as if they were 'planting' or through carving the holes into a half-buried stone for example.

Warri encouraged the development of critical thinking skills and mental strategy, which would have been counter to any measures of European efforts to 'civilize' the workforce. Testimony to this theory, is its inclusion in the Mind Sports Olympiad in London. It may be said that the resulting mental tenacity of this game still exists in Barbadian society today but is at risk of being diminished by the temptations of

\footnotetext{
${ }^{92}$ Fanum-Badley, William L. Personal interview. 20 Dec. 2011

${ }^{93}$ Ibid.

94 http://www.barbadosphotogallery.com/warri/warrigame.htm
} 
prevailing visual culture on the current generation; the result being tainted perception of self and others. The way in which the game was passed on and the basic rules of etiquette are also remarkably reminiscent of the manner through which the island's cultural values are shaped:
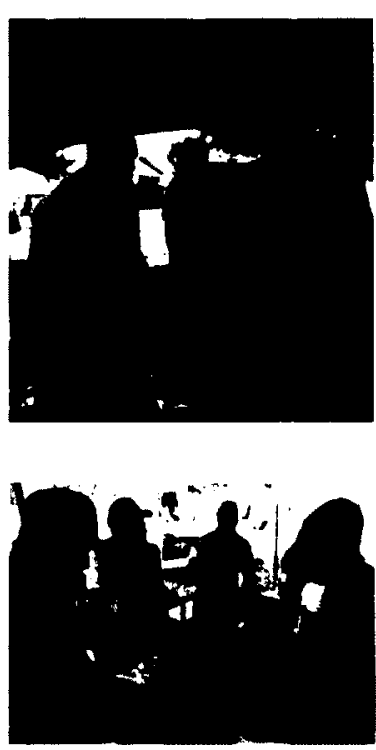

Figure 32 - The commencement of a Warri game (at top) and the game in session (below)
- Warri etiquette translated

- Rule \#1: In the first game the senior player has the right to make the first move, and it is he/she who may give up this privilege.

- Lesson learnt : Young Barbadians are always reminded of the saying "age before beauty", meaning that you should always give way to those who are more senior than you; as a sign of respect.

- Rule \#2: You may not move the pieces in a hole in order to count them - a hole touched, is a hole played.

- Lesson learnt: The values of confidence and fairness are instilled here. You must be certain of your play because there is no going back. Trickery is not tolerated, you must play by the rules.

- Rule \#3: It is extremely discourteous to ask to check that a move just made by your opponent is within the rules. This applies even when expert players drop the seeds into the holes very quickly, and when there are a large number of seeds, in which case it is highly unlikely that you will be able to ascertain if your opponent has obeyed the rule which says that he must drop one seed in each hole.

o Lesson learnt: You must be trustworthy and learn to trust others, giving them the benefit of the doubt.

Like many other folk arts, the game's deceptive simplicity conceals formidable complexities. This form of calculated deception is reminiscent of the tactical approaches through which many Caribbean cultural practices have survived. Its survival as a source of entertainment must be attributed to its ingenuity and the resilient character of the Barbadian people who played the game. Artisans would never waste much time fashioning beautifully carved Warri boards because of the game's thorough repression. As a result, Barbadian Warri board craftsman held one specification uppermost: it had to be 


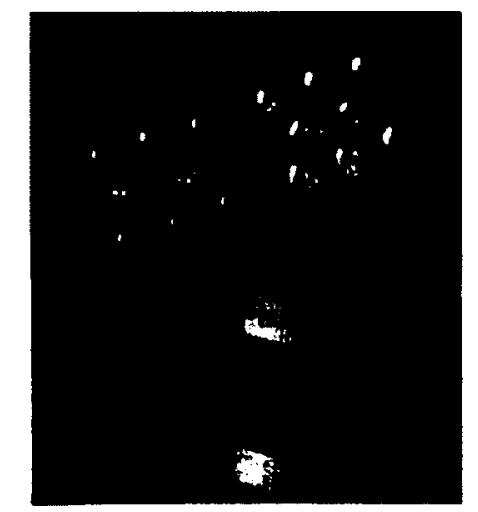

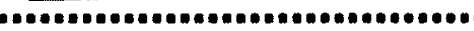

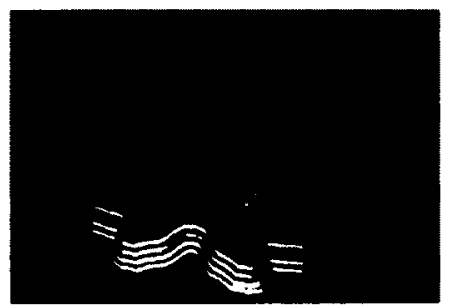

PROECT DESKCN LONROS

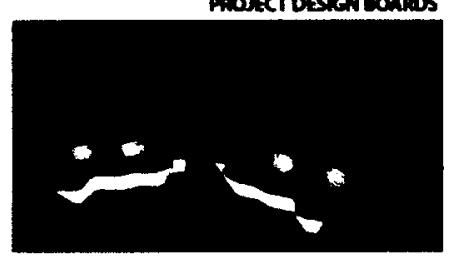

Figure 33 - Traditional Warri boards versus contemporary designed boards a piece of wood that could 'dash way easy' ${ }^{95}$. Given the preceding specification and the period of the game's existence, it is clear that Barbadians had to consider practicability before aesthetic for several hundreds of years. This point may be further aligned with the seemingly conservative nature of the Barbadian society which might then provide an argument for an architectural intervention which places function before form.

The Warri game board was usually made from a rectangular wooden surface with two rows of six holes carved into it. Each hole is called a house, and each house contains four game pieces - seeds to begin. The object of the two-player game from here on is to capture as many houses as possible along with their contents. Each opponent sits on opposite sides of the board watching over the six holes on his/her side of territory. The seeds are 'harvested and sown' in an anti-clockwise direction around the board. The seeds themselves are undifferentiated, and at the beginning of the game do not belong to either of the two players.

Based on the previous statement, the seeds of play may be likened to the people of the Caribbean in general, and also more specifically, the Barbadian-Caribbean subset. Though the Caribbean people's ancestors may have originally been 'collected' from many other places and redistributed throughout the Caribbean region, their experiences through this redistribution has provided the base for the creation of the Caribbean cultural experience. The ancestral bonding through this experience made them similar to the undifferentiated seeds of the Warri game; they became a group of people who no longer solely belonged to any one territory prior. The use of this game therefore can provide the theoretical framework for how the proposed site can be manipulated as a tribute to the cultural experiences of the Barbadian-Caribbean people.

${ }^{95}$ Dash way - to throw away. 


\section{PLAYING IN THE FIELDS AND HILLS BEYOND RECALL: THE QUEEN'S PARK}

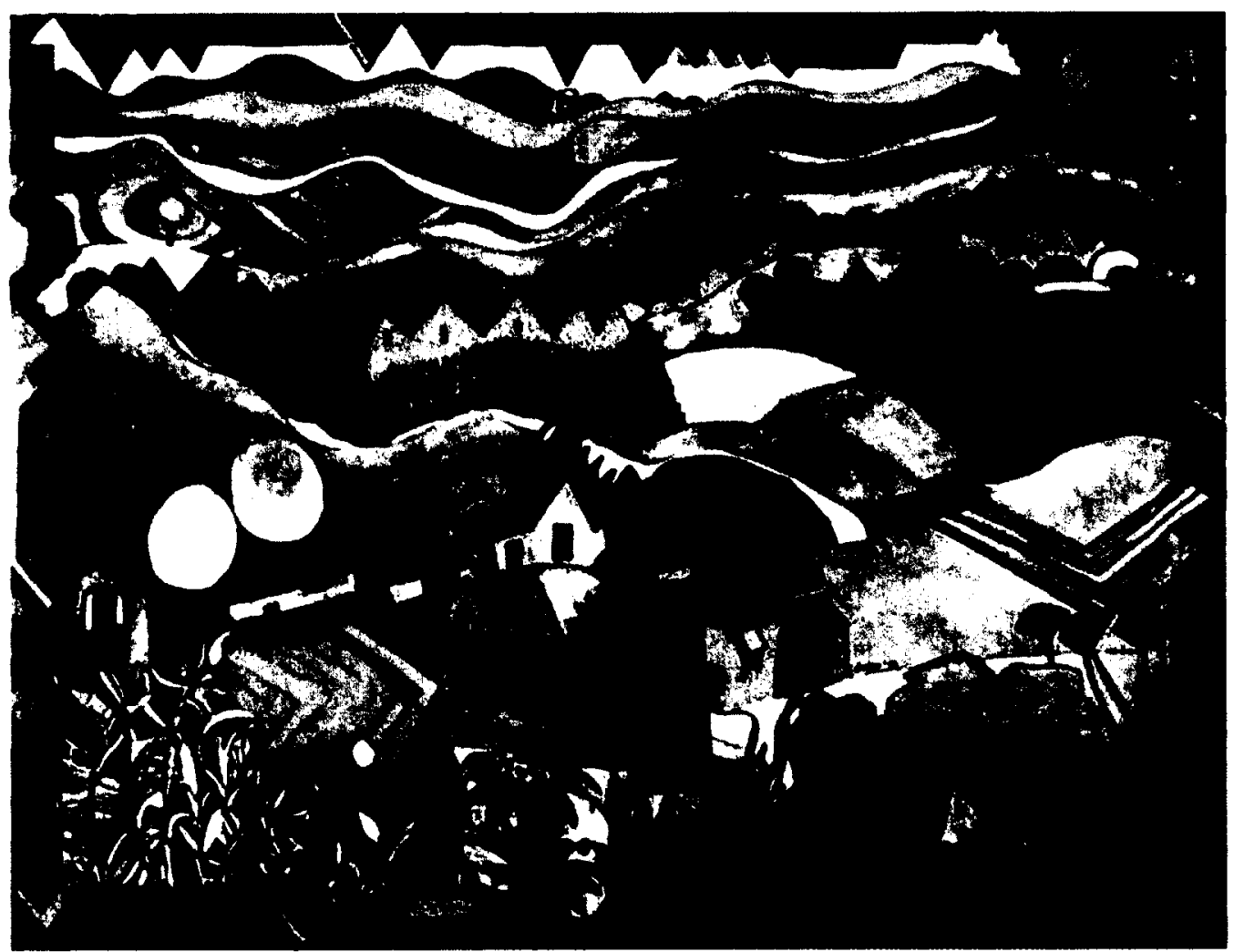

"We loyal sons and daughters all Do hereby make it known These fields and hills beyond recall Are now our very own. We write our names on history's page With expectations great, Strict guardians of our heritage, Firm craftsmen of our fate..."

Figure 34 - This Good Earth 


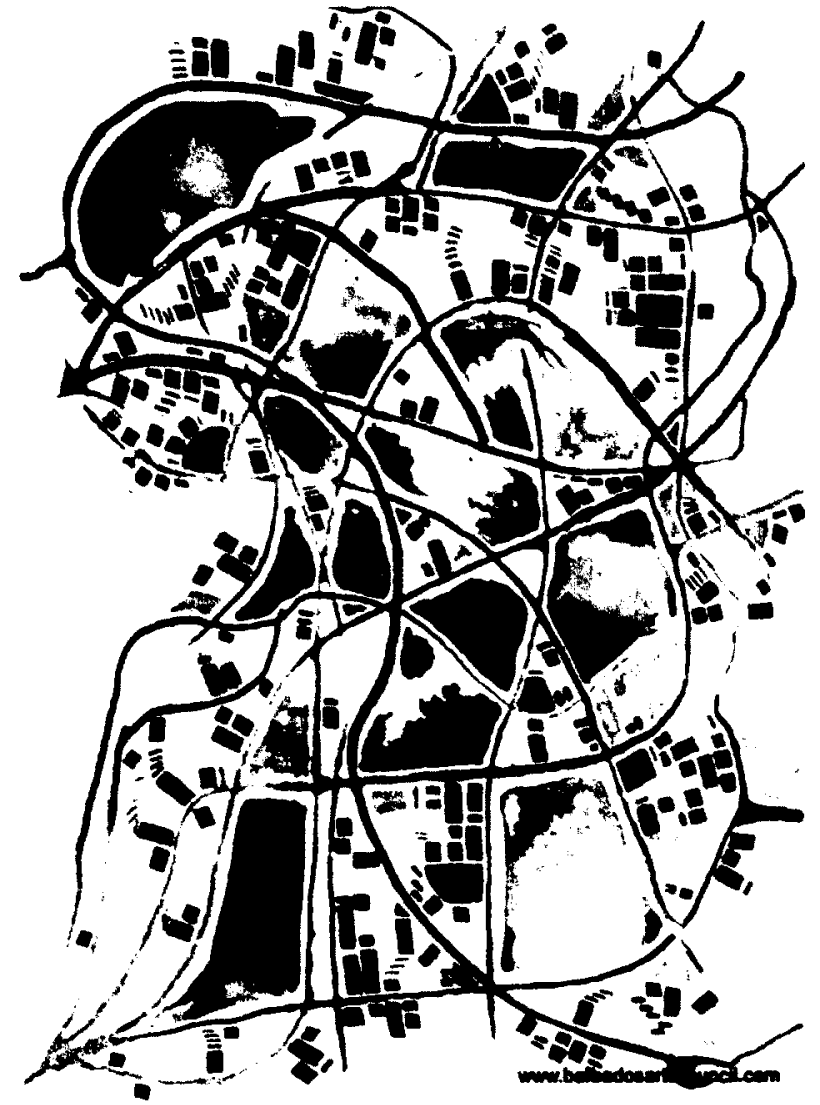

Figure 35 - Barbadian artist's impression of the city's plan

Source: www.barbadosartscouncil.com

\section{SITE INTRODUCTION AND TERRITORIAL BACKGROUND}

No longer do Barbadians need to 'dash way de boards' of game play, they are now free to firmly craft the fate of their culture. The re-crafting of the Queen's Park in the country's capital city Bridgetown, will be a strategic means of expressing the pride of nationhood; Barbadian Culture.

\section{In 2011, Bridgetown received UNESCO designation as a World Heritage Site} for recognition of the city's retention of its original footprint for almost four centuries. The organic serpentine street layout supported the development and transformation of creolized forms of tropical architecture, including the Caribbean Georgian style. The UNESCO designation notes that "the preservation of the historic street layout has also continuously supported both the preservation and evolution of functions in the colonial and post-colonial urban space, with administrative, commercial, cultural and residential uses still relatively intact. The communities that inhabited the town, made their mark on the townscape with their urban tropical architecture and monuments. Historic Bridgetown and its Garrison participated in international trade, not only of goods, but also the transmission of ideas and cultures that characterized the developing colonial 
enterprise in the Atlantic World. By the $17^{\text {th }}$ century, trade relationships were established with England, North America, Africa and the colonial Caribbean, making the port a cosmopolitan centre of commerce, settlement and exploitation" ${ }^{96}$.

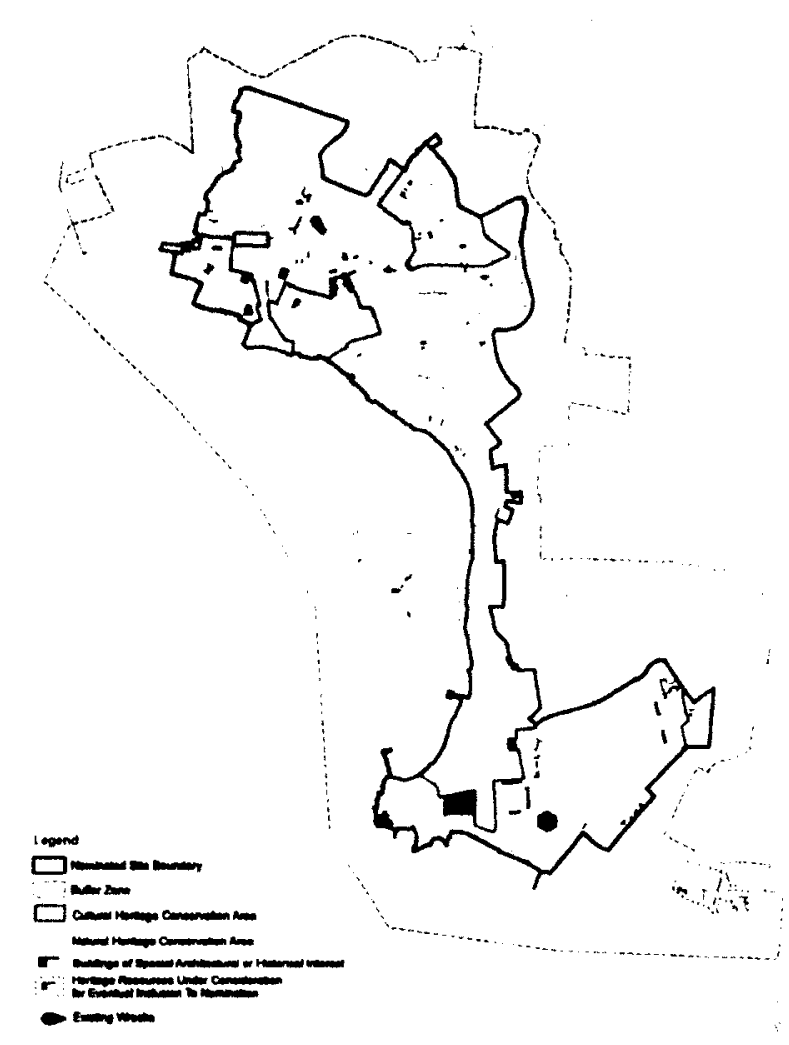

Figure 36 - Map of Historic Bridgetown and its Thematic Zones

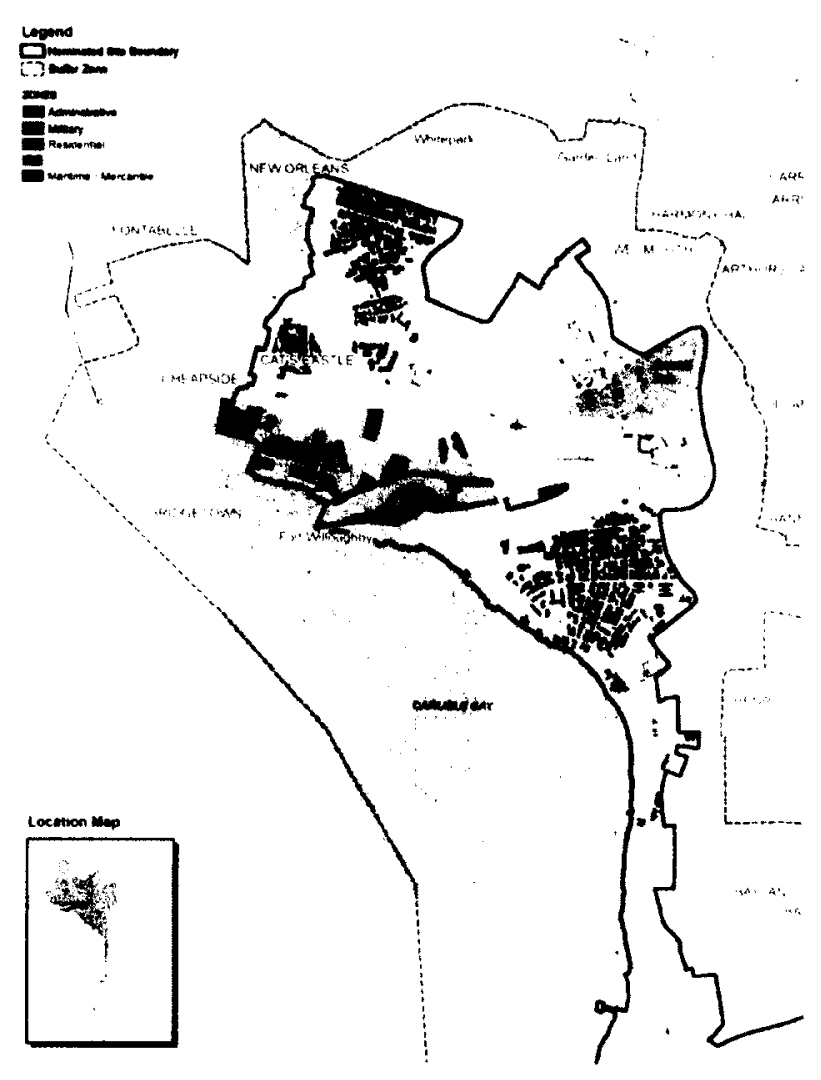

Figure 37 - Map of the Natural and Cultural Heritage Conservation Areas \& Buildings of Specific Architectural Historic Interest

\footnotetext{
96 "Decision - 35COM 8B.42 - Cultural Properties - Historic Bridgetown and its Garrison (Barbados)." UNESCO: Building Peace in the Minds of Men and Women. UNESCO World Heritage Committee, n.d. Web. 23 Sept. 2011. <http://whc. unesco.org/en/decisions/4313>.
} 
Queen's Park was handed over as a recreational space for the city after military forces withdrew in 1905. Both the renovations to the main house and the new site landscape were awarded to the former military commander's wife, Lady Gertrude Gilbert-Carter, based on the fact she "had some artistic ability but also on the fact that she was an American" ${ }^{\prime 97}$, a gesture which implied preference of foreign expertise over local. Following the site's opening as a park in 1909, activities such as agricultural exhibitions, police band concerts, promenade balls and political rallies were held within the space. Given the site's historical space usage allocation, the recent UNESCO designation has listed the Queen's Park site and its buildings as important cultural structures to be maintained within Bridgetown (see Figures $35 \& 36)$.

The Queen's Park site is flanked by the original sites of two of the oldest secondary level institutions, Queen's College and Harrison College. Harrison College has remained relatively unchanged as a school ground over the last few hundred years whilst the Queen's College school has been relocated to a larger, more modern facility outside of the city core. The old Queen's College site has now houses the headquarters for the Ministry of Education, Youth Affairs and Culture. The park has three entrances: The Governor's gate to the east, Queen's gate to the south facing the old Queen's College school, and Nelson's gate which faces the city and ultimately the location of Lord Nelson's statue. The park site is largely used as a pedestrian thoroughfare between the Governor's gate and the Nelson gate since high walls and sidewalks on the main street do not allow easy or safe pedestrian travel along Constitution Road, the street which bounds the south of the site. Constitution road is a major vehicular traffic artery leading into and out of the city which is met by a one-way vehicular traffic artery Crumpton Street - at the western point of the site. The junction with these two streets thus makes the

${ }_{97}$ Pena, Miguel. "Our American Lady: The Story of Lady Gertrude Gilbert-Carter and her contribution to Barbados." The Journal of the Borbodos Museum \& Historical Society LV Dec. (2009): 12. 
point at Nelson's gate into a chaotic meeting of people and vehicles, a less than ideal situation for serene entry into the city's park space. The following images illustrate the previously described site context:
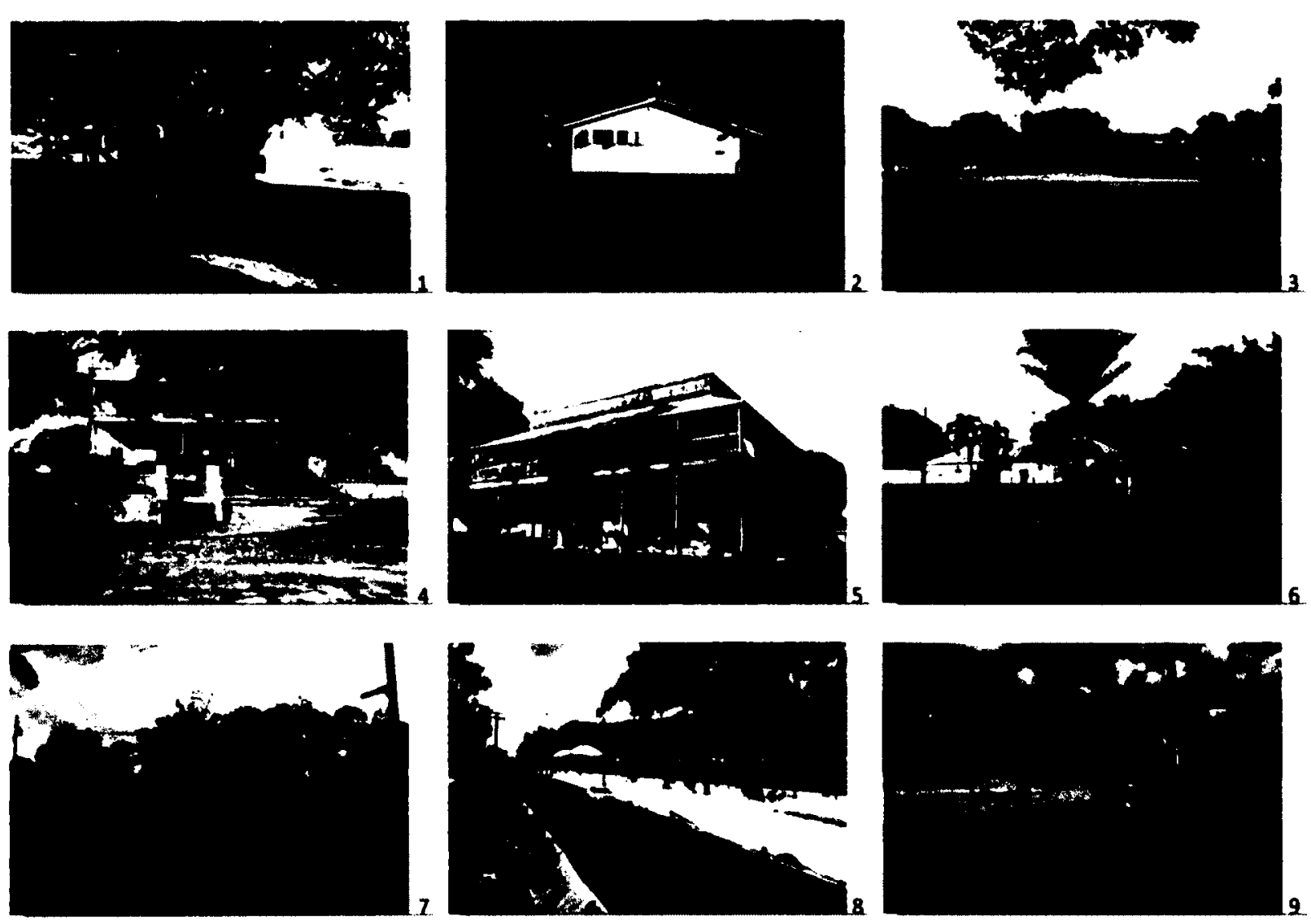

1. The Baobab Tree

4. East elevation of Queen's House

7. Nelson's Gate pedestrian entrance
2. Existing Cricket pavilion

5. North East angle of Queen's House

8. High walls along Constitution Road
3. Existing Cricket pitch and field

6. Stables to north of Queen's House

9. Exit gate from the Ministry of Education

(former QC) on to Constitution Road 

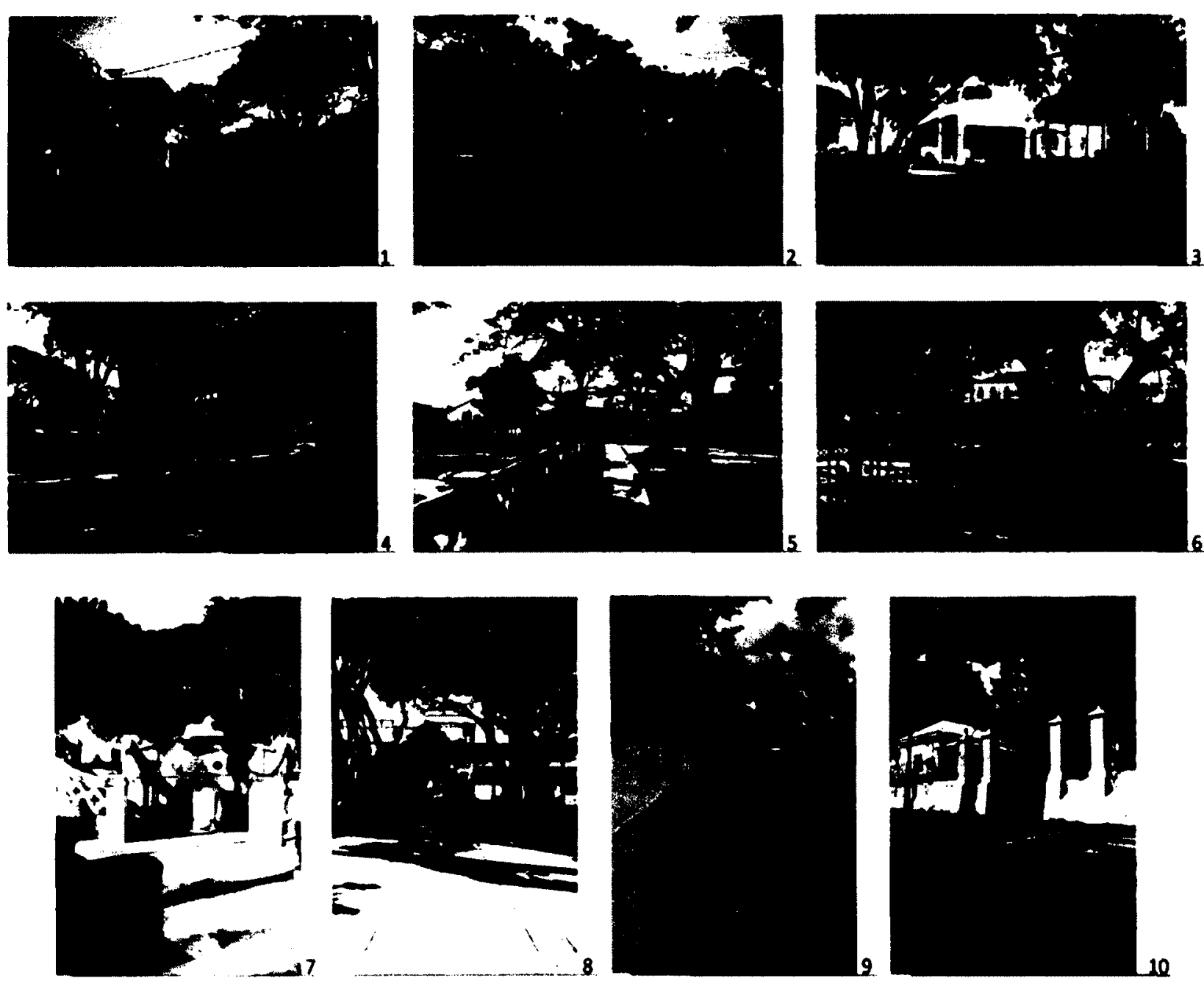

1. Existing artery through site passing directly infront Queen's House

2. Existing Pump House

3. Recently renovated Steel Shed

4. Path towards Band Stage
5. Axis with adjacent site (former QC)

6. View from Band Stage towards Ministry of Education complex (former Queen's College)

7. Lion's Head scultpure atop stair to Band Stage
8. Entrance artery to Queen's House

9. Lack of pedestrian walkwors alons Constitution Road

10. Queen's Gate entrance 


\section{FIRST ROUND - ASSESSING THE FIRST MOVE}

\section{PROVIDING THE FRAMEWORK OF WARRI THOUGHT}

The rules of game play and etiquette, from the Warri game are used metaphorically to generate the new proposal for the site. The game's devices provide the underlying framework for which design modifications are to be justified. The basic rules of the game are as follows:

- Moving

- Once it has been decided which player starts the game, that player picks up all of the seeds contained in any chosen hole in his/her territory and 'sows' them one by one into the holes that follow, in an anti-clockwise direction. Depending on the hole selected and the seeds contained, 'sowing' in your opponent's territory will occur.

- You must make a move each turn.

- You may only start moving from a house in your territory/on your side of the board.

- You may not 'sow' more than one seed in each hole or skip holes, with the single exception described in the next instruction.

- Only when more than 11 seeds are to be deposited - and you therefore return to the starting point of the move - 'sowing' continues after skipping the hole from which the seeds were originally taken.

\section{Capturing}

- Capture occurs only in your opponent's territory.

- When the last seed deposited ends up in a hole in your opponent's territory which contains only one or two seeds, these are captured and eliminated from the game, together with the seed which has just been played.

- If the hole or holes before the one in which the above capture has taken place contains two or three seeds, these too are taken and eliminated from the game.

\section{Ending the game}

- If one of the players after making their move finds themself without seeds in their own territory, his/her opponent, if they can, must make their own move to 'feed' $\mathrm{him} /$ her with seeds. If this is impossible, the game is over.

- The game also ends when it becomes clear that no pieces can be taken. 
- Determining Victory

- At the end of the game, each player counts the number of seeds he/she has captured.

- The player who still has seeds in their territory adds them to the number of captured seeds.

- The winner is the player who has taken the most seeds. You must therefore have taken at least 25 seeds - 24 seeds each means that the game is drawn. ${ }^{98}$

The Warri game requires an even number of holes varying from 12 to 48; for the purposes of this project I suggest the use of six holes or 'houses' for capture. The traditional game, as it is found in Barbados requires 12 holes, i.e. six holes per player and therefore two territories over which the game is to be played. The proposed six 'houses' are a gesture of the two things:

(1) The idea that there are no longer two opponents or territories; but only one territory and one culture of which all 'seeds sown' are now a part of. The multiplicity of the seeds sown is representative of the multicultural atmosphere that now exists.

(2) The six houses do not signify that any one territory has won the game. It is an acknowledgement of the past within the present. The pieces for capture are the pieces of the existing 'territory' which are now being retrofitted to exist within the newly defined territory. The pieces for sowing are native cultural seeds which are to be sown into the existing context.

${ }^{98} \mathrm{http}: / /$ www.barbadosphotogallery.com/warri/warrigame.htm 


\section{Appropriation of the game into the site}

The above are the standard rules of the game. However, a variation of these rules exists in Barbados called 'Round De Town' Warri, whereby multiple sowing is practiced but all other rules of capture, ending the game and determining victory are the same. For example, if you decide to start play with a hole that contains four seeds, on placing the fourth seed into a hole of play, the player picks up the seed placed in that hole along with any seeds already in the said hole and continues playing until he/she reaches an empty hole with only one seed in hand. Since we are playing in the urban setting of Bridgetown, this version will be used for the site appropriation.

To start the appropriation of the game on to the site, we start by playing two seeds. Two seeds are suggested since the game has been compressed into half its scale with six holes instead of twelve, and likewise, play should begin with two (2) seeds instead of four (4). The first seed will be played into the Nelson's gate hole and play will be continued in a counter clockwise direction into each adjacent hole until the last seed is played into an empty hole.

Holes for play:

1. The Nelson's Gate Entrance

2. The Band Stage $\&$ Lion's Head Garden Feature

3. The Lady Gilbert's Garden and Governor's Gate Entrance

4. The Cricket Pitch \& Field

5. The Baobab Tree and Existing Playground

6. The Queen's House and Stables 
MARRISON COULEG SCHOOL GROUNDS

THE BAOBAB TREE :

EXISTING PLAY AREA

STABLES

QUEEN'S HOUSE

LSON'S GATE ENTRY

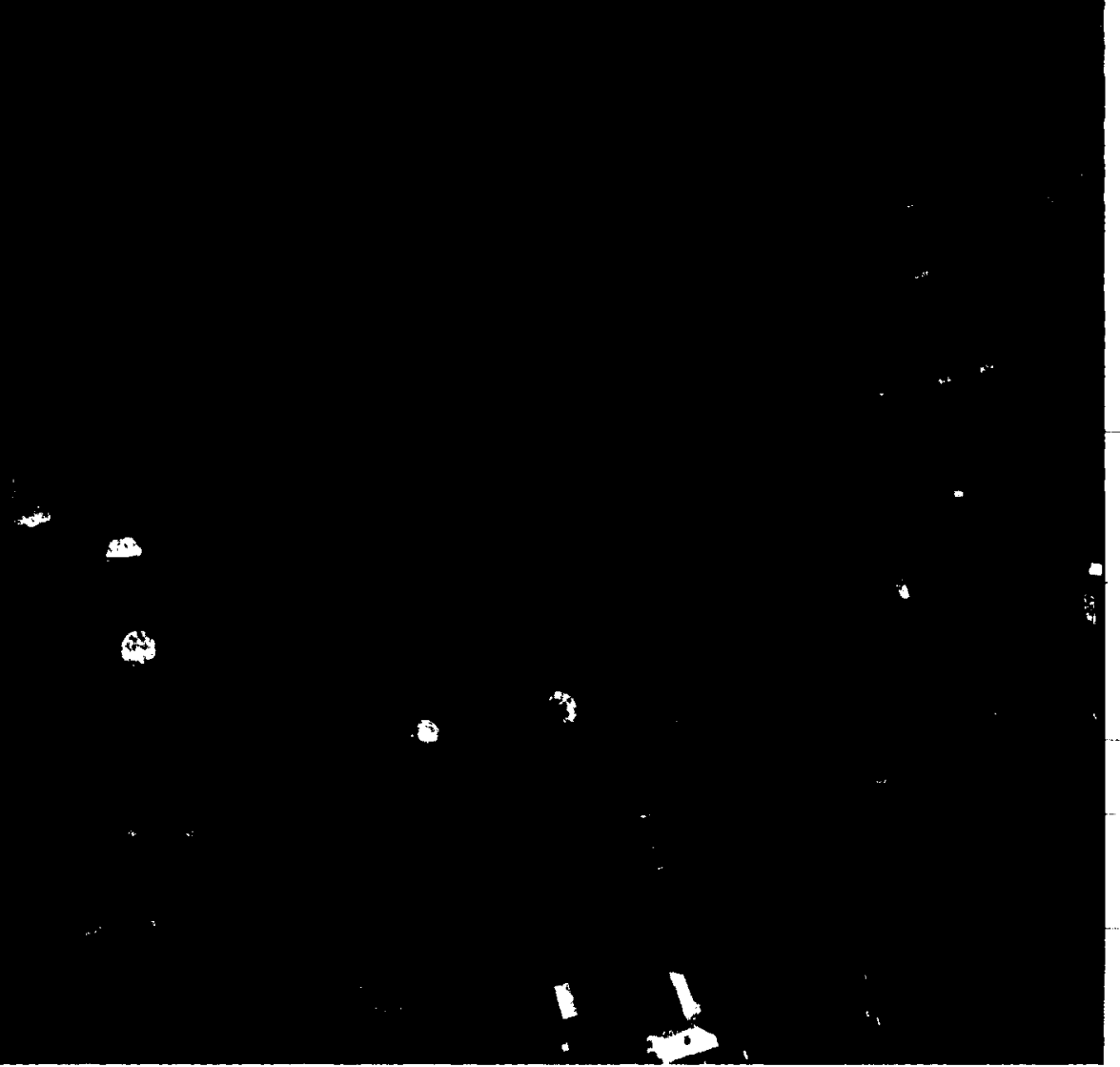

ㅍ

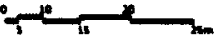

CRICKET PTICH

FIELO

FOUNTAN a

GONERNOR

GENERAL'S GAT
ENTAY

GARDEN FEATURE

BAND 5TAGE

FORMER QUEen's

COLLGE SITE \&

OF EDUCATION

Figure 38 - Aerial photo the Queen's Park site with superimposition of theoretical Warri game holes 
The below diagrams illustrate the progression of play from the condition of the holes illustrated on the previous site plan (figure 37 ):

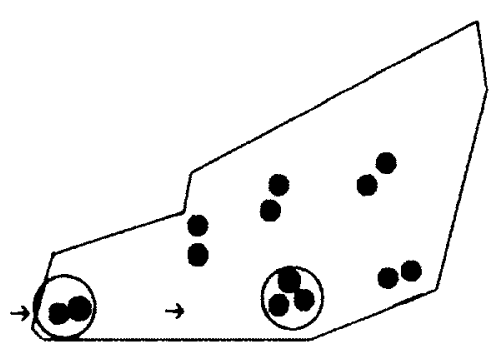

Figure 39 - First seed played here and play continues in a counter clockwise direction
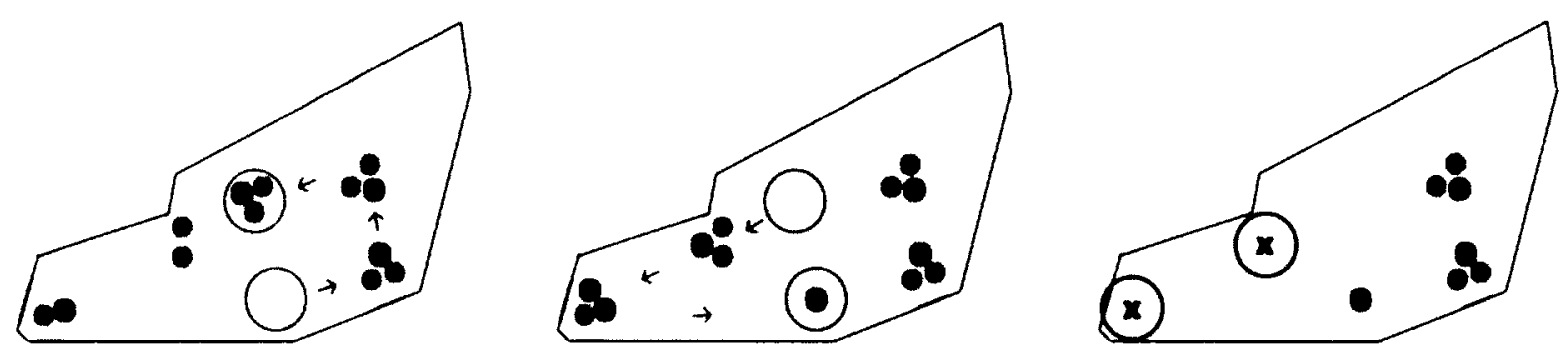

Figure 40 - Seeds are collected from the Figure 41 - Again seeds are collected last hole of play highlighted in the previous image and sowing continues from the last hole of play and sown until the lost seed is sown into an emotv hole
Figure 42 - The preceding holes contain three seeds each and can be claimed

It must be noted that at the end of play, the two preceding holes now contain three (3) seeds which signals eligibility for capture and design manipulation.

Pieces for sowing:

1. Queen's House - A claimed hole (demarcated by the ' $X$ ' symbol) - Art Gallery with Resource Facility function to be positioned between the existing Queen's house and stable which will be allowed to remain.

2. Nelson's Gate - A claimed hole (demarcated by the ' $X$ ' symbol) - New Nelson's Gate entrance articulation with old gate posts remaining. The entry continues on to the existing pathway and branches off with a new path into 
a coved seating area which features 'directional proverbs' and 'standpipe' water spout elements.

3. Band Stage - Originally held two seeds, now holds one seed - Band Stage area to remain and lion's head element to be removed since only one 'seed' now exists here according to the game. This move upholds the stage area as the more culturally significant piece.

4. Governor's Gate and Gilbert Gardens - Originally held two seeds, now holds three seeds - Relocation and re-articulation of play area into a culturally themed playground with interactive folkloric sculptures. Playground location to be placed in a visible location, close to main street circulation as a method of inviting children and parents in. Concession Kiosks (chattel structures) which reintegrate informal social gatherings.

5. Cricket Pitch \& Field - Originally held two seeds, now holds three seeds Cricket pitch area to be articulated into a multi-purpose sports recreation area with the additions of a walking track encircling the field and a new pavilion.

6. Baobab \& Playground Area - Originally held two seeds, now empty - Given that the Baobab hole is now empty, the design proposal for this space is pre-empted on the second round of play whereby it is open for sowing of an additional element or elements. The emptiness of the hole does not signify that the tree has been removed, only the previous playground space which has been dispersed to another location. 


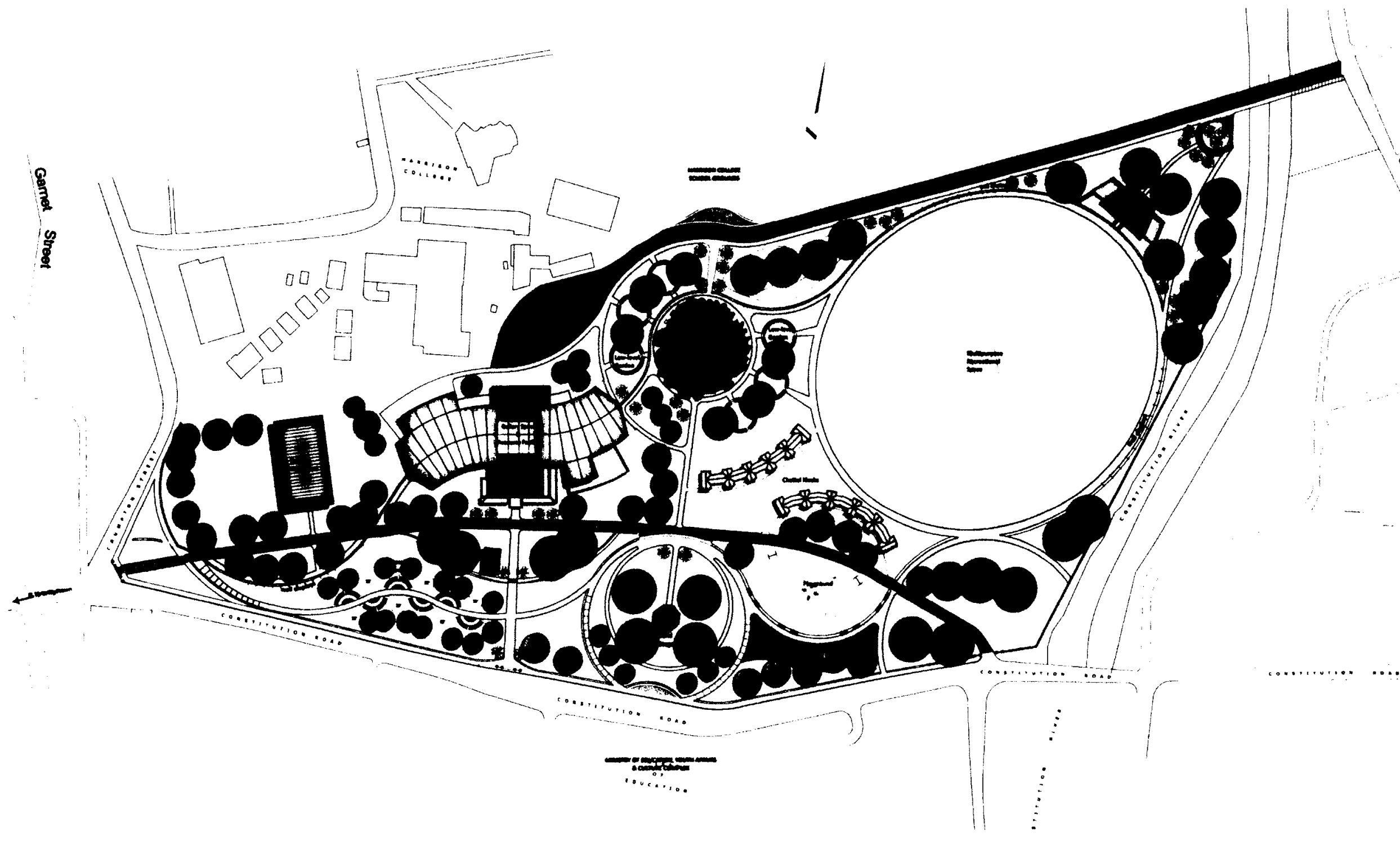

Figure 43 - Proposed Site Plan for Queen's Park Barbodos 


\section{SECOND ROUND - PICKING UP PIECES AND MOVING AGAIN}

\section{SOURCES OF ANCESTRAL ORIGIN}

\section{Queen's House \& Stables}

"I want to know what kind of mirror image

do you have of

yourself? Do you really like yourselves?... Why should only one man have a mirror image of you that you do not want to have of yourself? What kind of society are we striving for?"

- Errol Walton Barrow

l'The Father of Independence'), excerpt from preelection speech at Independence Square in Bridgetown, 1986
Sitting at the point of climax of the gently sloping uphill progression into the site, is the Queen's House; in all its empty, colonial grandeur. The house was the most important feature within the park's existence and now leaves much to be desired in terms of its purpose and future intention. The house is now open as a 'house' for play in the park's game of Warri.

The Queen's House (formerly known as King's House) was the official military residence of the English Commander. The National Cultural Foundation formally established an art gallery in Queen's Park House (QPH) in 1984; however from 1910 when Queen's Park was adopted as the home of the annual Agricultural and Industrial Exhibition, the park space in general, was already settled as the center of commercial success for Barbadian artists. Traditionally, recognition at the exhibition meant success in the market place due to the close alliance of the exhibition with the upper and middle classes, and the lack of available exhibition/gallery space on the island. Some of the most "significant art exhibitions to be mounted in Barbados took place in Queen's Park. It was the aim of most Barbadian artists to be granted an exhibition at Queen's Park" ${ }^{\prime 99}$. In 2011 however, the QPH was deemed unsuitable for occupancy and was closed pending future plans for renovation.

\footnotetext{
${ }^{99}$ Whittle, Janice. "Queen's Park Art Gallery." Message to the author. 16 Oct. 2011. Web - current curator of the relocated gallery.
} 
For at least 100 years, visual art has been one of the strongest mediums for the animation of cultural life in Barbados. Through art, the personalities, experiences and emotions of Barbadian artists exist in a dynamic yet static state; art allows the capture of moments in time which can later be referenced and compared to periods before and after. The images depicted, the style of representation, choice of media and method of display are all layers which begin to create an identifiable artistic expression which not only identifies the artist on a personal level but also on a cultural level. It is an expression of identity which cannot be captured or expressed by any external entity.

In 1934 Marcus Garvey, black cultural activist and founder of the Pan-Caribbean Movement, urged Caribbean people to "develop artistic standards of their own" ${ }^{100}$, citing that art was the "highest form of intelligence, the highest form of genius" ${ }^{101}$. Garvey insisted that pride and self-esteem were largely dependent on one's perception of one's history. An article by the Barbados Museum and Historical Society laments that the absence of a national art gallery "plagues the cultural consciousness of a growing society, while the paucity of written materials such as art critiques, essays, monographs and exhibition catalogues have reminded us of the lack of a comprehensive assessment of national art in the $20^{\text {th }}$ century, and may inhibit the development of an indigenous aesthetic capable of responding to the demands of the $21^{\text {st }}$ century" 102 .

As a response to the previous concerns and the concerns of this thesis in general, it is proposed that the Queen's House, as a physical and metaphoric point of reference, should become the home of the National Art Gallery with an attached resource center. The gallery and its resource center will seek to exhibit the expressions of cultural identity in the form of visual art display and to encourage the

${ }^{100}$ Cummins, Alissandra, Allison Thompson, and Nick Whittle. Art in Barbados: What Kind of Mirror Image? Kingston, JA: lan Randle Publishers, 1999. 45

${ }^{101}$ Ibid. 45

${ }^{102}$ ibid. 7 
immersion, assessment and development of cultural identity through the functions of the resource center.

The existing QPH structure will house traditional displays on the lower level and the reference section of the resource center on the upper level of the former stables. The new gallery space and the above resource reception and reading spaces, will sit between the existing QPH and its stables. The interface of the original and proposed spaces is a suggestion of the removal of the prestigious perception behind exhibiting within the walls of the Queen's House. However the new space is still within reach, as the outer walls now become the inner walls and therefore still contain the gallery to some extent. This is a reflection of the independent society as is, with Governor General still present.

The formality of this space for visual expression, learning and dining, is a suggestion of the 'proper' way of experiencing these cultural elements. The adjacent exterior spaces however exhibit the opportunity for similar experiences but with less formal frameworks. These gestures are reminiscent of the remarks made in the previous Brought-upsy section where it was suggested the values of Bajan society are such that they allow for the accommodation of varying and possibly opposing social functions within close proximity to each other, without issue. The programs of the adjacent spaces will be addressed in the text that follows.

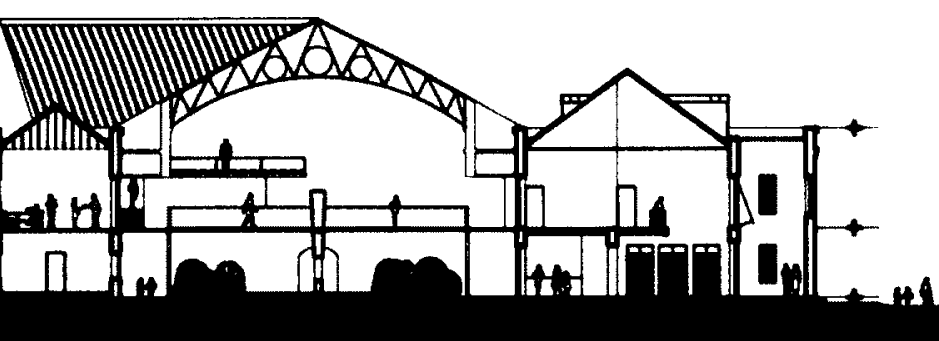

Figure 44 - Site section through Gallery 


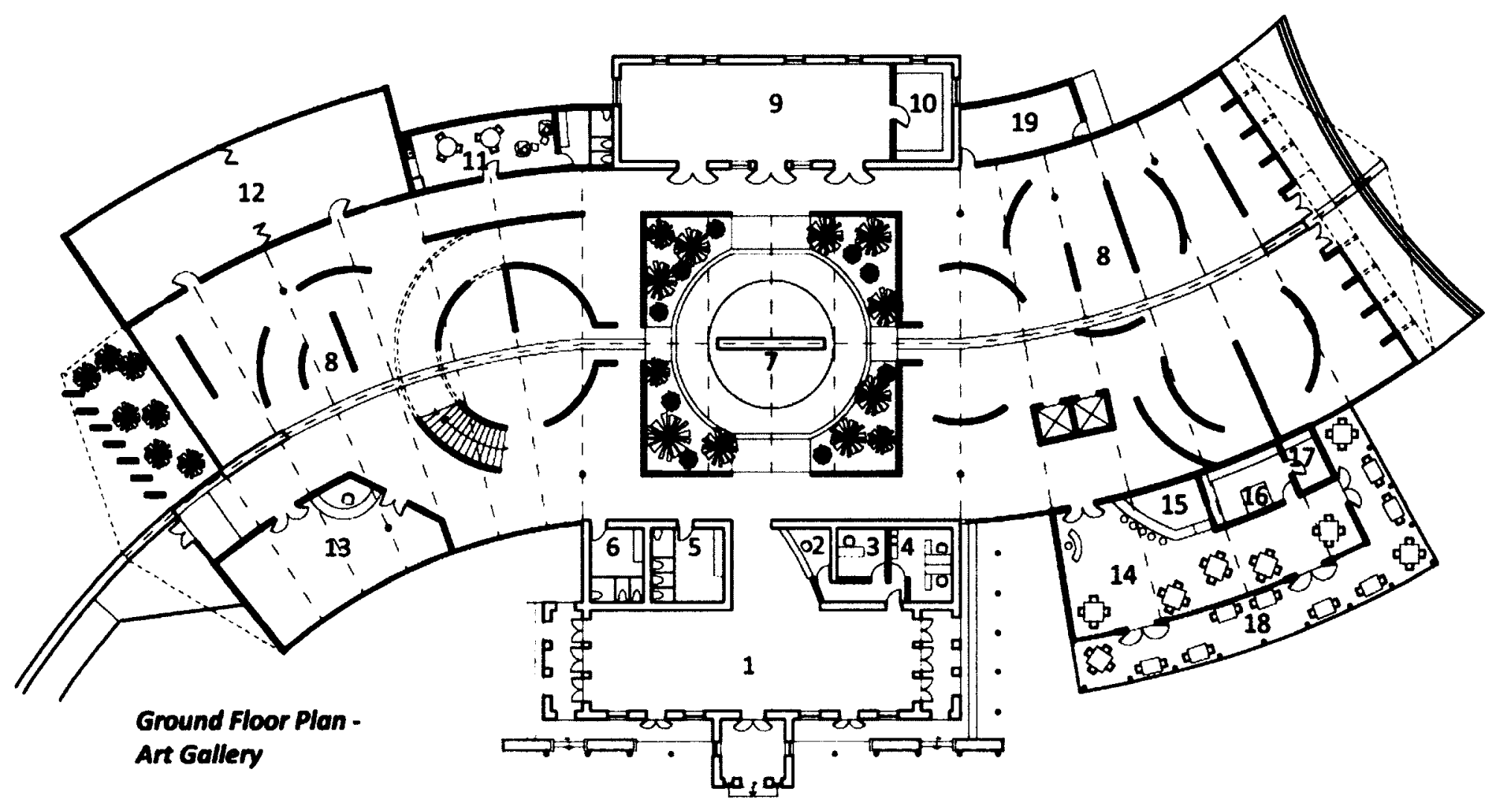

1. Lobby

2. Ticket Booth

3. Curator's Office

4. Administrative Office

5. Female Washroom

6. Male Washroom

7. Courtyard
8. Exhibition Space

9. Multipurpose Room

10. Servery

11. Staff Lounge

12. Workshop Space

13. Gallery Retail Space

14. Restaurant

Figure 45 - Gallery Plans
15. Bar

16. Kitchen

17. Kitchen Storage

18. Verandah Seating

19. Gallery Delivery Area 


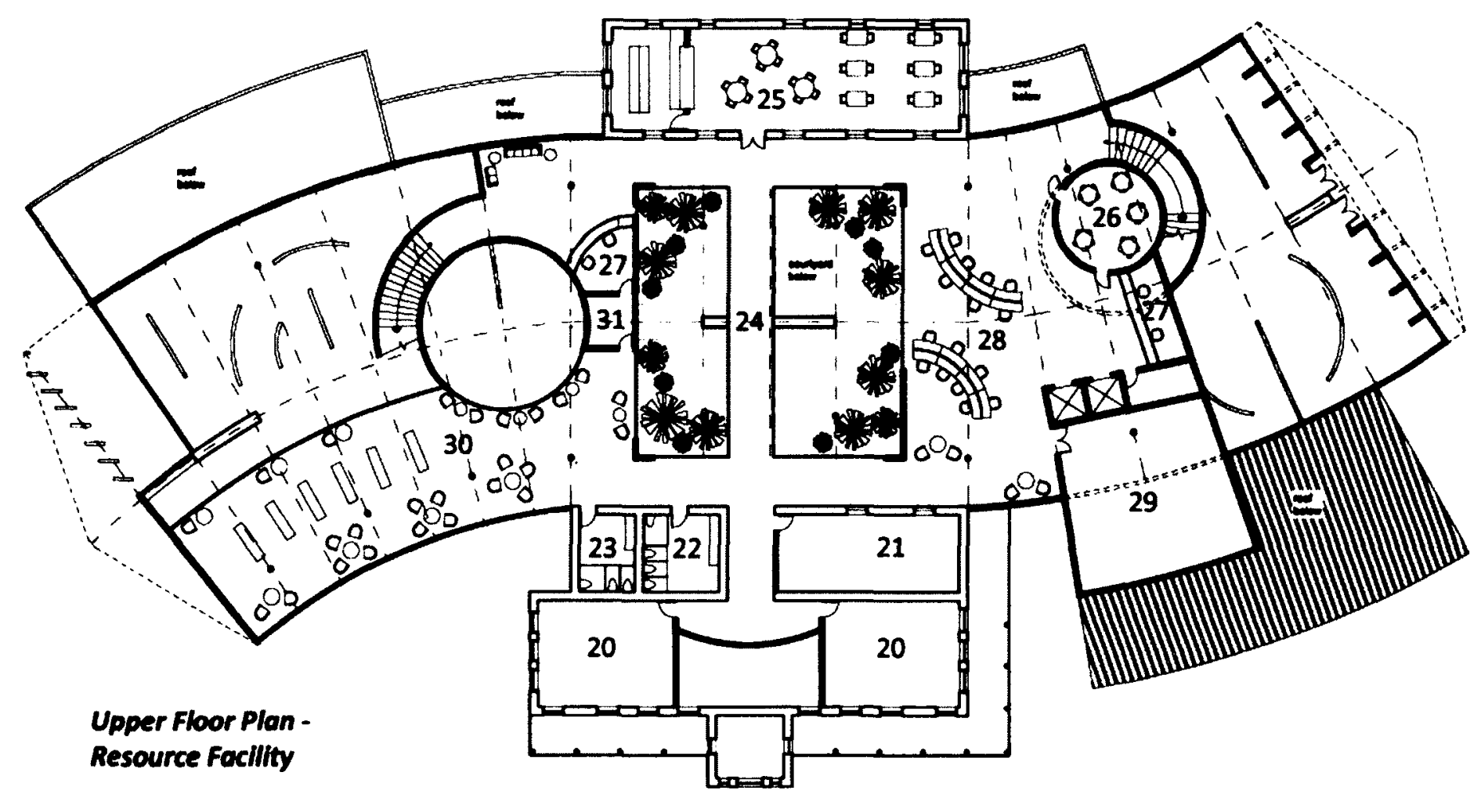

20. Seminar Room

21. Audio Visual Room

22. Female Washroom

23. Male Washroom
24. Bridge over Courtyard

25. Reference Room

26. Kid's Room

27. Circulation Desk
28. Computer Stations 29. Presentation Room 30. Stacks \& Reading

31. Storage

Figure 46 - Gallery Plans 

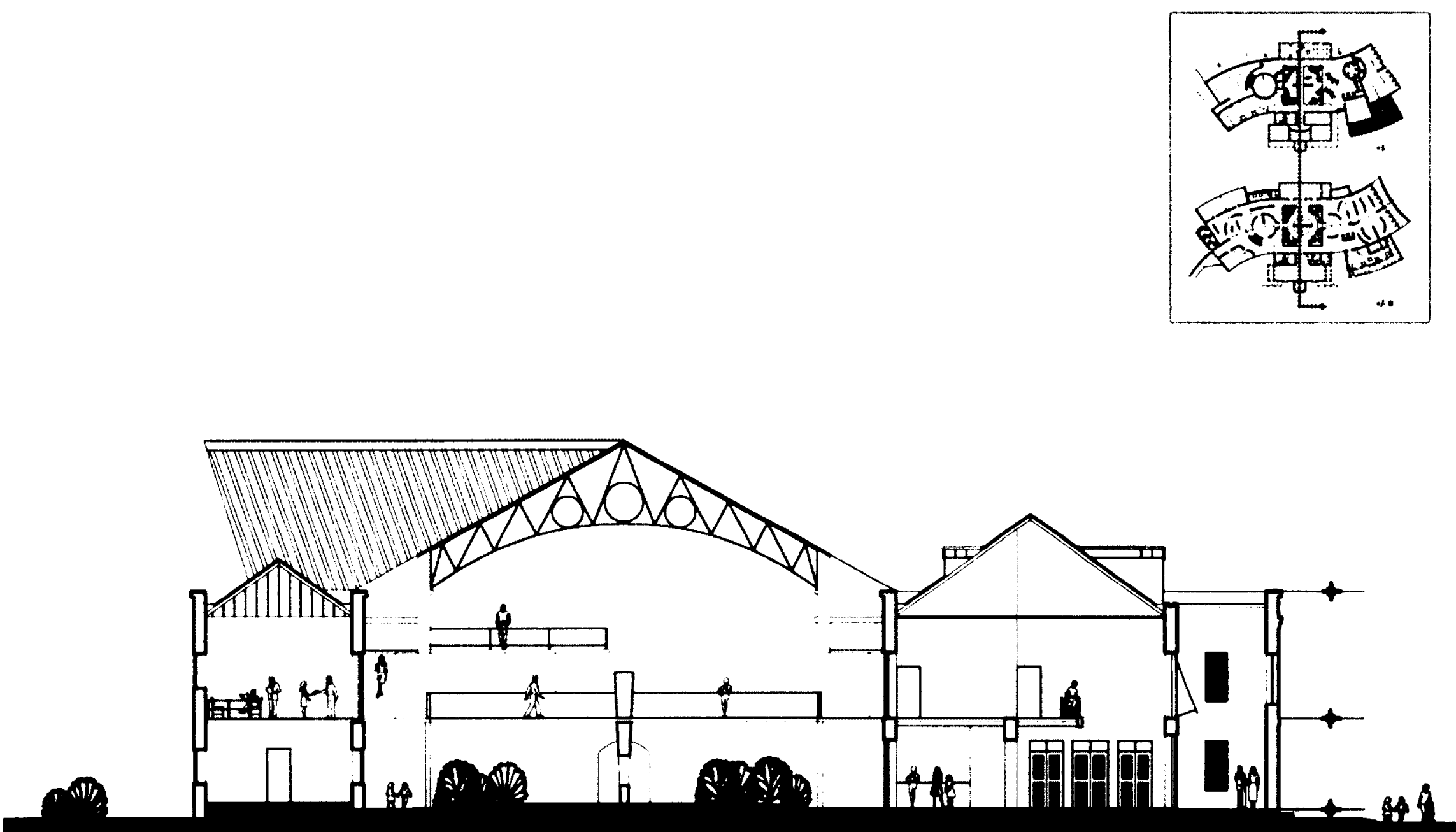

Figure 47 - Gallery Section 



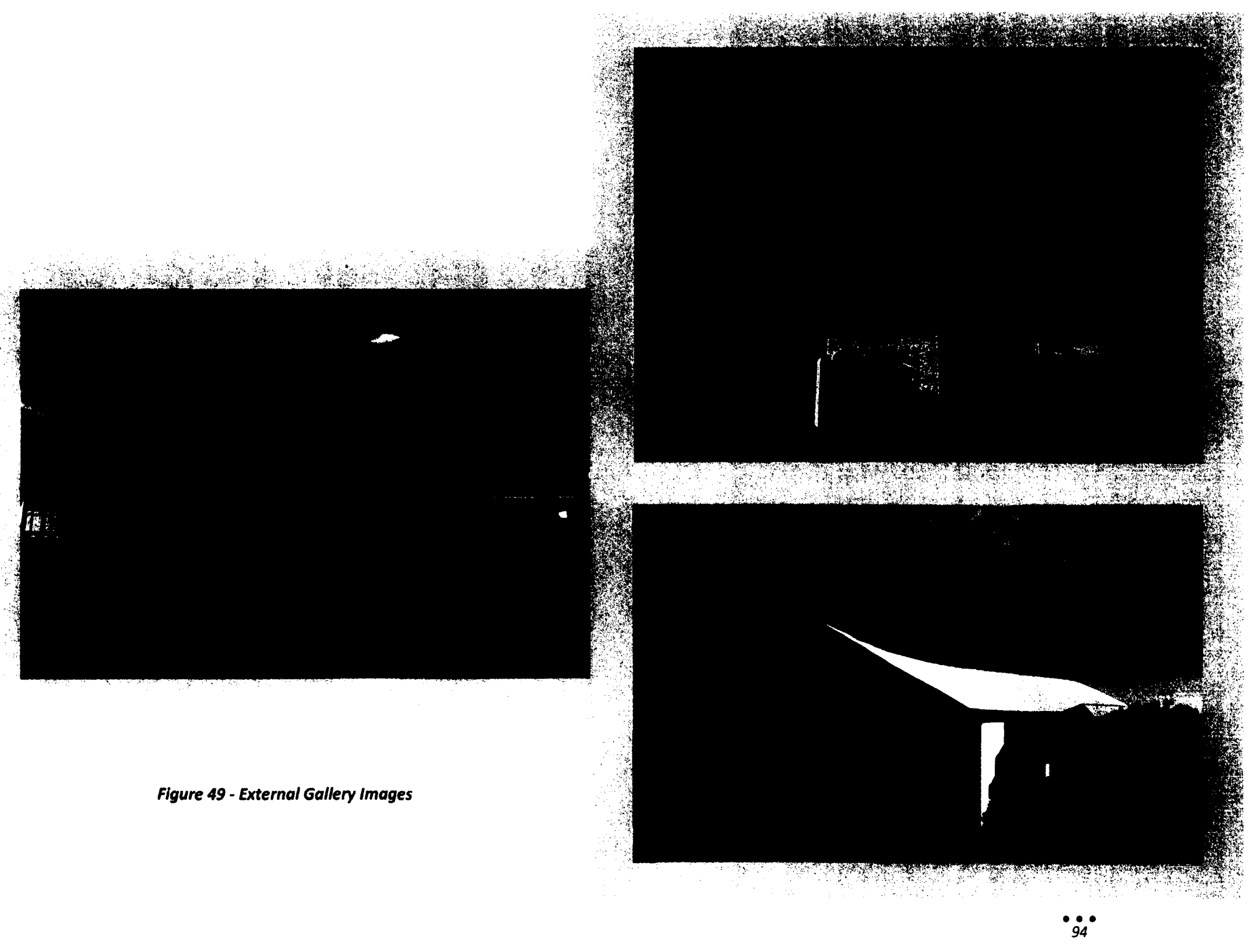


The grassy surface which the cricket game has controlled for several years, is now shared turf for any activity to utilise, removing the purity of its identity as the Englishman's imported game of dominance. The cricket pitch and its surrounding field are a significant feature in the history of the Barbadian (and the wider Caribbean) society, being the surface on which opposing teams, classes and races engaged in cricket game play for which the winner's trophy held several levels of recreational and socio-political meanings. A sample shot of the immediate city core, shows that the majority of green spaces within Bridgetown are all cricket pitches, and are no more than 'a stone's throw' away from each other. In removing the pitch's exclusivity and by extension the game's, the pitch remains as an active remnant of European ancestry, now blended with current societal programmes. The wide open space then becomes suitable for the hosting of previously held events such as the Agricultural Expo, Christmas Morning in the Park Parade and the Crop Over Opening Gala Ceremony, in addition to use for other recreational activities such as walking, jogging and playing of other sports. The 'sacred' rectangular surface of the cricket pitch in the center of the field can easily be protected with a removable protective surface layer, giving way to the use of the remaining green space for other cultural layers of activity.

Lastly, the player's pavilion and spectator's seating have been relocated to the top of a west facing mound where they symbolically overlook what West Indian cricket has become. 


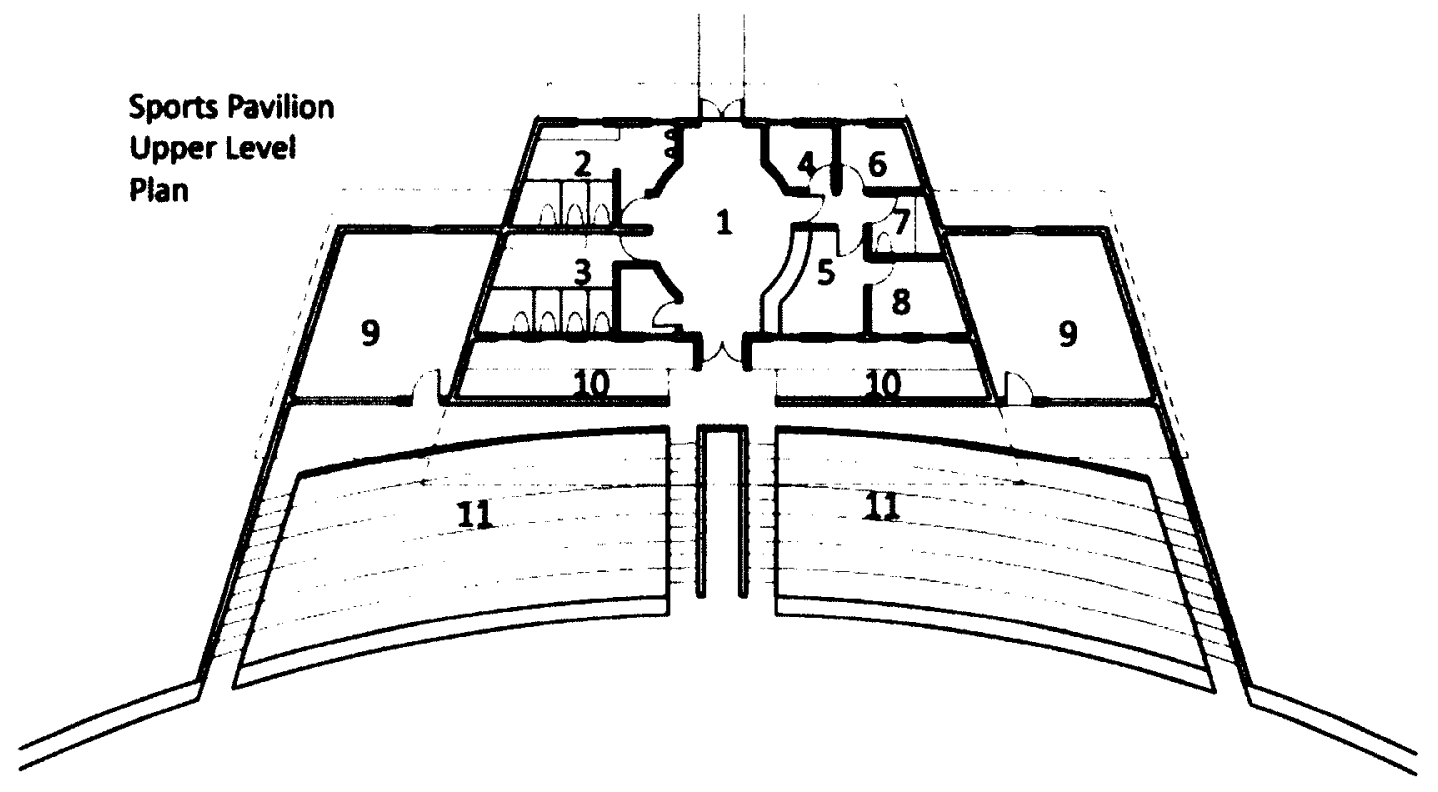

Lower Leve

Plan

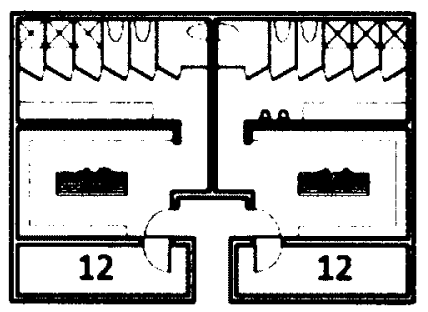
1. Entrance Vestibule
8. Bar Storage
2. Male Washroom
9. Meeting Room
3. Female Washroom
10. Covered Seating
4. Storage
11. Tiered Seating
5. Bar
12. Equipment Store Room
6. Office
13. Female Locker Room
7. Staff Washroom
14. Male Locker Room

Figure 50 - Multi-purpose Sports Pavilion Plans 


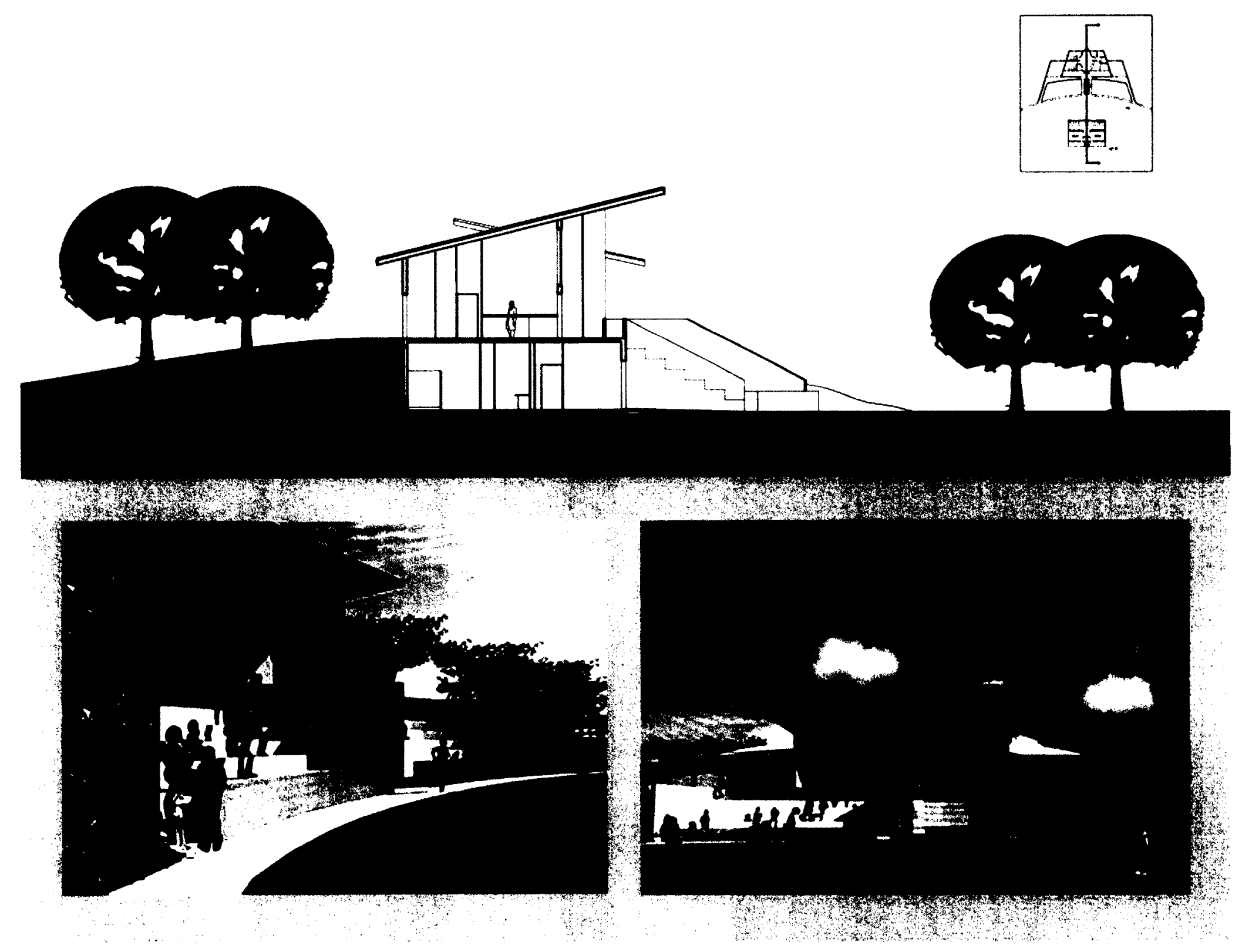

Figure 51 - Multi-purpose Sports Pavilion Section \& External Images 


\section{The Baobab Tree}

Figure 52 - Images of the Queen's Park Baobab
The Baobab tree is an important focus element in the park's Warri home base. It is a symbol of life and the medium through which descendants symbolically connect with their past. With a girth of over 60 feet, the tree is robust in its stance as a symbol of ancestral heritage.
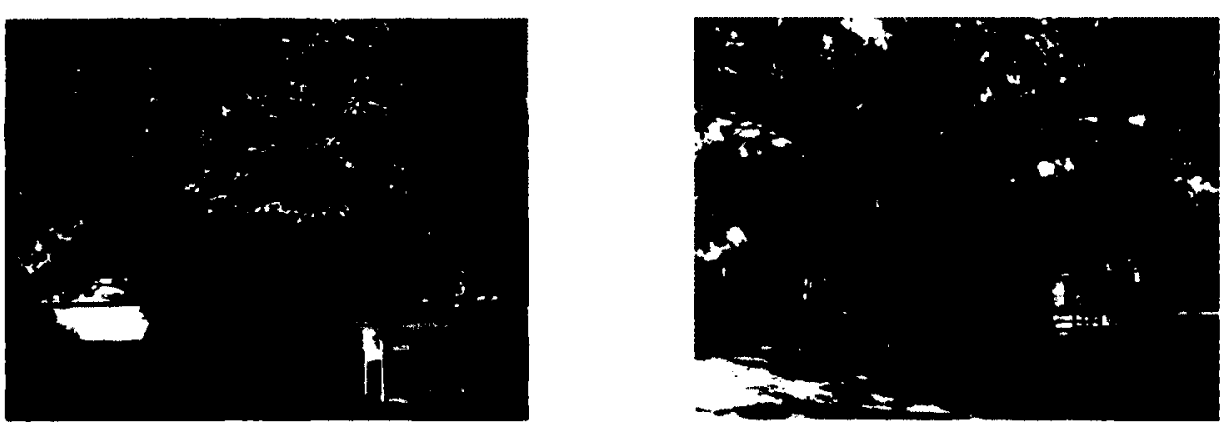

It is unknown how the tree came to exist in Barbados since its species is native to the desert region of Africa. There are only two such trees in Barbados, both near 300 years old; the younger of the two residing in Queen's Park. It is believed that through the African cultural practice of carrying seeds as emergency rations whilst on a journey, the Baobab seeds where brought from West Africa to the tropical Caribbean island of Barbados, as a 'fail safe' means of survival. The Baobab has had to "suffer changes in both the number and names of its species. [But] somehow it has managed to survive the identity crises ${ }^{\prime 103}$. The confusion surrounding the identification of this tree and even its existence within the tropical climate of Barbados is reminiscent of the situation of the island's Amerindian ancestors. Therefore, while being of African origin, the tree is multifaceted in its symbolism.

\footnotetext{
${ }^{203}$ Pakenham, Thomas. The Remarkable Baobab. New York, NY: W.W. Norton \& Company, 2004. 2.
} 
The tree is extremely resilient and almost every botanical feature is useful: the pulp of the fruit can be made into a drink, its seeds are edible if roasted, the flowers and leaves can be eaten as salad, and without killing the tree, the bark can be stripped from the trunk and pounded into rope, cloth or roof tiles. The tree was therefore a significant provider of food, shelter and clothing to the African locales where it grew. It was also the provider of several legends due to its great age, huge size and astonishing shapes. "The tree was like a God...[and] they associated it with the spirits of their ancestors, who had to be worshipped and appeased" 104 , therefore when a Baobab died "the tree was accorded the privilege of a solemn burial" ${ }^{105}$.

Surrounding the Baobab, it is proposed that twelve circular features be moulded into the landscape: six mounds and six depressions as a reference to the Warri game. One palm tree will be planted at the top of the six mounds. The palm tree was once the symbol of wealth on many sugar plantations and the amount of wealth of a sugar estate was often determined by the number of palms which lined its entrance. The palm tree is now being used as a symbol of richness, but of the cultural kind, passed on by all ancestors. The mounded feature is symbolic of the accumulation of several seeds in one of the holes of the Warri game board, a play which often times results in the claiming of several the opposing player's seeds. The depressed areas are intended to be reflective garden spaces where the kind of calm thought can be had that might result in a clever round of Warri game play.

\footnotetext{
104 Pakenham. Thomas. op. cit. 15 ${ }^{105}$ Ibid.
} 

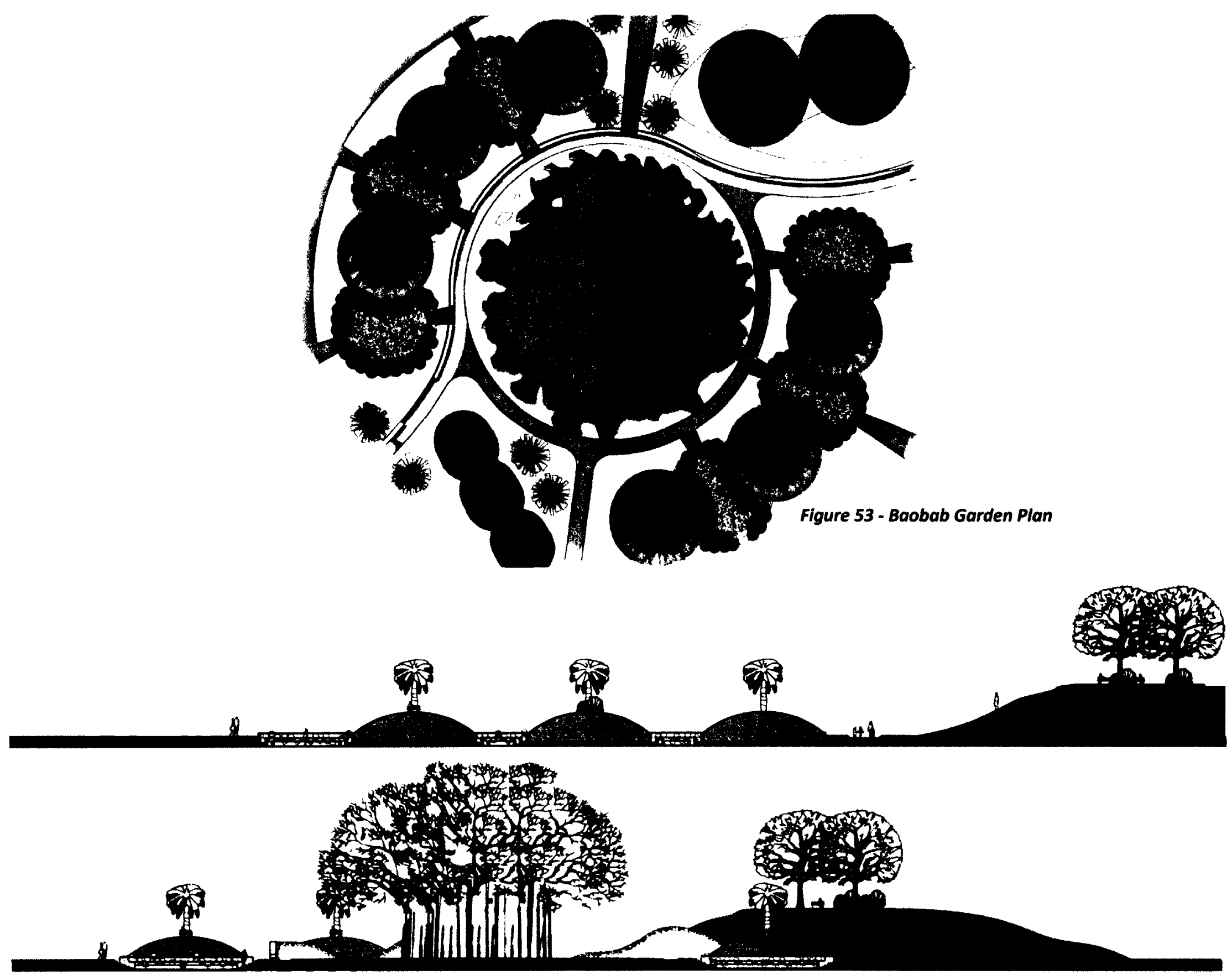

Figure 54 - Baobab Garden Site Sections 


\section{THIRD ROUND - PLAYING THE LAST HOLE \& WAITING FOR THE NEXT PLAY}

The 'Path' Of Cultural Expression

As we have observed, culture is a continuously changing feature which becomes obsolete at the moment it is asked to 'stand still'. It should therefore be understood and embraced as it is experienced or lived. The conceptualisation of a continuously changing path of visual art display, as an expression of self and as an extension of the formally proposed gallery space, is intended to be a public device which showcases local perceptions of self within the existing cultural climate. The display will provide two and three-dimensional representations of cultural identity directly from the source rather than from foreign interpretation as was done in the past; the gesture is intended to be a counter-approach for consciously removing stereo-types of cultural reality at the visual level and replacing them with images that are much closer to the reality, if not the reality itself. Thus the discriminating observer is now given a less biased point of departure from which the fourth dimension - imagination - can emerge.

Where the 'path' emerges as a wall, a tangible point for the sharing and recognition of local cultural identities will be articulated, through the visible placement of cultural expressions in an outdoor setting for viewing by locals and non-locals alike. At some points, the wall acts as the feature which aids in the moulding and retention of the soil surface where it is needed and then disappears into the earth at other points where it is not. The rising and falling of the feature is symbolic of the uncovering and emergence of ancestral heritage when needed to strengthen sense of 'being' or identity. Buried Amerindian ancestry in the island is a key example of this. For several years it was believed that the 
Amerindians only temporarily inhabited the island along the coastal areas. The uncovering of archeological evidence however has shown that the Amerindian population was far more permanent and had penetrated the island much further than was previously understood. Perhaps the wall can be understood as a pre-empted attempt to install a consciously placed cultural artefact to be left behind, for others to reflect on at a later date, as an element of material culture.
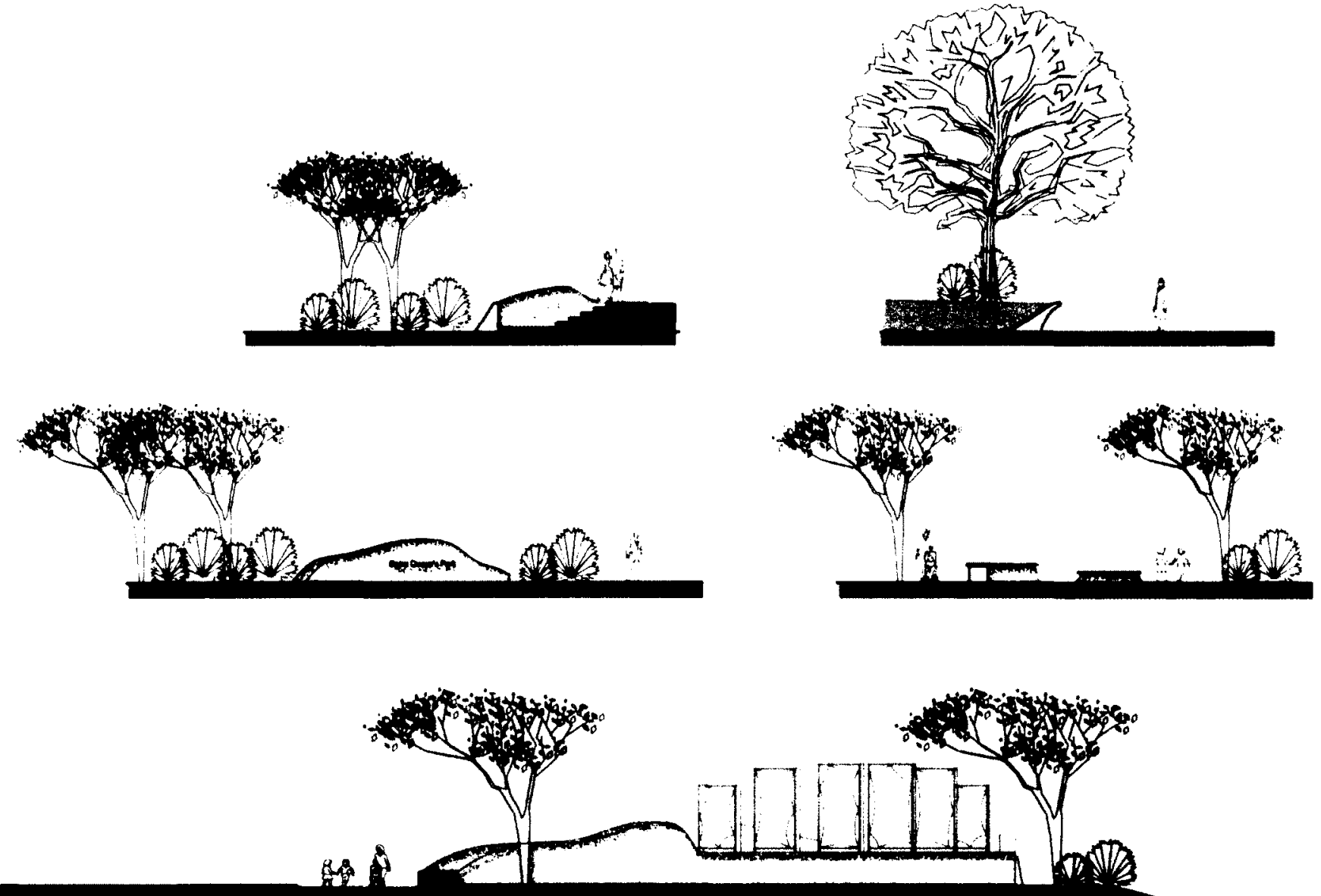

Figure 55 - Selected Sections through Wall Feature 


\section{The Changing Terrain}

In manipulating the site's terrain, considerations were made in the inclusion of the proposed main features or 'holes' of activity. The paths through the site and their levels consider the ideas of alignment, the crossing and elimination of the existing paths with the new ones which speak to the decided priorities given to the original framework based on the theory of the Warri game. The original path through the site for example, still exists but now terminates at the Nelson's Gate in a modified fashion which now allows a more pleasing landscaped entrance point with park signage.

The use of mounds as signifiers of highpoints of historical or contemporary climaxes are similar to the ideas exhibited in the works of Andy Goldsworthy in his documentary titled 'Rivers and Tides'106. In the documentary, Goldsworthy uses egg-shaped sculptures made from on-site materials to mark places which hold sentimental significance. The use of displaced earth from the rest of the site will be used for the creation of the site's mounds which sit around the former cricket pitch area. The mounds are intended to be the high points from with the park's occupants can observe activities around the site

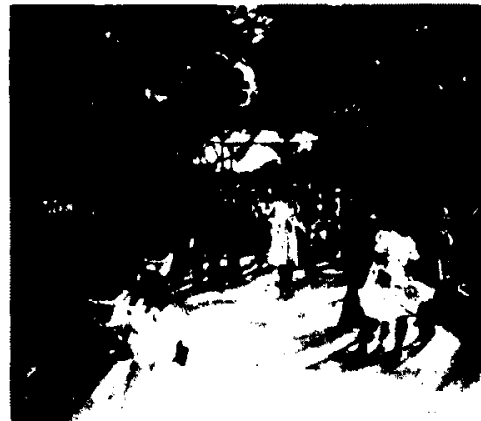

Figure 56 - Annual Christmas Morning Concert in the Park with the Band Stage in background (Source: Art in Barbados) without being disturbed by the activities themselves.

The Band Stage sits in its original location with the surrounding terrain lowered to highlight its significance as a performance stage and the area around which Bajans have traditionally paraded on an annual basis. Adjacent to the Band Stage area are interconnected Chattel kiosks which are intended to provide traditional setting for concession areas which will service both the Band Stage area and any activities taking place in the area of the former cricket pitch.

\footnotetext{
${ }^{106}$ Goldsworthy, Andy, perf. Rivers and Tides. Narr. Andy Goldsworthy. Mediopolis, 2003. Web. 3 Jan. 2012.
} 

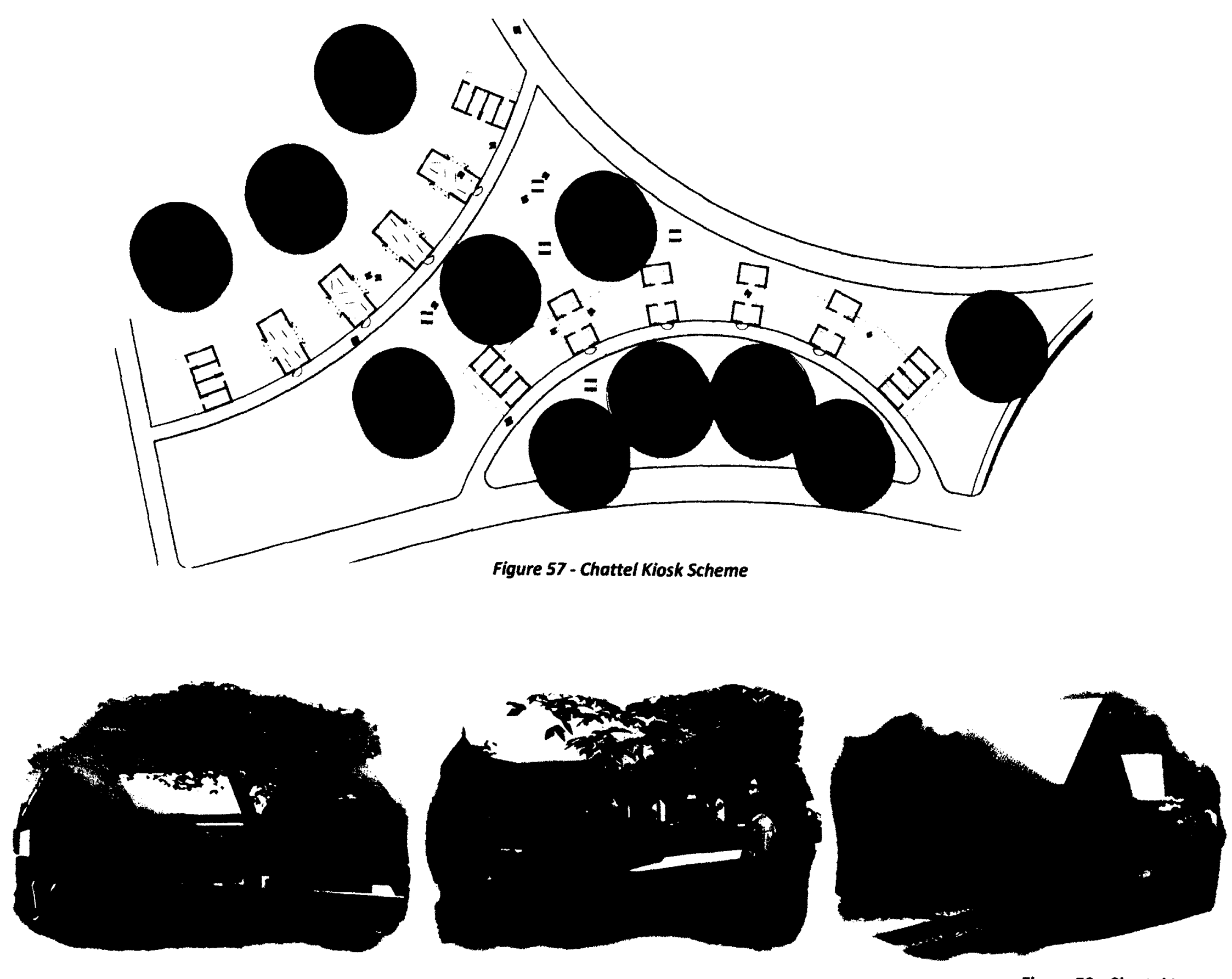

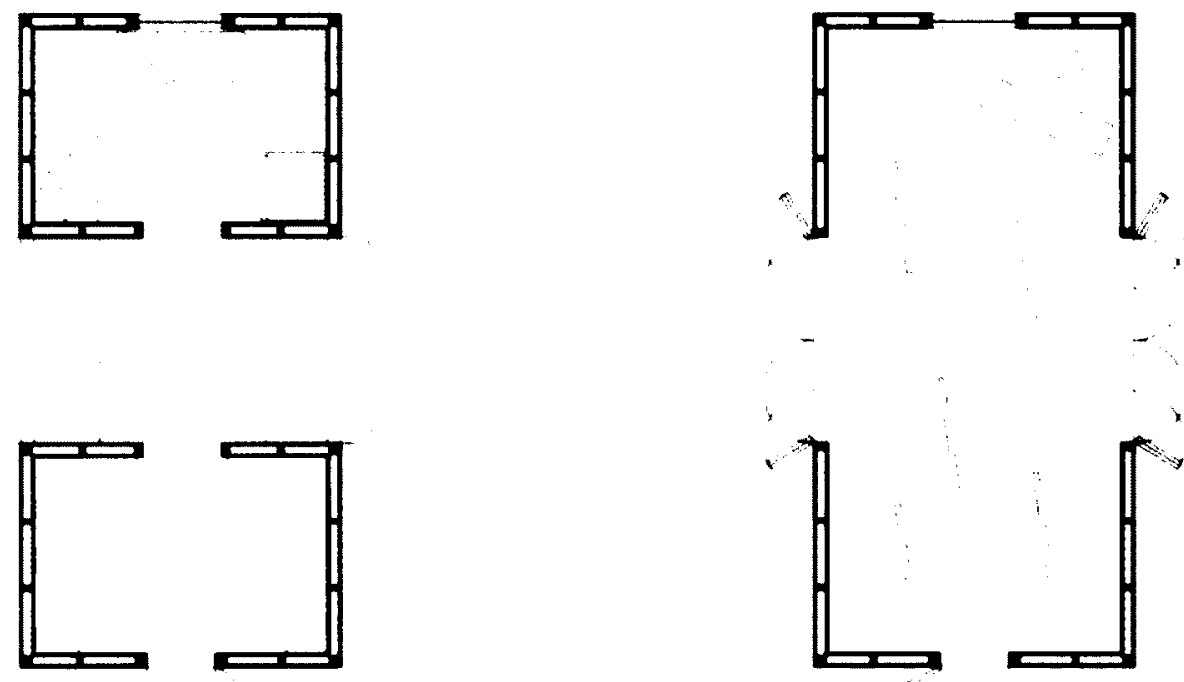

CONFIGURATIOM *1

CONFigunanion wa

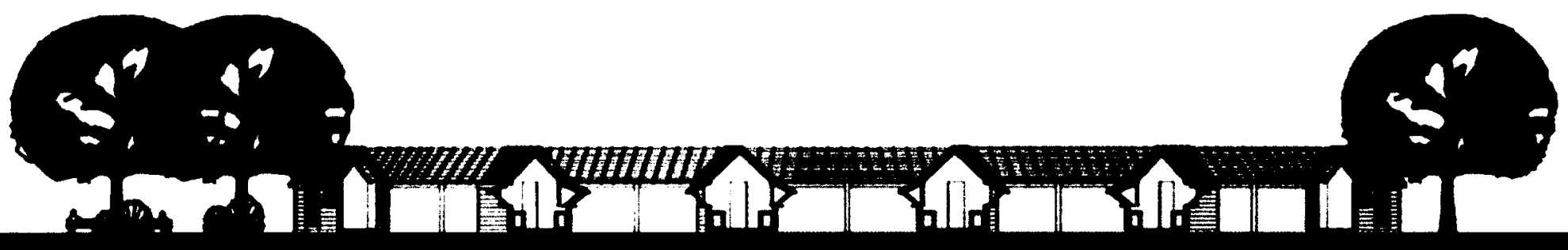

Figure 59 - Chattel Configurations \& Section 

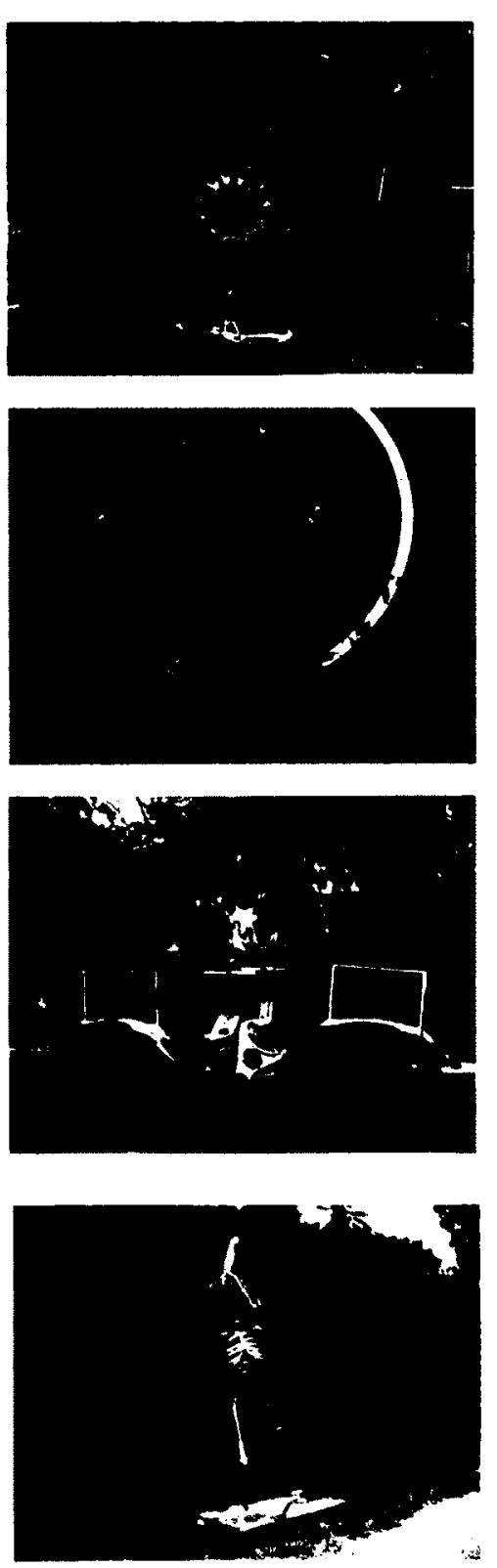

Figure 60 - Interactive sculptures by Bajan artist Dr. Lance Bannister. All sculptures are mode from recycled car parts and have a story behind their creation.

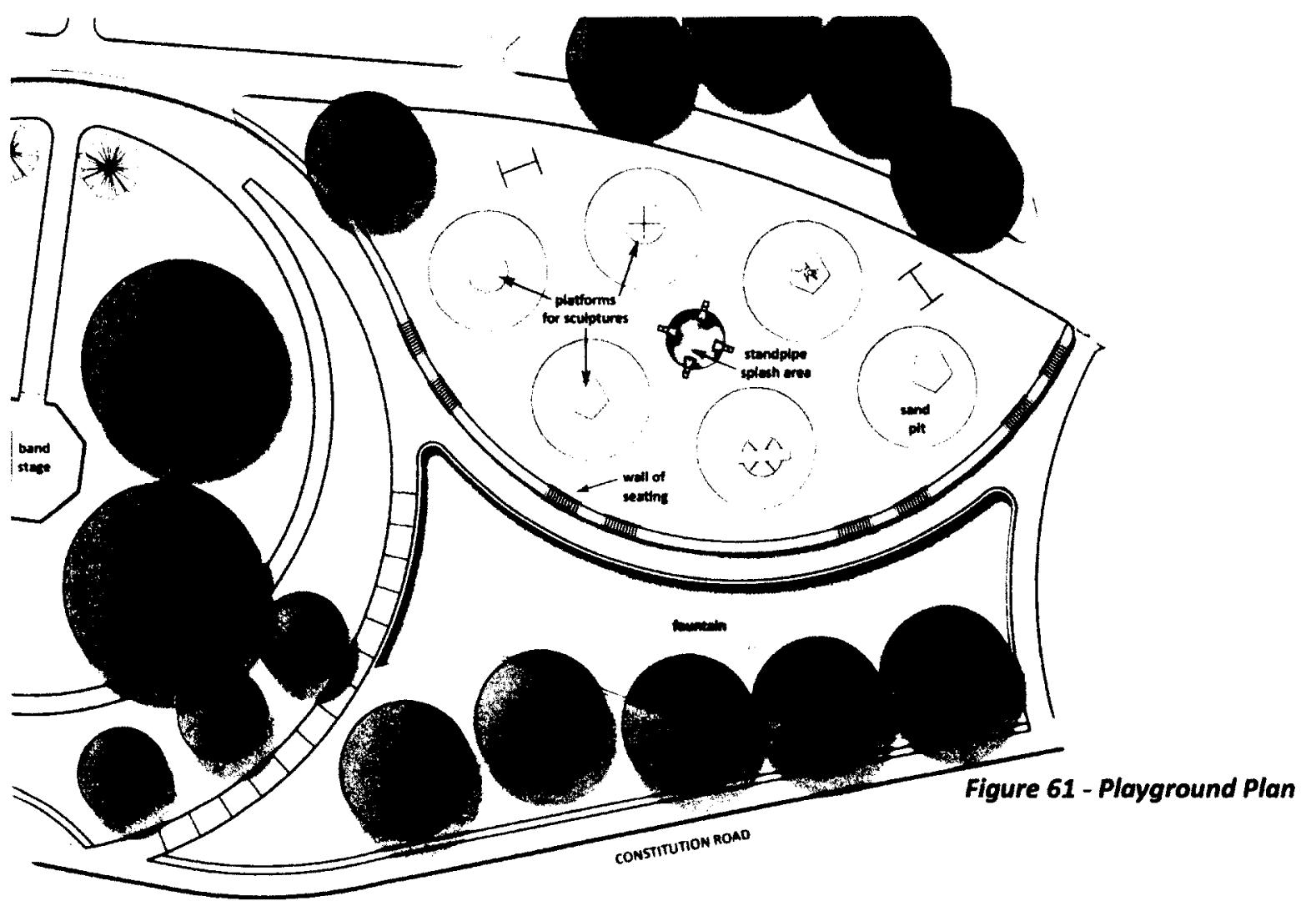

The new playground area is positioned in close proximity to the Band Stage and Chattel kiosks and within view of the street. This location is ideal as it entices parents with children into the space from street view. In addition, the observation of the adjacent activities of within the Band Stage area and Chattel area provide a necessary closeness for both monitoring children at play and for having them observe any cultural activity going on. The inclusion of interactive folkloric sculptures also provides another medium through which children are sensitised to local culture through interaction with the pieces while at play. The images displayed at left, are examples of interactive playground sculptures which have been created by local Barbadian artist Dr. Lance Bannister. 


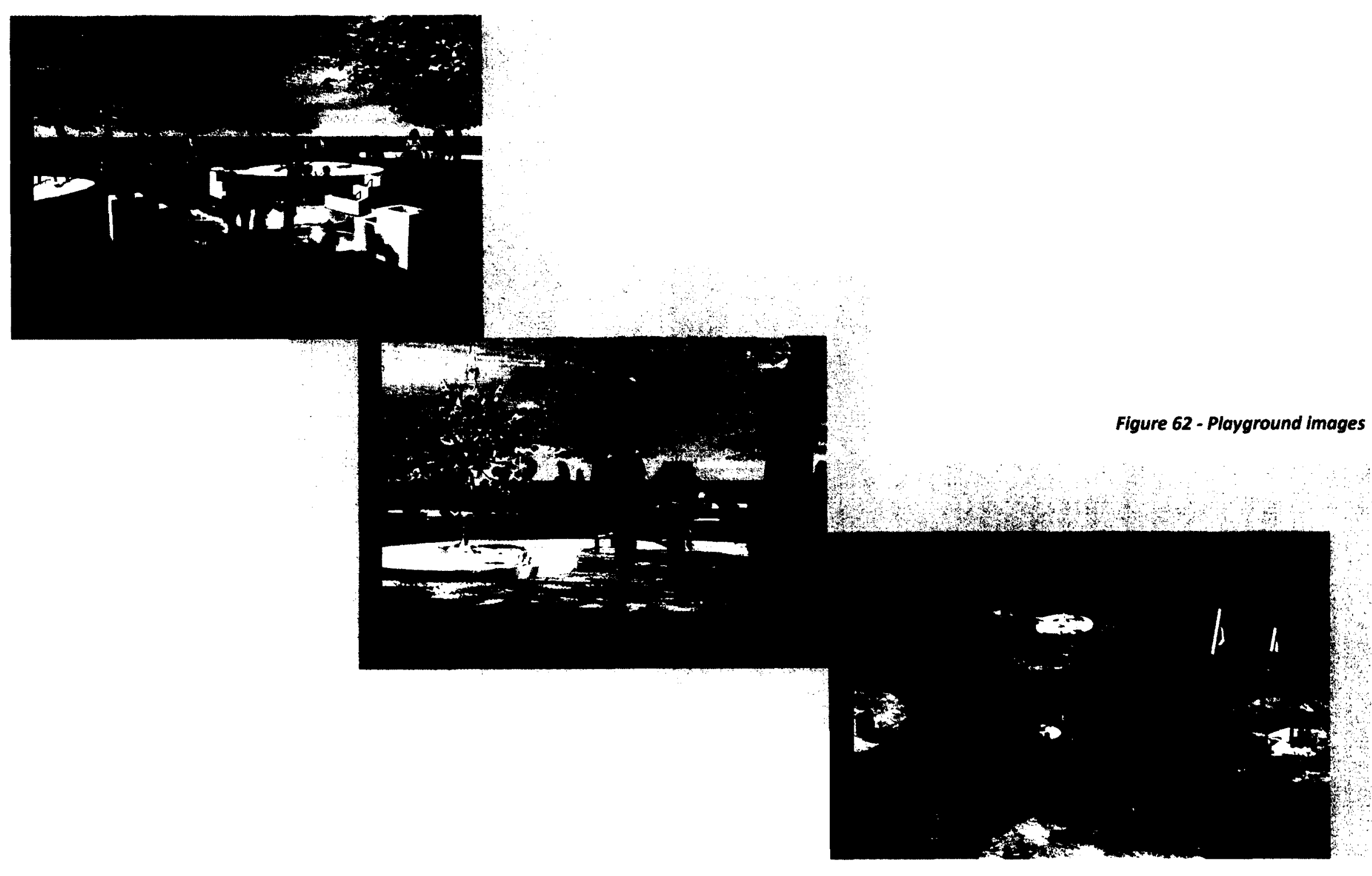


The gossip cove area on the opposite (west) side of the Band Stage is intended to be the adult version of social space. The incorporated fountain features are an adaptation of the running water of the standpipe setting previously discussed in the Mekkin Sure Ya in de Know section. These coves are now the park's version of the points of small social gatherings where personal and public affairs are shared. The cove space looks up to more public areas of the original Queen's House and new gallery and over to the Band Stage area.

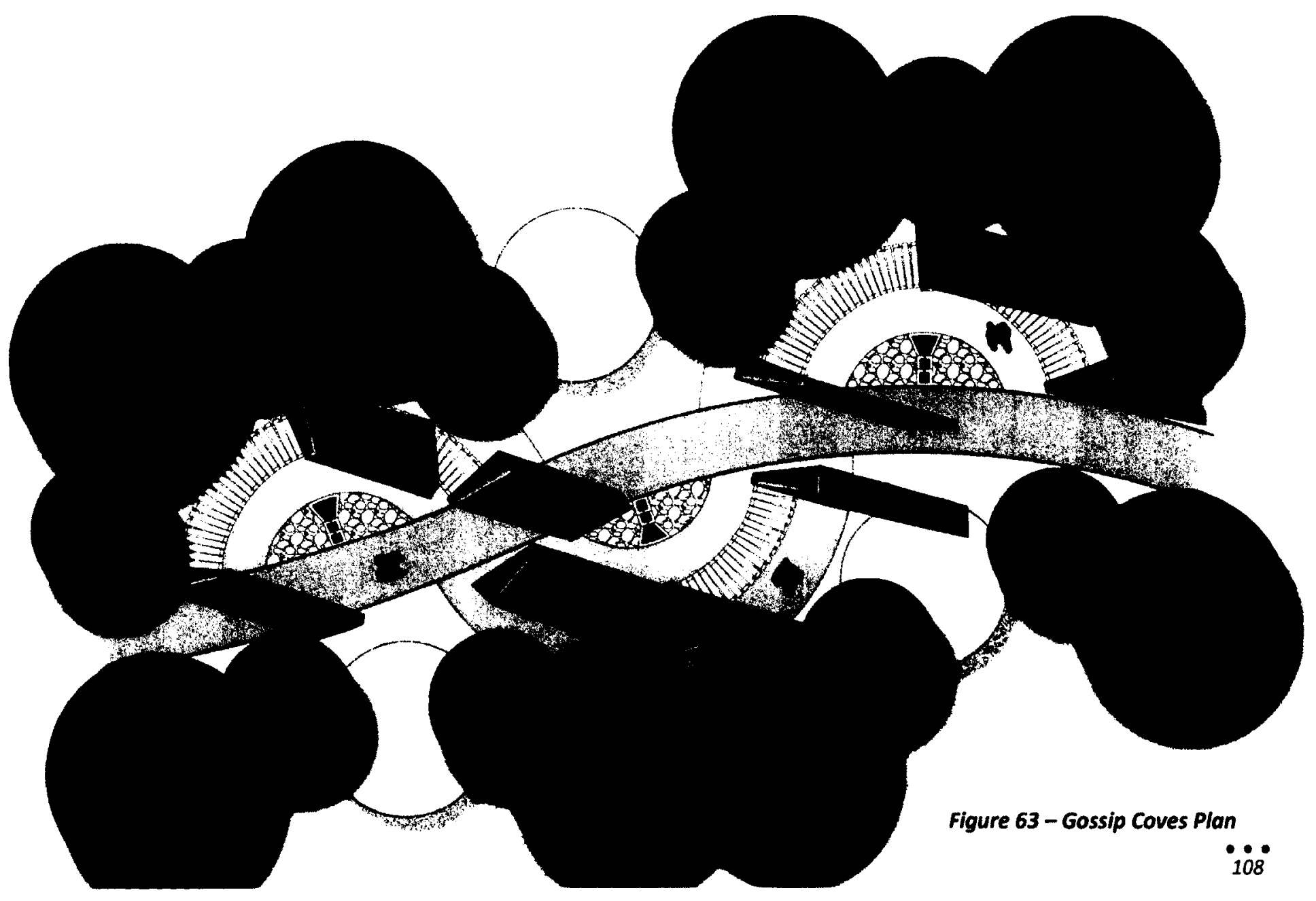




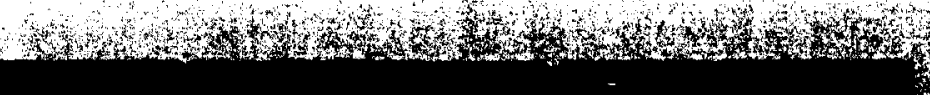

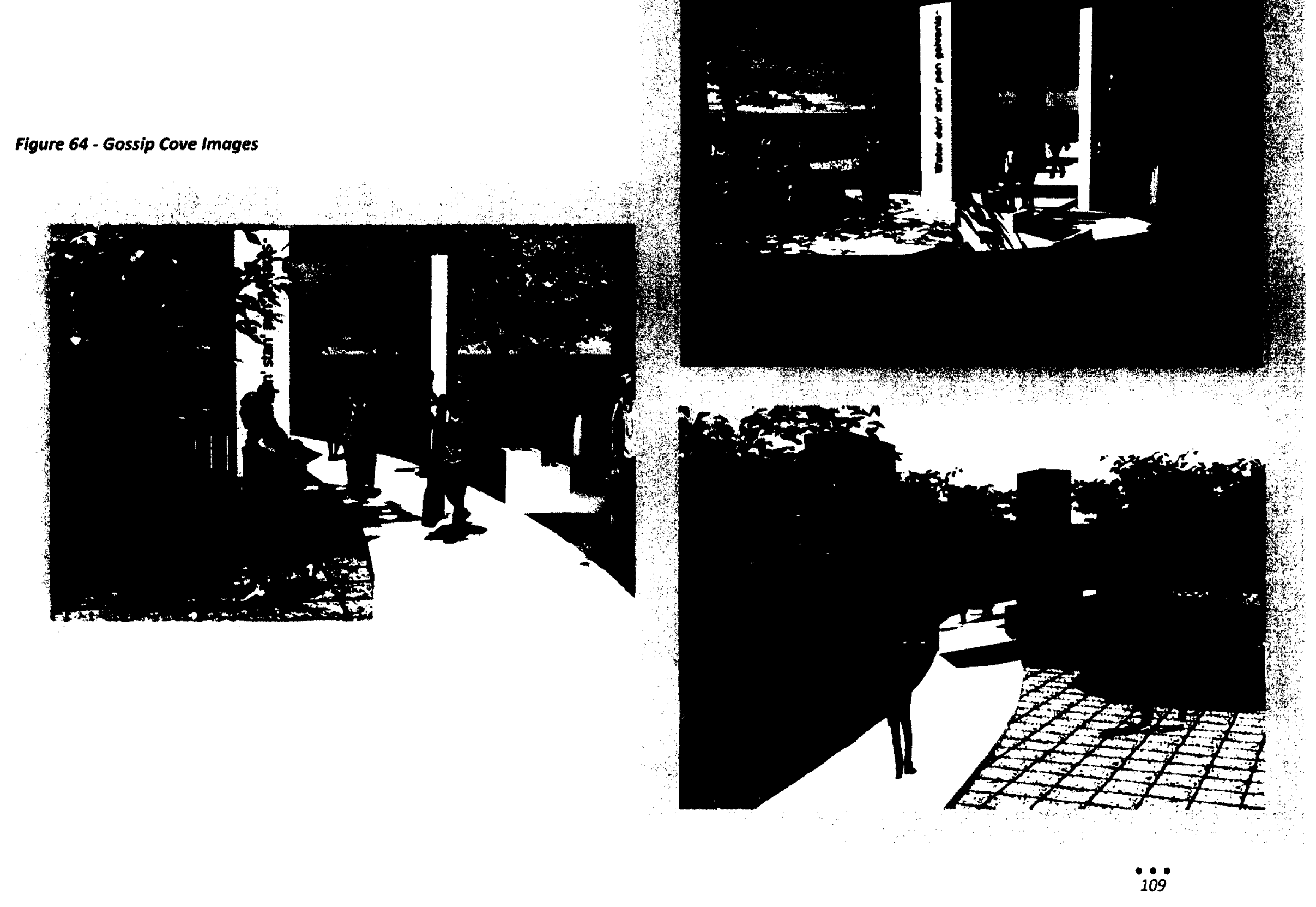


V) TALLYING THE SEEDS

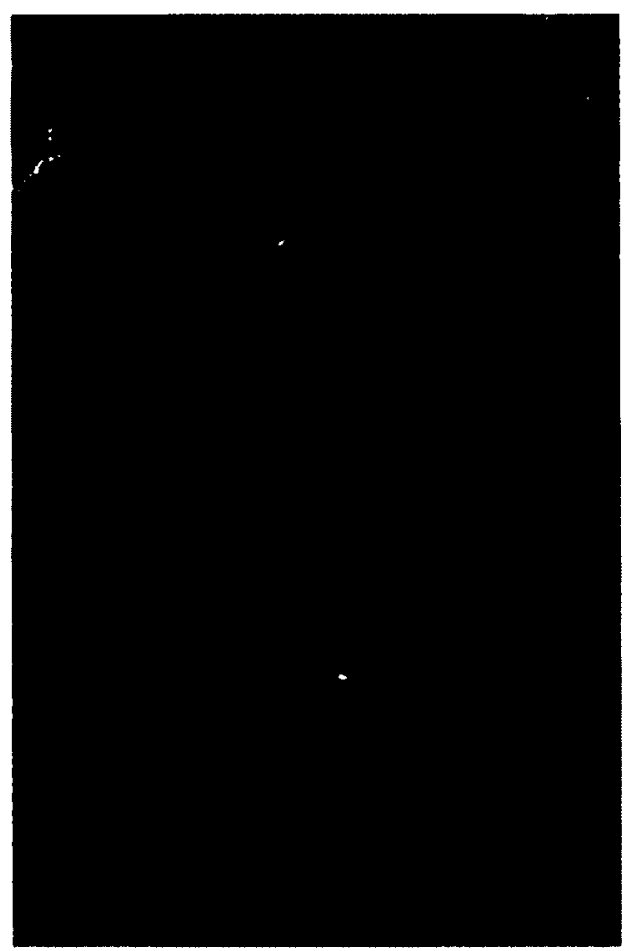

Figure 65 - Warri game board at final round of play 


\section{PREPARATION FOR NEXT CROP SEASON - FINAL REMARKS}

The re-design of the Queen's Park site as a cultural park, with the main architectural interventions being an art gallery and resource center, firstly speaks to the need to realise the importance of the expression of self in the context of one's own cultural environment. I believe that encouraging self-expression and its display through visual art is a significant point of departure, as it was shown to be a powerful medium during and after colonial times. In the current period however, where the immediacy of colonialism is in the distant past, the depictions of the cultural sensibilities of the 'independent' Barbadian-Caribbean people are now questions of identity and knowing of self. The advocacy of local internal expressions of cultural identity therefore seeks to formulate responses for questions of identity at the point of its con-fusion. In my opinion, through stimulating an internal cultural consciousness, the displacement of imagery and perceptions which may have permeated and distorted the Barbadian-Caribbean understanding of self, can be easier dismissed.

The park's design's structure for cultural display provides both formal and informal spaces which speak to the context in which the Barbadian society has developed. The inclusion of a resource facility provides a formal information channel which creates a foundation for cultural education within the park. The Barbadian society is underscored by the formal attributes of British government, social and educational structures which therefore draw appeal to the formality of the gallery and cultural resource facility interventions. As a counter to the inclusion aspects of colonial cultural framework, the winding, undulating paths through the park speak to the rethinking the traditional chronological timeline of history and the development of culture into a rhizomatic line of thought whereby the paths flows in several directions and touches many areas of activity throughout the park space, in the same manner that the Barbadian-Caribbean should be understood as having evolved in a similar way. 
In closing, it is my belief that the undertaking of such a project should primarily be the responsibility of the Barbados National Cultural Foundation (NCF) - a government entity, with direct input from the local community. The project's realisation would in effect be a starting point from which new perspective can be gained at the local level. While the intentions for the fulfilment of this proposal may in finality have some economic basis, the benefits will extend into an increased consciousness of the importance of preservation of historic and cultural elements; the Ministry of Tourism's recent addition of the heritage tourism niche will ensure this. Amongst the Barbados Tourism Authority's objectives are the aims to: "facilitate, monitor and encourage the enhancement and sustainable development of Barbados' tourism product...and to conceptualise and execute public education and awareness programmes which foster in Barbadians, a positive attitude towards the tourism industry and encourages service excellence throughout the industry" ${ }^{107}$. Resulting from these aims and the new development of the heritage tourism product, the Barbados National Trust now receives special sponsorship from the Barbados Tourism Authority. It might then be fair to say that subservience is only the surface quality of the tourism product, above the true strategy of industriousness for the overall betterment of the nation; a nation far more complexed than it appears.

${ }^{107}$ Barbodos Ministry of Tourism: Encouraging Sustainable Tourism Development. Barbados Ministry of Tourism, n.d. Web. 2 Mar. 2012. <http://www.tourism.gov.bb/about-the-ministry.html>. 


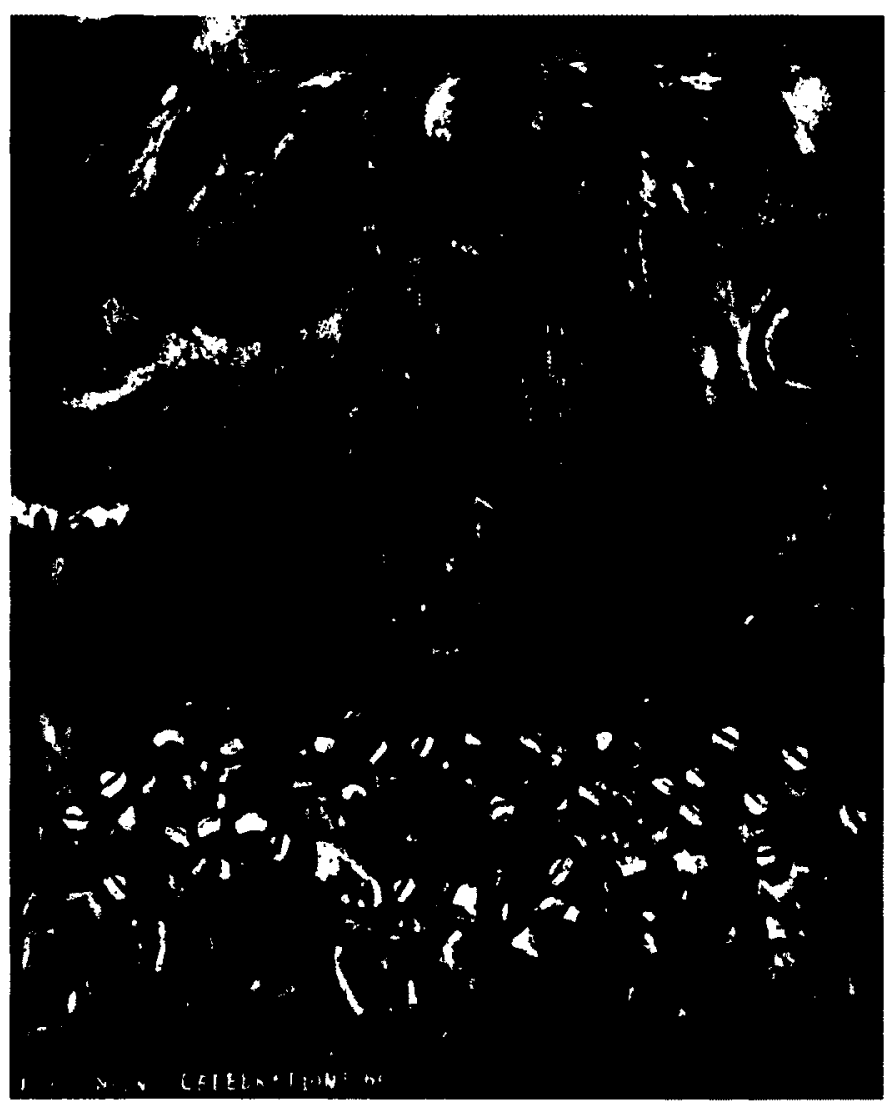

Figure 66 - Barbados Independence Celebrations 1966 
VI) FINAL MODELIMAGES
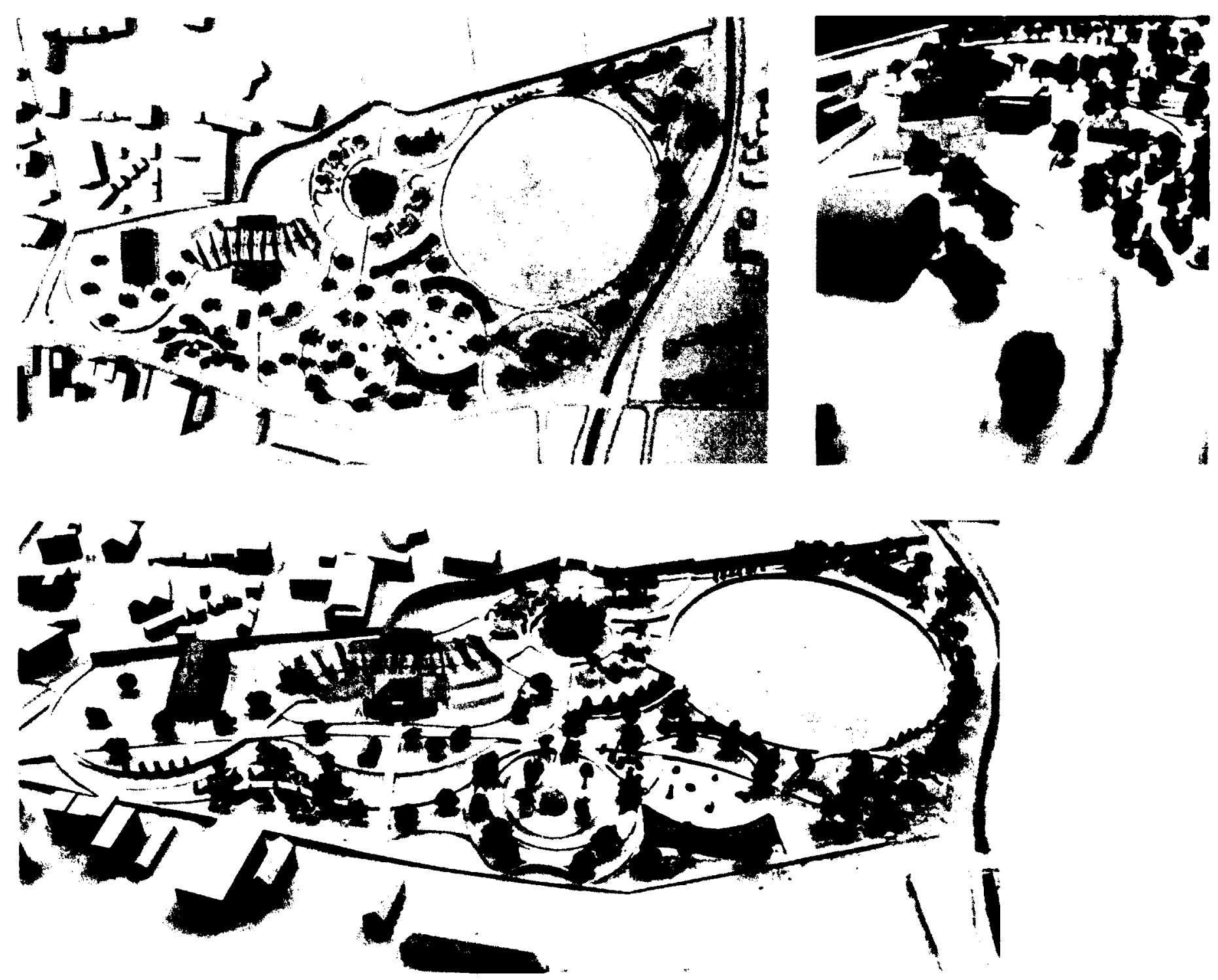

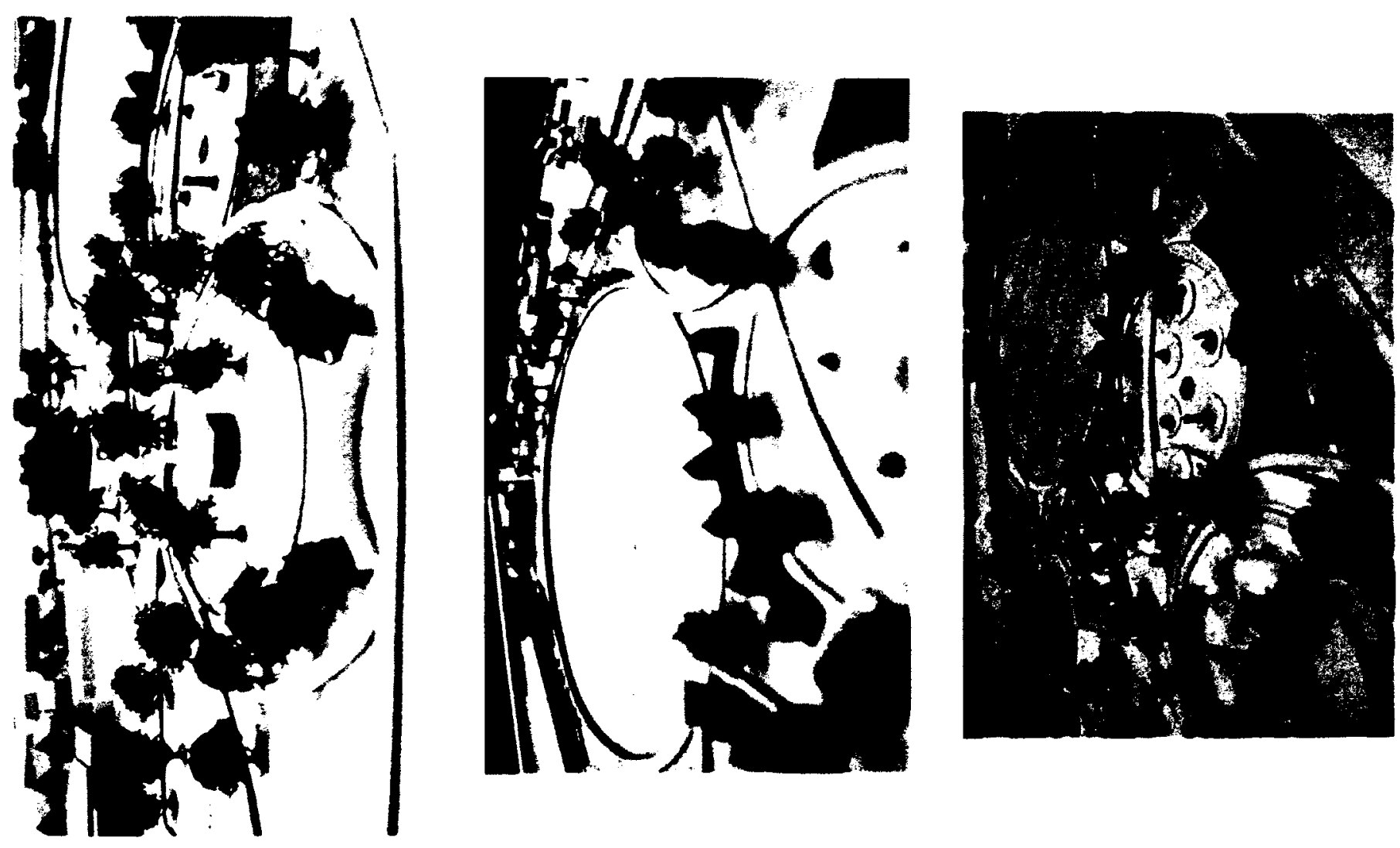
- Bajan - Barbadian dialect term used to refer to persons of Barbadian nationality, or of anything originating from the country of Barbados.

- Baobab - a native tree of Africa suited to the dry savannah areas of the region. Two of this species of tree strangely exist on the tropical island of Barbados and are estimated to be almost 300 years old, an estimation which leads to the assumption that the trees' seeds may have been transported by the African slaves during $18^{\text {th }}$ century.

- Brought-upsy - upbringing, referring to the manner of raising a child, e.g. no brought-upsy meaning no manners or respect for others.

- Caan' - meaning 'can't' or 'cannot'

- Chattel - movable possession. Usually referring to the traditional typology of the Barbadian home which was designed so that it could be easily dismantled in sections and reassembled.

- Creole - the result of an incorporation of a considerable range of features (e.g. blending of ethnicity, food, language, music, etc.) from one or more unrelated cultures, as the result of contact between cultural communities.

- Cricket - a sport introduced to the Caribbean by English colonisers which bears significant social, cultural and recreational importance throughout the Anglophone Caribbean.

- Crop Over - festival revived in the 1970's as a celebration of the end of the cane crop or agricultural season. The festival is now a major feature of the Barbadian year and a significant marketing point for the island's tourism sector.

- Dan - meaning 'than'

- De-meaning 'the' 
- Dem - meaning 'them'

- Doin' - meaning 'doing'

- Duh - meaning 'there' or sometimes 'they' depending on context of statement, e.g. Duh got more in de mortar dan de pestle - There is more in the mortar than the pestle. Duh caan' believe it - They can't believe it.

- Ef-meaning 'if'

- En - meaning 'isn't' or 'is not', e.g. Tekkin' time 'en laziness - Taking time isn't laziness.

- Fuh-meaning 'for'

- Guh-meaning 'go'

- Gypsy - meaning to have an inquisitive nature, e.g. Ya too gypsy fuh ya own good!

- Kadooment - Barbadian dialect term referring to a fuss, or an important occasion. The name was adopted by the Ministry of Education and Culture as the name for the final event for the Crop Over festival.

- Landship - a friendly society founded by Moses Ward more than 100 years ago, as a recreation of the comradeship and discipline of the Royal Navy. Members dance and 'parade' in uniforms of naval pattern, and have naval ranks and titles assigned to them. The landship movement was also a form of working-class resistance to middle-class and elite culture.

- Lime - to lime equivalent to the act of 'chilling out' or 'hanging out' with friends, e.g. I'm having a lime at my house.

- Limer-Someone who likes to lime.

- Malicious - same as gypsy, meaning to be excessively inquisitive. 
- Mortar and pestle - A two-piece utensil of African origin, used to pound and blend condiments and other ingredients together. The mortar is the hollowed container and the pestle is the pounding stick.

- Mekkin' - meaning 'making'

- Picong - any teasing or satirical banter, originally a verbal duel in song.

- Proppa' - meaning 'proper'

- Stick Lickin' - meaning 'stick licking'. A local Barbadian game...

- Tekkin'- meaning 'taking'

- Tuk - music originating from the fife and drum marching band of an eighteenth-century British regiment, created as a creolised version of British military music by the black African slaves in the Barbados militia.

- Warri - A game of African origin belonging to the Mancala family of 'pit and pebble' games. It is a game of strategy based on calculation and 'capture'. It is believed that this game was often played by African royalty to gamble away or acquire property.

- Wuk-meaning 'work'

- Wuk-up - Wine up. Associated with the Caribbean dance motion of wining involving the movement of the waist and hips in a circular motion, to the tempo of music.

- Yuh-meaning 'you' 
VIII) BIBLIOGRAPHY

Acworth, Angus W. Treasure in the Caribbean: A First Study of Georgian Buildings in the British West Indies. London: Pleiades Books, 1949. Print.

Alleyne, Warren. Historic Bridgetown. Bridgetown: Barbados Government Information Service, 2003. Print.

Barbados Statistical Service. Barbados Population and Housing Census 2010. Bridgetown, Barbados: Barbados Statistical Service, 2012. Print.

Barrow, Errol. "What kind of mirror image do you have of yourself?" Democratic Labour Party. Bridgetown, Barbados. 13 May 1986. Web. 26 Feb. 2012.

<http://notesfromthemargin.wordpress.com/2008/01/21/happy-errol-barrow-day-for-all/>.

Beckles, Hilary M. A History of Barbados: From Amerindian Settlement to Caribbean Single Market. 2nd ed. UK: Cambridge University Press, 2006. Print.

Blouet, Olwyn M. The Contemporary Caribbean: History, Life and Culture since 1945. London: Reaktion, 2007. Print.

Bobb, June D. Beating A Restless Drum: The Poetics of Kamau Brathwaite \& Derek Walcott. N.J.: Africa World Press Inc, 1998. Print.

Bowden, Martyn. "The Three Centuries of Bridgetown: A Historical Geography." The Journal of the Barbados Museum \& Historical Society XLIX Nov. (2003): 1-142. Print.

Carrington, Sean, Henry Fraser, John Gilmore, and Addinton Forde. A-Z of Barbados Heritage. 2nd ed. Oxford: Macmillan Publishers Ltd, 2003. Print.

Carmichael, Trevor A., ed. Barbados: Thirty Years of Independence. Kingston, JA: lan Randle Publishers, 1996. Print. 
Clarke, Austin. Growing Up Stupid under the Union Jack : A Memoir. Kingston, JA: Ian Randle Publishers, 1980. Print.

Countries and their Cultures: Barbados. Ed. W Penn Handwerker. Advameg Inc., 2005. Web. 28 Feb. 2012. $<$ http://www.everyculture.com/A-Bo/Barbados.html>.

Crain, Edward E. Historic Architecture in the Caribbean Islands. Gainesville: University Press of Florida, 1994. Print.

Cummins, Alissandra, Allison Thompson, and Nick Whittle. Art in Barbados: What Kind of Mirror Image. Kingston, JA: lan Randle Publishers, 1999. Print.

Douglas, Robert. Caribbean Heritage: Architecture of the Islands. Trinidad: Darkstream Publications, 1996. Print.

Downes, Aviston. "Women Civilising the City: The Civic Circle and Public Urban Spaces in Barbados." The Journal of the Barbados Museum \& Historical Society LV Dec. (2009): 49-61. Print.

Drayton, Kathleen. "Art, Culture and National Heritage." Barbados: Thirty Years of Independence. Ed. Trevor Carmichael. Kingston, JA: lan Randle Publishers, 1996. 199.

Fanum-Badley, William L. Personal interview. 20 Dec. 2011.

Forde, G. Addinton. De Mortar-Pestle. Barbados: National Cultural Foundation, 1987. Print.

Forte, Maximilian C., ed. Indigenous Resurgence in the Contemporary Caribbean. New York: Peter Lang Publishing Inc., 2006. Print.

Frankl, George. The Unknown Self. London: Open Gate, 1921. Print. 
Fraser, Henry. "The Barbados Experience." Ins \& Outs of Barbados 2011 Jan. 2011: 13-28. Print.

Gergen, Kenneth. The Saturated Self: Dilemmas of Identity in Contemporary Life. NY: Basic Books, 1991. Print. Gilmore, John. Glimpses of our Past : A Social History of the Caribbean in Postcards. Kingston, JA: lan Randle Publishers, 1995. Print.

Gravette, Andrew G. Architectural Heritage of the Caribbean: An A-Z of Historic Buildings. Princeton, NJ: Markus Wiener Publishers, 2000. Print.

Handwerker, W. Penn. The Origin of Cultures: How Individual Choices Make Cultures Change. Walnut Creek, CA: Left Coast Press, 2009. Print.

Heckenberger, Michael J. "Rethinking the Arawakan Diaspora: Hierarchy, Regionality, and the Amazonian Formative." Comparative Arawakan Histories: Rethinking Language Family and Culture Area in Amazonia. Ed. Johnathan D. Hill and Fernando Santos-Granero. Chicago: University of Illinois Press, 2002. Print.

Hoyte, Harold. How to be a Bajan: A Souvenir Handbook for Those Who Want to Learn the Bajan Way of Life. Bridgetown, Barbados: HH Investments Ltd., 2007. 120. Print.

Jain, Jasbir, and Supriya Agarwal, eds. Shifting Homelands and Travelling Identities: Writers of the Caribbean Diaspora. Miami: Ian Randle, 2009. Print.

Lamming, George. "The Occasion for Speaking." The Post-Colonial Studies Reader. Ed. Bill Ashcroft, Gareth Griffiths, and Helen Tiffins. New York: Routledge, 1995. Print.

Ledgister, F.S.J. Only West Indians: Creole Nationalism in the British West Indies. Trenton, NJ: Africa World Press, 2010. Print.

Marien, Mary W. Photography: A Cultural History. London: Laurence King Publishing, 2006. Print. 
Mohammed, Patricia. Imaging the Caribbean: Culture and Visual Translation. Basingstoke: Palgrave Macmillan, 2009. Print.

Moore, Keith D., ed. Culture, Meaning, Architecture: Critical Reflections on the work of Amos Rapoport. England: Ashgate Publishing, 2000. Print.

National Anthem of Barbados. Ministry of Foreign Affairs \& Foreign Trade, n.d. Web. 22 Jan. 2012. <http://www.foreign.gov.bb/pageselect.cfm?page=23>.

Nettleford, Rex M. Caribbean Cultural Identity: An Essay in Cultural Dynamics. 2nd ed. Kingston, JA: Ian Randle Publishers, 2003. Print.

Nettleford, Rex M. "Ideology, Identity, Culture." Vol. 5. The Caribbean in the Twentieth Century. Ed. Bridget Brereton. Paris: UNESCO, 2004. 6 vols. 537-58. Print.

Pena, Miguel. "Our American Lady: The Story of Lady Gertrude Gilbert-Carter and her contribution to Barbados." The Journal of the Barbados Museum \& Historical Society LV Dec. (2009): 1-27. Print.

Population \& Education. Ministry of Foreign Affairs \& Foreign Trade, n.d. Web. 10 Jan. 2012. <http://www.foreign.gov.bb/pageselect.cfm>.

Psarra, Sophia. Architecture and Narrative: The Formation of Space and Cultural Meaning. New York, NY: Routledge, 2009. Print.

Rahim, Jennifer, and Barbara Lalla, eds. Beyond Borders: Cross-Culturalism and the Caribbean Canon. Kingston, Jamaica: University of the West Indies Press, 2009. Print.

Reid, Basil. Myths and Realities of Caribbean History. Alabama: University of Alabama Press, 2009. Print. 
Roberts, Peter A. Roots of Caribbean Identity: Language, Race and Ecology. New York: Cambridge University Press, 2008. Print.

Rudder, Antonio. Marching to a Different Drummer: Elements of Barbadian Culture. Barbados: Caribbean Chapters Pub., 2010. Print.

Scher, Philip W., ed. Perspectives on the Caribbean: A Reader in Culture, History, and Representation. Walden, MA: Wiley-Blackwell, 2010. Print.

Sheller, Mimi. Consuming the Caribbean: From Arawaks to Zombies. London: Routledge, 2003. Print.

Stoner, Michael. "Material Culture in the City: Barbadian Redwares in Bridgetown." The Journal of the Barbados Museum \& Historical Society XLIX Nov. (2003): 254-268. Print.

Table of Precedence for Barbados. Ministry of Foreign Affairs \& Foreign Trade, n.d. Web. 10 Jan. 2012. $<h t t p: / / w w w . f o r e i g n . g o v . b b / p a g e s e l e c t . c f m>$.

Thompson, Krista A. An Eye for the Tropics: Tourism, Photography, and Framing the Caribbean picturesque. Durham: Duke University Press, 2006. Print.

Tylor, Edward B. Primitive Culture. 6th ed. Vol. 1. London: John Murray, 1920. 2 vols. Print.

Tzonis, Alexander, Liane Lefaivre, and Bruno Stagno, eds. Tropical architecture: Critical Regionalism in the Age of Globalization. NY: Wiley-Academic, 2001. Print.

UNESCO. Decision - 35COM 8B.42 - Cultural Properties - Historic Bridgetown and its Garrison (Barbados) . United Nations, 7 July 2011. Web. 23 Sept. 2011. <http://whc.unesco.org/en/decisions/4313>.

Watson-Yates, Ann. Bygone Barbados. Barbados: Black Bird Studios, 1998. Print.

Williams, Jim. Hurricane City.com: Barbados History with Tropical Systems. N.p., Dec. 2011. Web. 1 Jan. 2012. <http://www.hurricanecity.com/city/barbados.htm>. 